WEB ANALYTICS, SOCIAL MEDIA, AND THE JOURNALISTIC DOXA:

THE IMPACT OF AUDIENCE FEEDBACK

ON THE EVOLVING GATEKEEPING PROCESS

\author{
A Dissertation presented to \\ the Faculty of the Graduate School \\ at the University of Missouri-Columbia
}

In Partial Fulfillment of the Requirements for the Degree

Doctor of Philosophy

by

EDSON C. TANDOC JR.

Dr. Tim P. Vos, Dissertation Supervisor

DECEMBER 2013 
The undersigned, appointed by the dean of the Graduate School, have examined the dissertation titled

WEB ANALYTICS, SOCIAL MEDIA, AND THE JOURNALISTIC DOXA:

THE IMPACT OF AUDIENCE FEEDBACK ON THE EVOLVING GATEKEEPING PROCESS

presented by Edson C. Tandoc Jr.

a candidate for the degree of doctor of philosophy

and hereby certify that, in their opinion, it is worthy of acceptance

Professor Tim P. Vos

Professor Esther Thorson

Professor Stephanie Craft

Professor Amanda Hinnant

Professor Steven Osterlind

Professor David H. Weaver 
My Mama and Papa, they always tease me that I will never outdo them no matter what I accomplish, for their biggest accomplishment is being blessed with good children. I still say I am better, for God gave me the greatest parents ever.

This dissertation is for you. 


\section{ACKNOWLEDGMENTS}

How do you survive graduate school?

First, you will need funding. Find a generous scholarship program that has changed the lives of countless students from around the world. Just like the Fulbright Scholarship Program. If you are an international student, it will help if you work with the most supportive and caring advisers and coordinators. Just like the people of the Philippine-American Education Foundation. Be grateful.

Second, choose the best journalism school in the world. Find great mentors there who will always be willing to help you. Just like Margaret Duffy, Glenn Leshner, Glen Cameron, Yong Volz, Earnest Perry, and Berkley Hudson. Smart people, you will realize, can also be very nice. Ryan Thomas will introduce you to his detailed grading rubrics, as well as to Thip Thai, which will be your most favorite Thai restaurant. And Mike Jenner will give you a great dissertation idea and go out of his way to help make that idea work. Brad Best and Joy Mayer will help you in your survey. Outside the journalism school, Ze Wang and Ben Warner will let you sit through their classes. Becky Shoemaker will help you survive as an international student in the US. Back in the journalism school, Sarah Smith-Frigerio and Martha Pickens will always be willing to hear out your numerous questions. Pat Kelly will even help in your interview transcriptions. Dorothy Carner and Sue Schuermann will be awesome, and Dorothy will even make you tear up when she says the journalism library "will always be here for you." 
Third, find a good dissertation chair. He will be your mentor, critic, and friend. He will make you work hard. And that's good, because you want a good dissertation. But he will also help make your life easier by always being there to address your questions, listen to your rants, read your emails even during weekends. And he will change your life by telling you to insert page breaks in your word documents. You need Tim P. Vos.

Fourth, form a strong dissertation committee. Find someone who can do just anything because she is so smart and yet so accommodating. Just like Esther Thorson. You also need someone who will encourage you to speak in class and teach you to believe in yourself, someone very sharp to help you refine your ideas. Just like Stephanie Craft. You also want someone who will comfort you when you feel overwhelmed and offer you helpful suggestions when you need them. Just like Amanda Hinnant. You also need an outside member to make sure you are doing your statistics right. Just like Steven Osterlind. And you should find a prominent scholar in journalism studies, whose body of work you cite all the time, whose humility, wisdom, and words of encouragement will inspire you. Just like David H. Weaver. Fifth, observe at three newsrooms staffed by warm, accommodating, and helpful editors. Send survey invitations to online editors and be surprised by how helpful most of them will be. And be grateful.

Sixth, find good friends to keep you sane. Start with your own cohort. Spend a lot of time with Seoyeon Hong, Heather Shoenberger, and Jon Peters. Write a lot of papers with Pat Ferrucci, and be really, really good friends with him, especially because he likes Asian food and he will go to Teppanyaki with you anytime. You will learn to drink because of them, but you will also learn that drinking with them is the best. Outside your awesome cohort, be roommates with Saleem Alhabash, for he is ever helpful and a good 
cook; be friends with David Wolfgang, for he is helpful and he also likes Asian food; and hangout with Erin Willis, Adam Maksl, Chad Painter, Lea Hellmueller, You Li, Alecia Swasy, Manu Bhandari, Russell Clayton, Yulia Medvedeva, Erika Johnson, and many others. You need good friends outside your university, too. Filipinos in Missouri will help you battle homesickness with great Filipino food, and phone conversations with Sandy De Leon will help you cope. You also might just find an awesome research partner, like Bruno Takahashi, who will inspire you to become productive by listening to classical music. Or heavy metal. And keep in touch with your friends from back home, especially with your colleagues at the Philippine Daily Inquirer. Your best friend Tarra Quismundo will always be there if you need to rant, reflect on things, or just laugh. Be grateful.

Seventh, you need a loving family. Your brothers Edson III and Edson IV and your sister Eloisa Pearl will give your life a purpose, for they will always make you proud. They will grow up to be smart, kind, and respectful. This will inspire you to be a better person. You need great parents, like Edson Sr. and Perlita, who will love you unconditionally, make you feel whole despite your insecurities, and make you believe in yourself despite your doubts. Love them dearly-it will be difficult not to, because you owe them so much, because despite all your imperfections they make you feel as if there is nothing you cannot do. Live by their example and listen to them. And be grateful.

This is how I survived seven semesters of the doctoral program. I came to Columbia knowing no one and will leave feeling loved. And I will forever be grateful to the Lord Almighty for blessing me with all these wonderful people whom I love dearly, who make my life meaningful. Thank you for all His love and greatness, even if a lot of times I prove unworthy. 


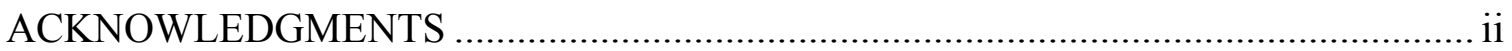

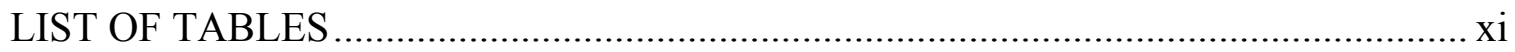

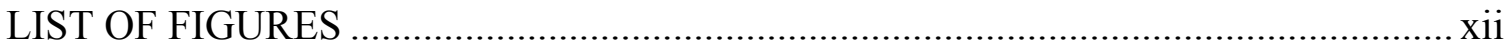

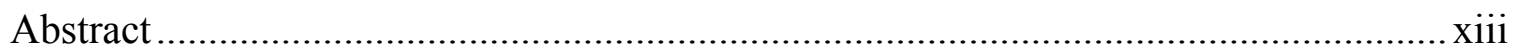

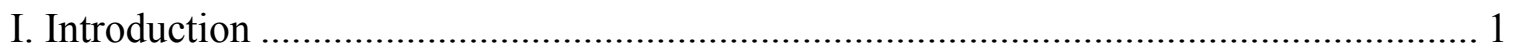

II. Toward a Theory of Influences on Journalists ....................................................... 8

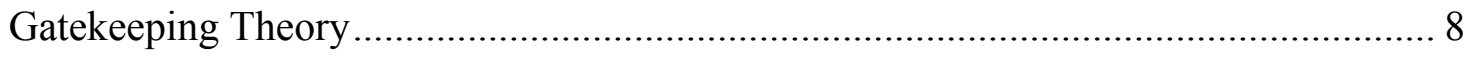

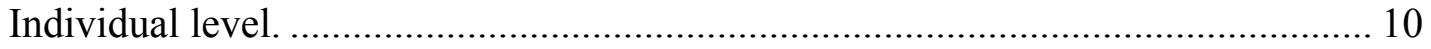

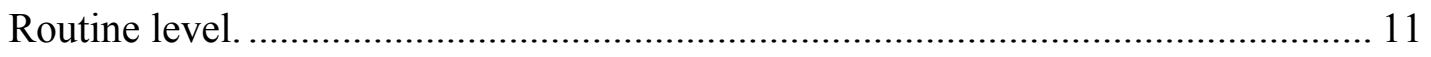

Organizational level........................................................................................ 12

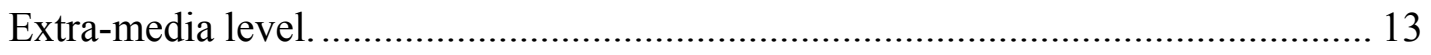

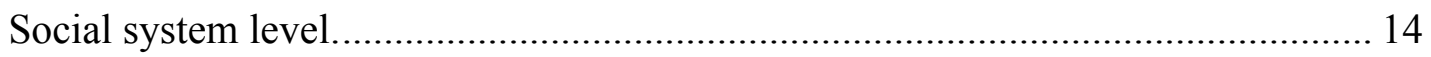

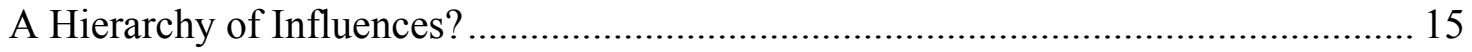

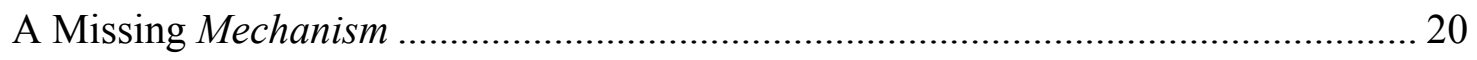

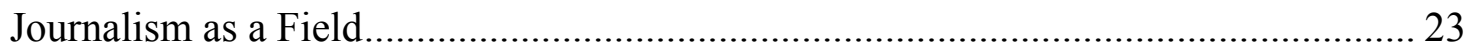

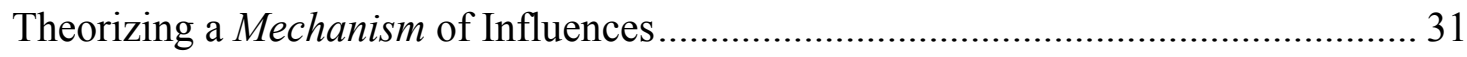

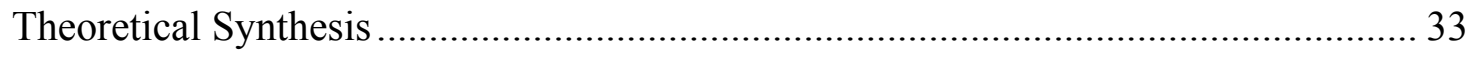

III. The Audience as a Form of Capital ………………….......................................... 35

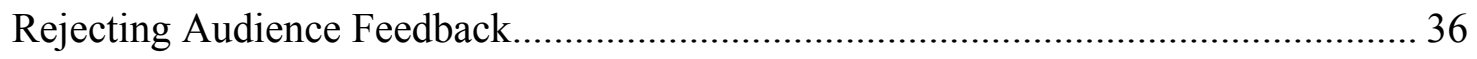

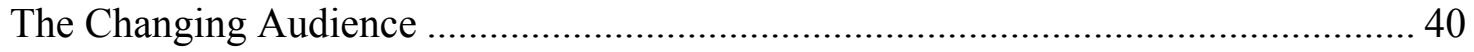




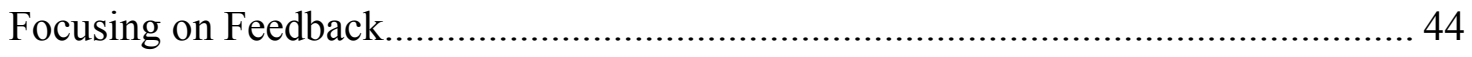

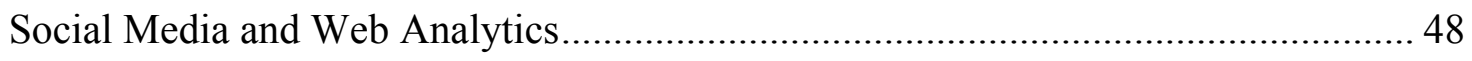

Challenges in Audience Measurement.................................................................... 51

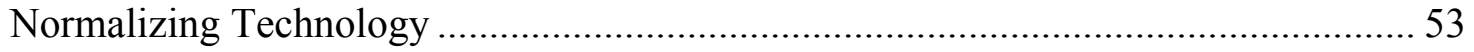

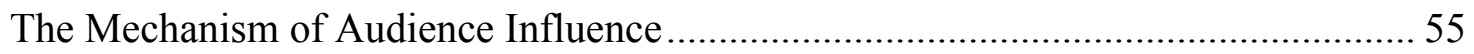

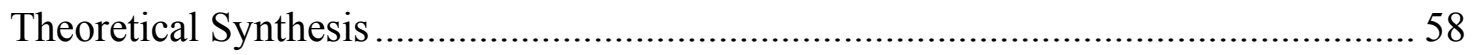

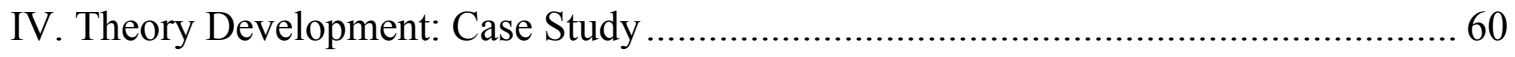

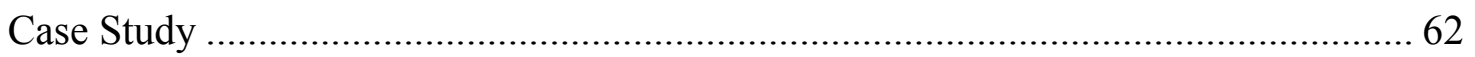

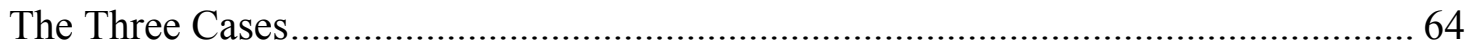

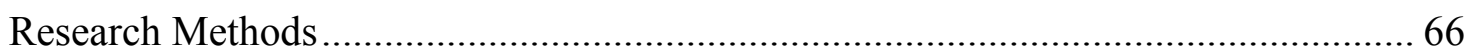

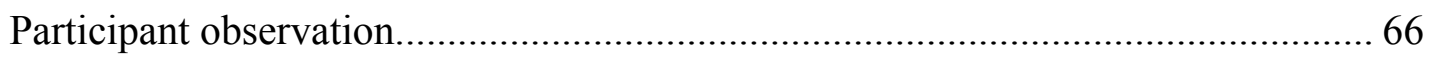

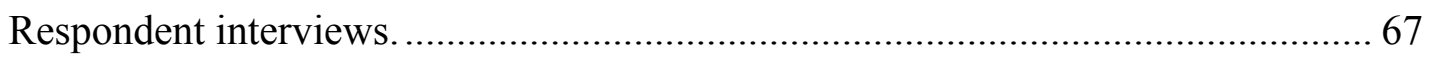

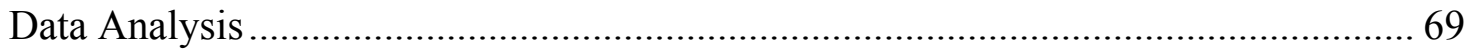

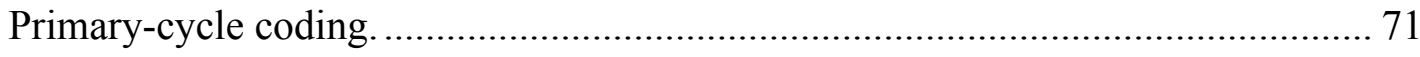

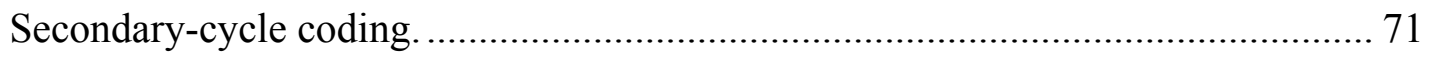

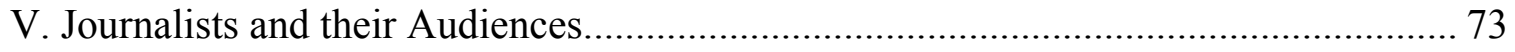

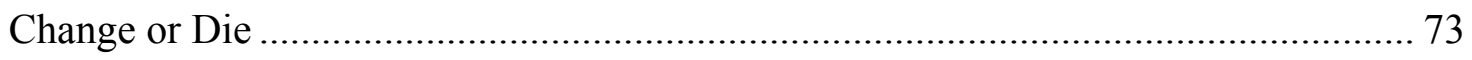

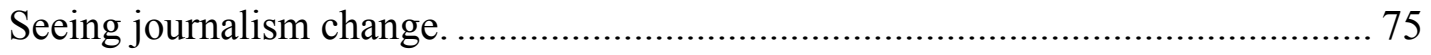

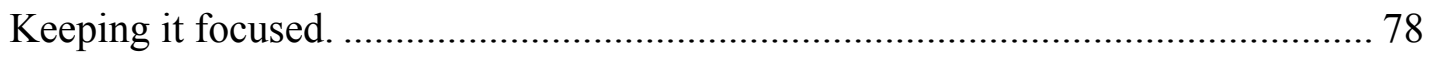

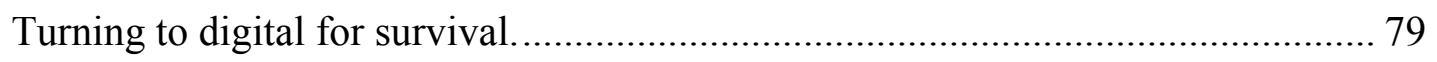

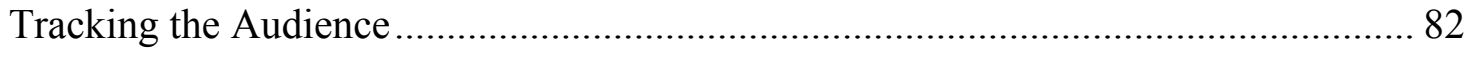

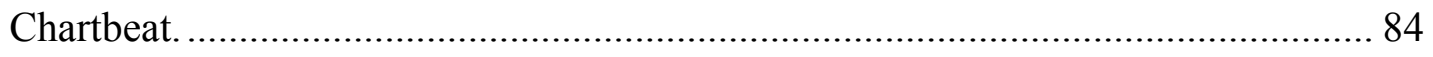

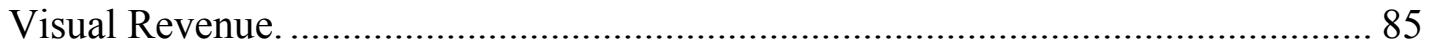




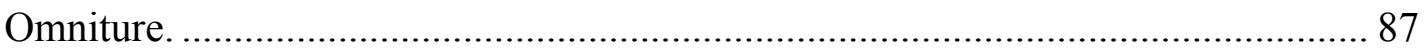

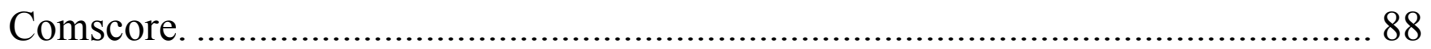

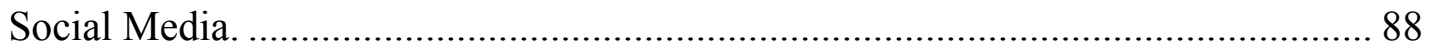

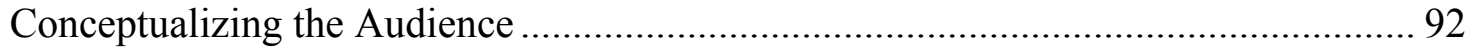

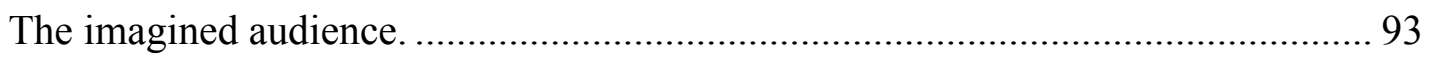

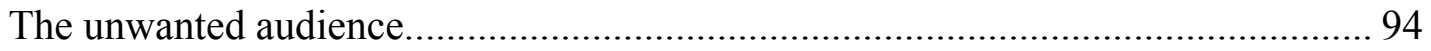

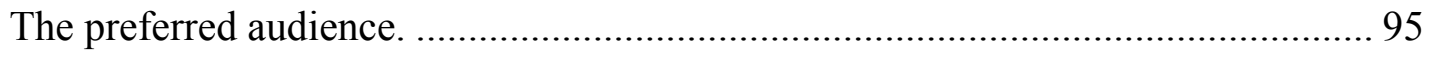

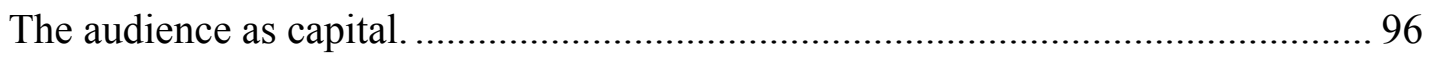

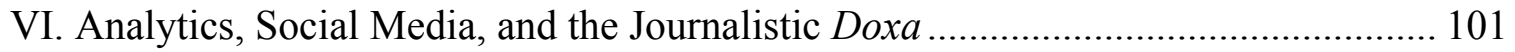

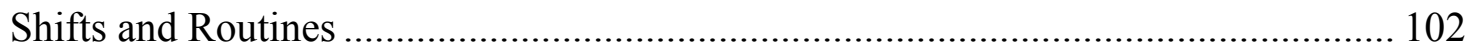

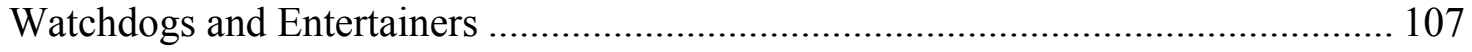

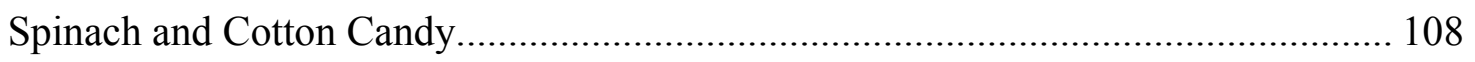

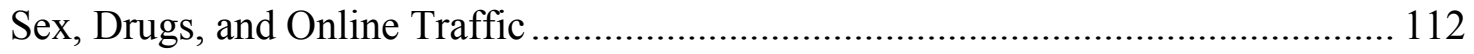

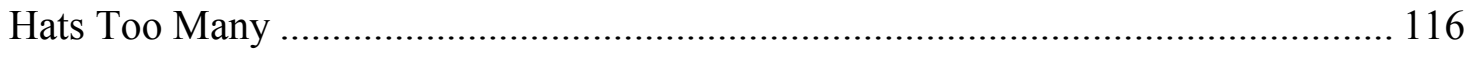

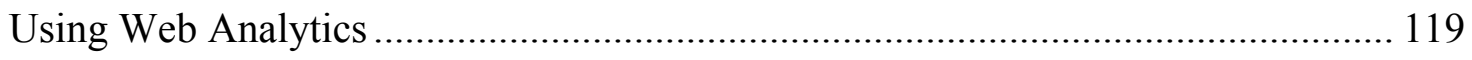

Selection................................................................................................. 120

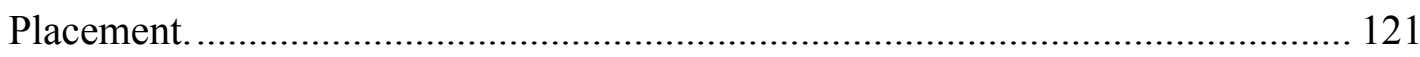

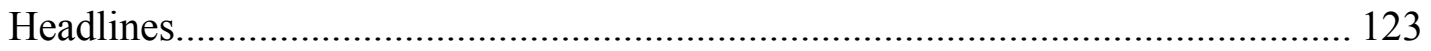

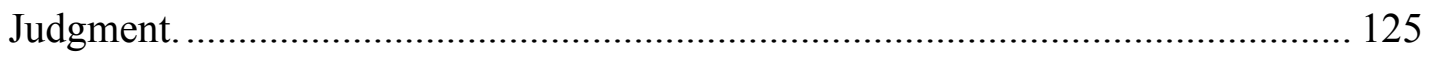

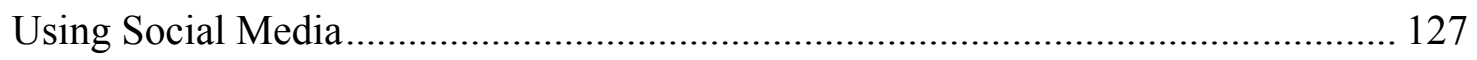

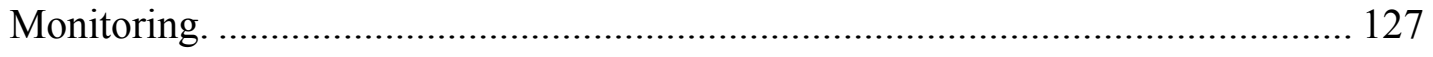

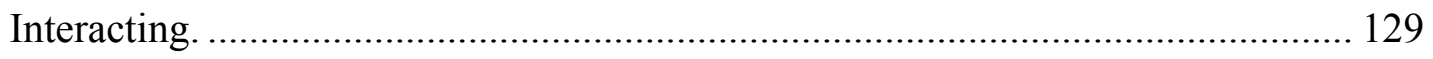

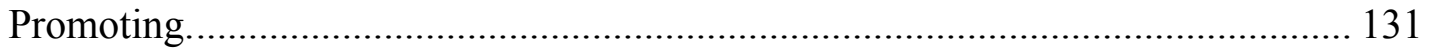


'Doing Well'

A Synthesis

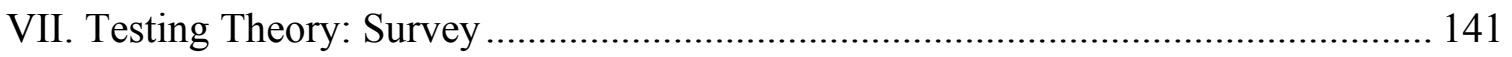

Complementing Case Study ............................................................................... 141

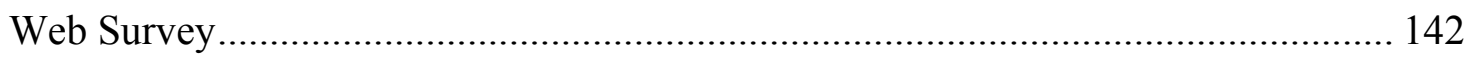

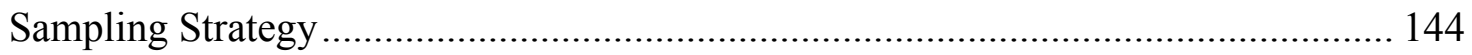

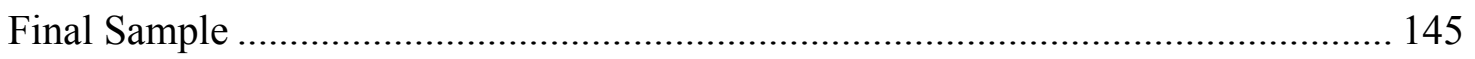

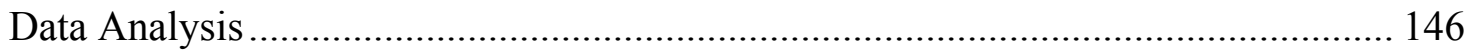

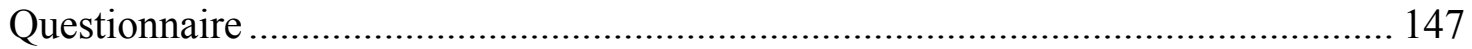

Variables, Hypotheses and Research Questions ..................................................... 148

Conception of the audience as capital.................................................................... 149

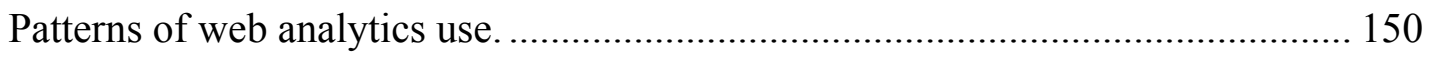

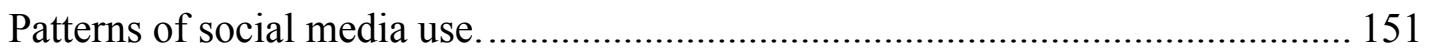

Perception of degree of competition................................................................... 154

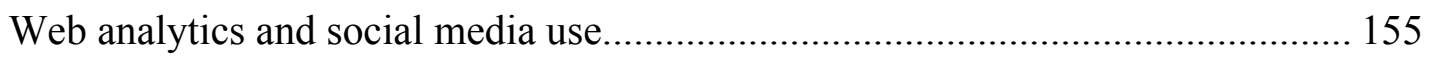

VIII. Pathways to Using Audience Information Systems .............................................. 157

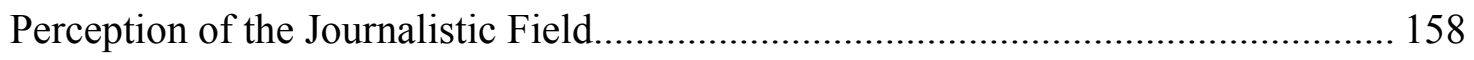

Patterns of Web Analytics Use ...................................................................... 158

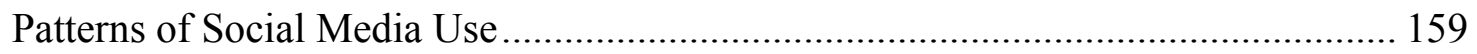

Explaining Web Analytics Use ........................................................................... 160

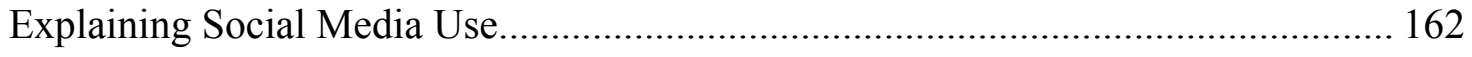

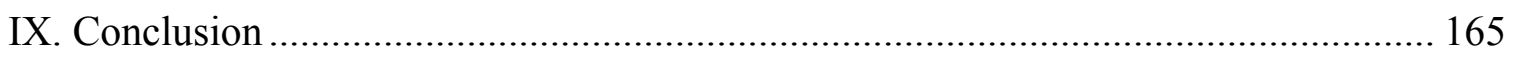

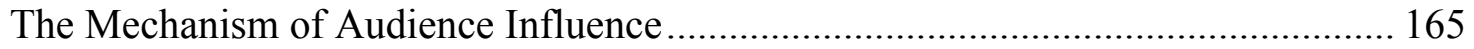




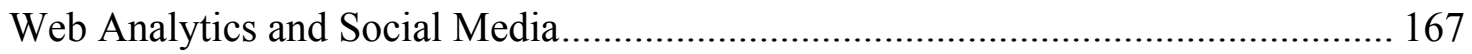

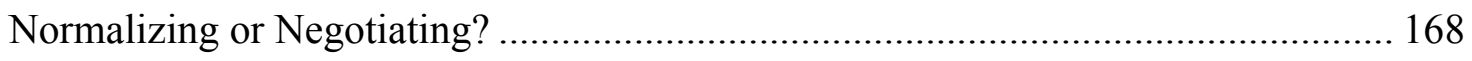

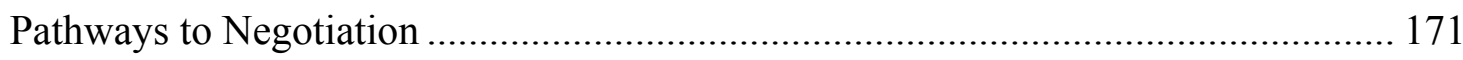

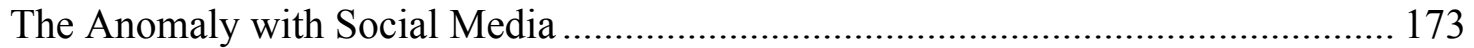

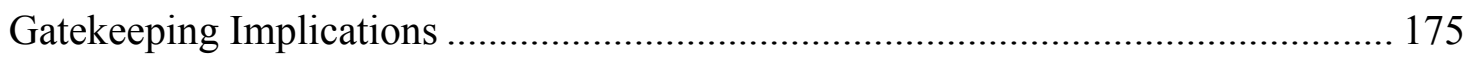

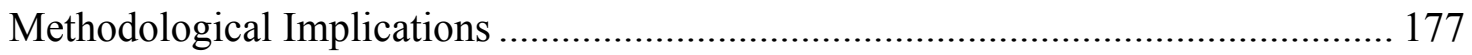

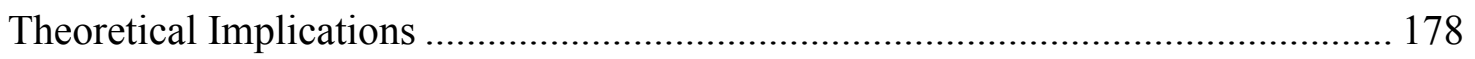

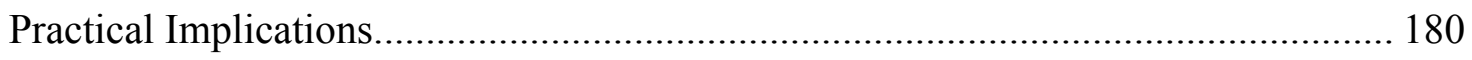

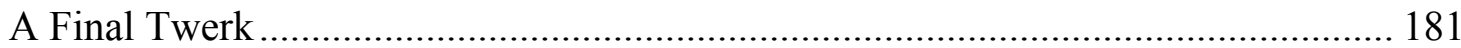

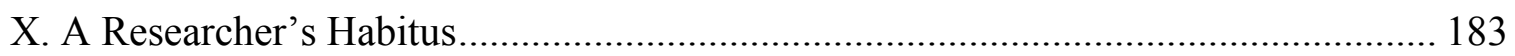

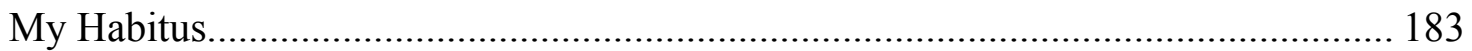

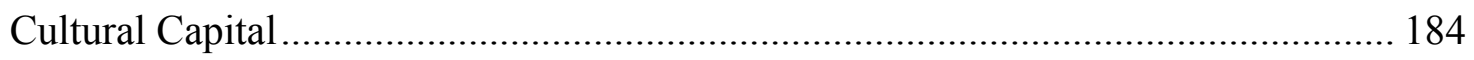

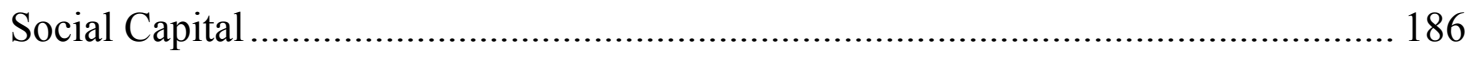

And Some Sort of Economic Capital......................................................................... 187

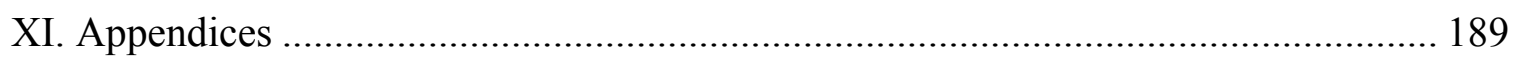

A. Proposed Mechanism of Influence................................................................. 189

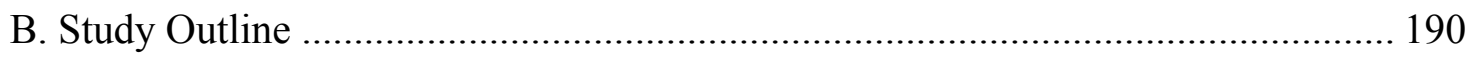

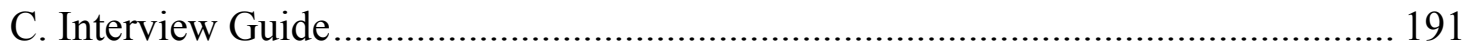

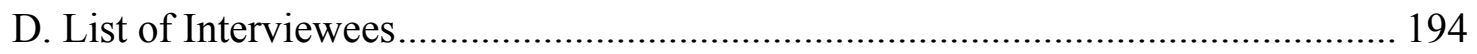

E. Theoretical Framework …………............................................................ 195

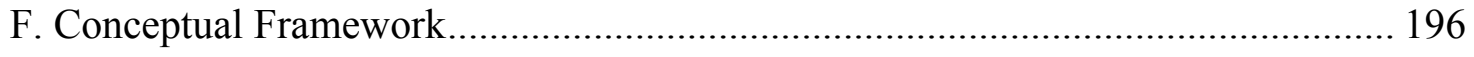

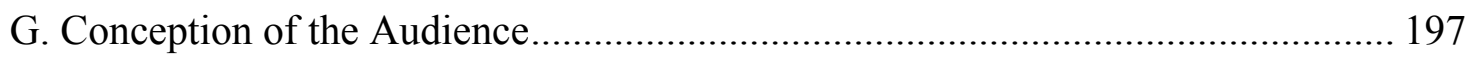

H. Patterns of Web Analytics Use ...................................................................... 198 


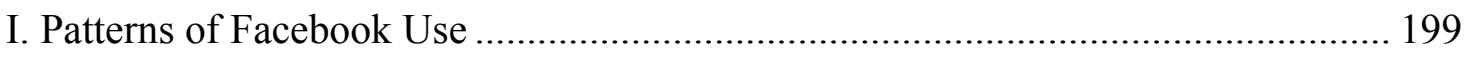

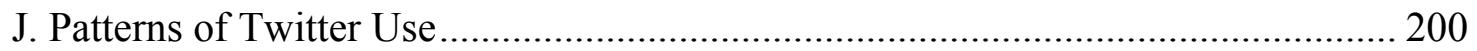

K. Hypothesized Model for Web Analytics............................................................. 201

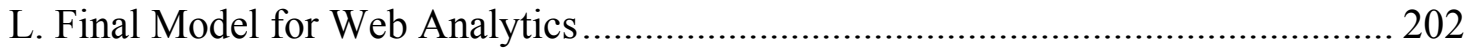

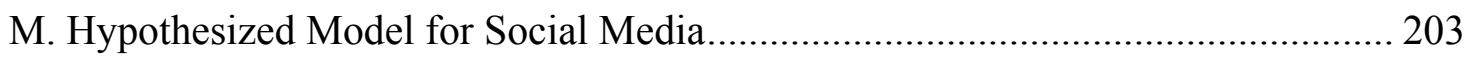

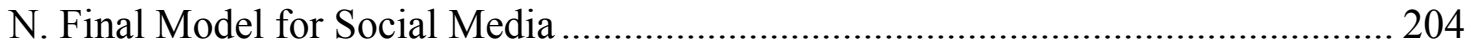

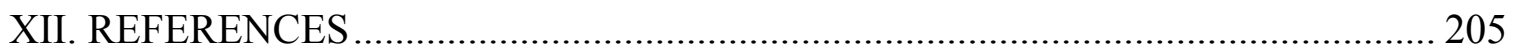

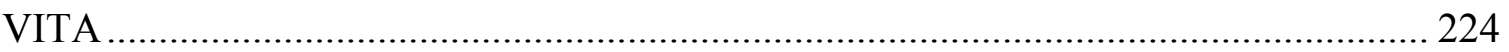




\section{LIST OF TABLES}

Table

Page

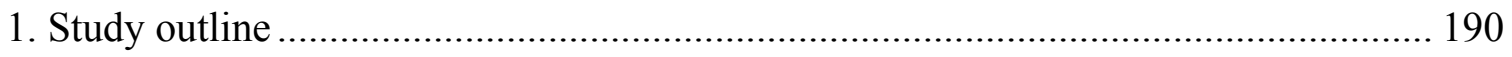

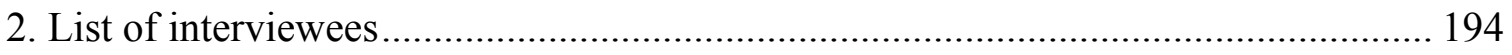

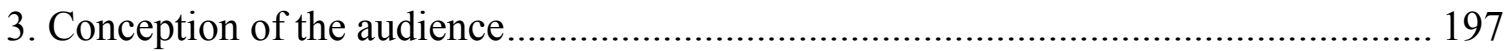

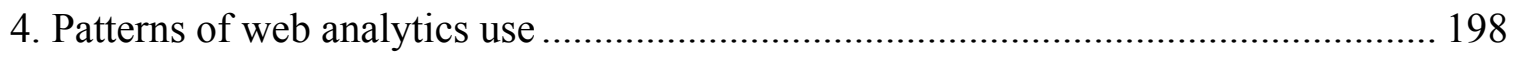

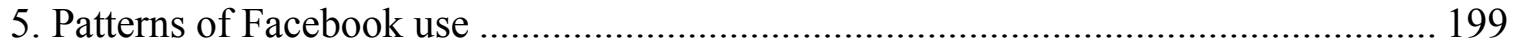

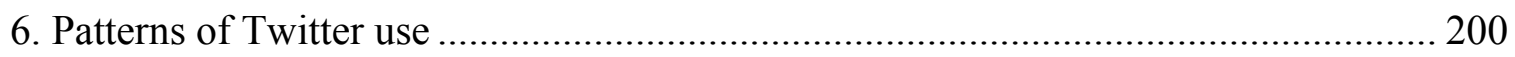




\section{LIST OF FIGURES}

Figure

Page

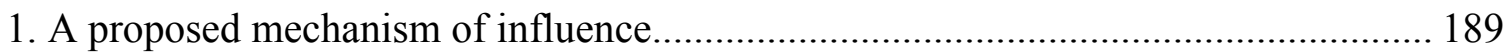

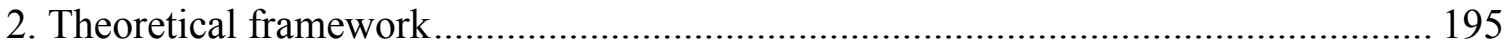

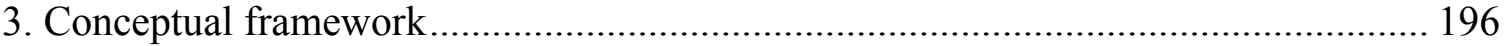

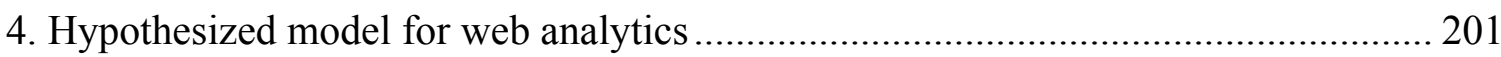

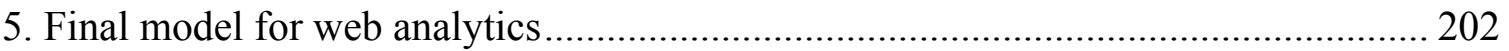

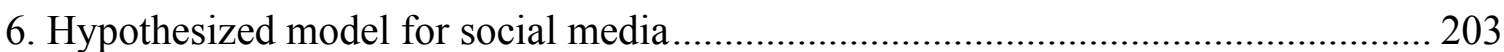

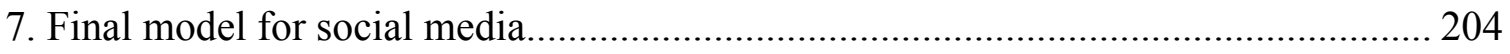




\title{
WEB ANALYTICS, SOCIAL MEDIA, AND THE JOURNALISTIC DOXA: THE IMPACT OF AUDIENCE FEEDBACK ON THE EVOLVING GATEKEEPING PROCESS
}

\author{
Edson C. Tandoc Jr.
}

Dr. Tim P. Vos, Dissertation Supervisor

\begin{abstract}
New communication technologies have allowed not only new ways in which the audience interacts with the news but also new ways in which journalists can monitor online audience behavior. Through new audience information systems - web analytics and social media - the influence of the audience on the news construction process is increasing. This occurs as the journalistic field tries to survive a shrinking audience for news. In this mixed methods research, I argue that how journalists conceive of the audience as a form of capital influences the extent to which journalists integrate audience feedback from analytics and social media in their news work. I developed this theoretical framework through case studies of three online newsrooms that included a total of 150 hours of observations and 30 respondent interviews. I subsequently tested the theoretical framework refined through my qualitative analysis using structural equation modeling (SEM) based on survey data collected from 276 online editors. The findings showed a process of negotiation - between providing what audiences need and what they want, between editorial autonomy and audience influence, and between individual agency and organizational constraints - that should clarify how we understand gatekeeping in this age of a knowable and quantifiable audience.
\end{abstract}




\section{Introduction}

Grinding and twerking in her skimpy flesh-toned latex underwear, wagging her tongue most of the time, 20-year-old singer Miley Cyrus shocked a lot of people with her performance at the 2013 MTV Video Music Awards (VMA). The next morning, news giant CNN shocked media critics. Not only did it upload a story about the stunt, but CNN.com also used the article as the main story on its homepage (Hare, 2013). In an online article explaining that decision, the website's managing editor Meredith Artley said: "It was an attempt to get you to click on CNN.com so that we could drive up our web traffic, which in turn would allow us to increase our advertising revenue" (Onion, 2013). Except that it wasn't really Artley who wrote the piece. It was published by the satirical news outlet The Onion, which was trying to make fun of CNN's editorial decision while also trying to make a point (D'Addario, 2013; Phillips, 2013). The point was, simply, that serious journalism appears to be losing out to financial pressures, making drawing traffic to the site through celebrity news, such as the Miley Cyrus story, the norm. The satirical editorial, passing itself off as written by Artley, further said: There was nothing, and I mean nothing, about that story that related to the important news of the day, the chronicling of significant human events, or the idea that journalism itself can be a force for positive change in the world... But boy oh boy did it get us some web traffic (Onion, 2013).

The real Artley later responded on Twitter, denying she had penned The Onion's satirical editorial that had been published with her byline and headshot. "But I accept all 
compliments and deny all accusations," she said on her tweet (Phillips, 2013). Not everyone laughed at $\mathrm{CNN}$, however, for within the field of journalism, a field that is seeing a continually declining newspaper readership and is turning to digital for survival, many journalists understand how drawing traffic to news sites is becoming more and more crucial. An editorial from Variety pointed out that the decision to display the Miley Cyrus story as the main story was not as easy as The Onion made it sound (Wallenstein, 2013). "It's difficult to subsist on substantive journalism," the Variety editorial said, "without some help from more crowd-pleasing content."

In short, journalism needs the audience.

News is meant to be read. Newsrooms institute layers of copy-editing and factchecking because of the expectation that their outputs will reach an audience. "The audience is the ultimate consumer of the media product - the end of the news process" (Shoemaker \& Reese, 2013, p. 177). News organizations, to sustain operations, usually need to maintain an audience to either sell to advertisers or to justify state subsidy. Therefore, in understanding the construction of news, one cannot divorce journalism from its audience.

The audience plays an important role in the news construction process and is considered by media theorists as among those that exert influence on news content (Baker, 2002; Gans, 1979; Shoemaker, 1991; Shoemaker \& Reese, 1996; Shoemaker \& Vos, 2009), and yet for the longest time journalists had the excuse of not knowing who exactly their audience was and what it wanted (Beam, 1995; Gans, 1979). Newspapers relied on readership surveys while broadcast news relied on rating systems- forms of 
audience research that provided limited clues about their actual audiences (Gans, 1979; Schlesinger, 1978).

But the onset of online news is changing not only how users interact with the news, for it has also provided journalists with a new way of learning more about their audiences (Napoli, 2011). Through web analytics, news organizations can collect and analyze the footprints that news users leave behind, offering immediate access to an unprecedented wealth of information about the audience. No longer do journalists second-guess which issues audiences are following. That information is now usually displayed on their websites' homepages: The most popular stories of the day—or even of the hour or the minute - are listed automatically based on users' actual clicks. These clicks guide subsequent decisions and influence editorial judgment (Lee, Lewis, \& Powers, 2012; MacGregor, 2007). Thus, CNN.com's decision to put the Miley Cyrus story as the site's main story that Monday morning was a decision made with an astute awareness, based on journalistic experience, of how the story would perform. It is an example of giving the audience what journalists think the audience wants, but this time with a more accurate picture of what the actual audience really wants.

Most online newsrooms already monitor web metrics (Lowrey \& Woo, 2010; McKenzie, Lowrey, Hays, Chung, \& Woo, 2011; Tandoc \& Jenner, 2013). If we conceive of web metrics as forms of detailed and immediate feedback from the audience — communicating audience preferences, among other things—-then, with web metrics being almost omnipresent in newsrooms, the influence of the audience on news construction should also dramatically increase. This is not as straightforward as it sounds, however, for the journalistic field is dominated by a particular set of rules, routines, and 
norms — what field theorists refer to as the journalistic doxa - that have long guided news work. Rules, routines, and norms persist for a reason. For example, they simplify news work, they make it more efficient, and because of these they are agreed upon by the community of journalists (see Tuchman, 1972, 1978). This means, however, that rules, routines, and norms can also be renegotiated and changed.

The journalistic field is an ever-evolving field and journalism has changed in many ways in the last few decades (e.g. Peters \& Tandoc, 2013; Tandoc, Hellmueller, \& Vos, 2012; Tandoc \& Takahashi, 2013). What does it mean now to be a journalist? What roles should journalists now serve in society, especially with an evolving audience? Technology is a major factor fueling a lot of these changes (Shoemaker \& Reese, 2014). Not only did the internet allow new forms of interactions between journalists and the "people formerly known as the audience" (Rosen, 2006) who can now produce and disseminate their own content (Bruns, 2003), but it also allowed journalists to know more about the audience and what the audience does with news (Napoli, 2011). Online news has swung right into the center of the journalistic field (Domingo, 2011) and the question now is not whether journalism has changed, but how it is changing.

This study is interested in understanding how journalism is changing. I am particularly interested in web analytics and social media as new audience information systems for tracking and understanding the audience. Access to these pieces of information can influence how journalists conceive of their audiences, and these conceptions can affect how much influence journalists allow their audiences to exert on their daily news work. Therefore, this dissertation begins with two general questions: 
How do journalists conceive of their audience, and how does this conception influence how they do their work?

In this study, analysis of news work will focus on the extent to which journalists incorporate audience feedback in their editorial decisions. News judgment is increasingly becoming a fragile balancing act between editorial autonomy on one hand and the increasing influence of the audience on the other. I am interested in understanding this intersection between traditional journalistic norms that have guided news work in the past and the affordances of new audience information systems that are challenging these journalistic traditions.

These goals require clarification of two main concepts. In Chapter 2, I attempt to clarify the notion of influence in the news construction process. I discuss how initial theoretical discourse on influences on news content (Shoemaker \& Reese, 1996; Shoemaker \& Vos, 2009) could be repositioned into a discussion of influences on gatekeepers. I also offer an extension of gatekeeping theory by borrowing the concept of journalistic capital from field theory (Bourdieu, 1998, 2005) to theorize a mechanism of influence that can explain how and why gatekeepers become vulnerable to influence. Field theory has been proposed as an appropriate framework for newsroom ethnographies because of its holistic approach to studying journalism (Willig, 2013). In Chapter 3, I illustrate the utility of these theoretical clarifications by focusing on the audience as an influence on gatekeepers. I also explicate audience as a form of journalistic capital, again turning to field theory as a framework to account for influences on how journalists conceive of their audience and how this conception subsequently influences particular aspects of news work. 
In Chapter 4, I describe my ethnographic case study approach in studying three online newsrooms (see Boczkowski, 2005 for an example). In adapting the term ethnographic case study to describe my qualitative approach, I am defining it as a case study approach that employs ethnographic methods. The study of online newsrooms is particularly important, for despite the seemingly similar patterns of work that mark both traditional and online newsrooms, marked schisms exist between them not only in terms of routines but also in terms of the nature of interactions between journalists and the online audience (Paterson, 2008; Singer, 2008). These interactions, allowed by particular affordances of online technology, are also plausibly influencing how traditional journalistic norms are being renegotiated. Studying the different facets of online news work requires detailed and comprehensive observation, which is most effectively accomplished by newsroom ethnographies (Domingo, 2011; Paterson, 2008; Singer, 2008). I spent a total of 150 hours in three online newsrooms over a period of three months, employing ethnographic research methods, particularly observation and interviews. Paterson (2008, p. 2) argued that only ethnographic methods "can come close to providing an adequate description of the culture and practice of media production, and the mindset of media producers." I present my findings in Chapters 5 and 6.

In Chapter 7, I discuss how case studies can be complemented by survey research. A goal of the ethnographic case study approach is to offer a theoretical framework that is both grounded in specific cases that were studied and useful in understanding other similar cases beyond the study. A useful case study is one that not only explains a phenomenon as unraveled by one or more cases but also provides theoretical lessons that can be used to understand the same phenomenon as experienced 
by other contemporary and future cases (Creswell, 2007). Observations in online newsrooms allow comprehensive and deep understanding of specific newsrooms that can inform theory. However, to move the results of my ethnographic case studies forward, I also conducted a survey of online editors to test the theoretical relationships that I found from my qualitative study of three online newsrooms. Singer (2008) pointed out that qualitative studies of online newsrooms could benefit from quantitative studies that offer a wider breadth of observations. The quantitative findings are presented in Chapter 8 . Finally, I offer connections between my qualitative and quantitative findings and argue theoretical and practical implications in Chapter 9. 


\section{Toward a Theory of Influences on Journalists}

News influences people, and because of this a lot of people try to influence the news. This puts journalists under a lot of pressure, balancing the different interests they are supposed to serve while navigating a process where autonomy is under constant attack. News is constructed (Reese \& Ballinger, 2001). If we are to understand how news becomes what it is, we have to understand the relationships between the individuals who construct it as well as the larger context within which this construction occurs.

\section{Gatekeeping Theory}

The process of news construction has been described using various metaphors (Mindich, 1998) such as: 1) providing a mirror image of society, initially construed as referring to news as a means of self-reflection but was later used to refer to the long discarded assumption of news passively reflecting social events; this metaphor also refers to the news as reflecting audience preferences (for a discussion of the mirror metaphor, see Vos, 2011); 2) functioning as a filtering process, such that raw materials for news pass through a series of filters until only the cleansed residue remains (Herman \& Chomsky, 2002); 3) working as a net that retains some information and lets go of others (Tuchman, 1978); and finally as something akin to 4) gatekeeping (Shoemaker, 1991; Shoemaker \& Vos, 2009; White, 1950). Psychologist Kurt Lewin is considered the first to use the metaphor of gatekeeping, and he initially used it to analyze how food ends up

on the dining table (Brown, 1979; Shoemaker \& Vos, 2009). In his original model, Lewin argued that food items pass through either the buying channel or the gardening channel; 
each channel is divided into sections where food items enter through a gate (Shoemaker \& Vos, 2009). These gates are governed either by a gatekeeper (e.g. a housewife deciding which dish to prepare) or a set of impartial rules (Brown, 1979; Shoemaker \& Vos, 2009). In a manuscript prepared before his death that was eventually posthumously published, Lewin applied the metaphors of gate and gatekeeper to the movement of news items through communication channels (Shoemaker \& Vos, 2009; White, 1950), a conceptualization that White (1950) later applied to a study of how a wire editor selected articles to publish.

Gatekeeping is a theory of news selection. It describes the process of how bits of information about issues and events pass through a series of gates, get transformed in the process, and end up in the news (Shoemaker \& Vos, 2009). Gatekeepers can close or open the gates, thereby constraining or facilitating the flow of information. Shoemaker and Vos (2009) defined gates as "decision or action points" and gatekeepers as those who "determine both which units get into the channel and which pass from section to section" (p. 15). These gatekeepers operate under several layers of influences that might affect their intention, capacity, or both, to either close or open the gates. For example, Gans (1979) classified seven considerations that affect news selection: source, substantive, product, value, political, commercial and audience considerations. The first four are those that journalists apply; the rest are those that are imposed on journalists (Gans, 1979). A survey of journalists across 17 countries also classified perceived influences on journalists into six factors: political, economic, organizational, procedural, professional, and reference groups (Hanitzsch et al., 2010). 
Influences on gatekeepers are supposed to operate in a hierarchy, from the micro to the macro level, ranging from the individual, to the routine, organizational, extramedia, and social system levels (Reese, 2001; Shoemaker \& Reese, 1996, 2013). A hierarchical structure argues that "these forces operate simultaneously at different levels of strength in any shaping of media content" (Reese, 2001, p. 179).

Individual level. In the first study to use the metaphors gate and gatekeeper in describing the news construction process, White (1950) asked a wire editor at a local paper, whom he named Mr. Gates, to collect the wire copies he decided to discard. For seven days in February 1949, Mr. Gates scribbled on each of the wire copies he had rejected to describe his reasons for closing the gate on these articles. White (1950) concluded: "Through studying his overt reasons for rejecting news stories from the press associations we see how highly subjective, how based on the 'gatekeeper's' own set of experiences, attitudes and expectations the communication of 'news' really is," (p. 390). Seventeen years later, Snider (1967) sought Mr. Gates again and replicated White's (1950) study. Snider (1967) did not find anything drastically different: "Mr. Gates still picks the stories he likes and believes his readers want" (p. 427).

White was exposed to Lewin's work on food gatekeepers when he worked as Lewin's research assistant at the University of Iowa (Shoemaker \& Vos, 2009). Though later on heralded as among the earliest studies to shed light on the sociology of news, White's (1950) study was earlier incorporated into the prevalent limited media effects paradigm during his time (Reese \& Ballinger, 2001). If news is based only on an editor's subjective judgment, it cannot exert powerful effects on those who read the news. 
The individual level looks at "how the characteristics, knowledge, attitudes, and behaviors of individual people affect the gatekeeping process" (Shoemaker \& Vos, 2009, p. 33). For example, the Mr. Gates studies found that an editor's personal preferences influenced his editorial decisions (Snider, 1967; White, 1950). Gender also influences editorial decisions: Female editors tend to encourage positive news reporting and do not differentiate between male and female reporters when assigning beats, unlike in maledominated newsrooms (Craft \& Wanta, 2004). Male journalists in Iraq also reported higher levels of perceived danger than did females (Kim, 2010).

Routine level. The second level of analysis focuses on routines, defined as the "patterned, repeated practices and forms media workers use to do their jobs" (Shoemaker $\&$ Reese, 1996, p. 105). For journalists who are confronted with an overload of expected and unexpected events and pieces of information, routines make their jobs more manageable (Tuchman, 1972, 1978). For example, journalists resort to typifications to classify events as hard news, soft news, spot news, developing news, or continuing news, as each classification comes with particular expectations and work demands, providing journalists some form of control in an otherwise uncontrollable and unexpected situation (Tuchman, 1978). News values, or elements that supposedly guide journalists in deciding what counts as newsworthy, such as timeliness and prominence (Harcup \& O'Neill, 2001; Shoemaker \& Vos, 2009), are also part of journalistic routines. News principles, such as adhering to the norm of objectivity, also form part of journalistic routines, enabling journalists to make their jobs easier and avoid legal complications, such as facing libel suits (Tuchman, 1972). 
Fishman (1988) described routines as the "crucial factor which determines how newsworkers construe the world of activities they confront" (p. 14). Shoemaker and colleagues (2001) did a content analysis of news articles about bills filed in the US Congress and conducted surveys of the reporters who wrote those news articles and the news editors of the organizations that published the articles about those bills. They found that editorial level preferences - and not individual characteristics of reporters who wrote about the bills - were correlated with the amount of coverage each bill got (Shoemaker, et al., 2001). They concluded that routine level influence exerted a stronger effect on news selection than did individual level influences (Shoemaker, et al., 2001). Similarly, Bissell (2000) concluded that newsroom routines, such as control exerted by wire editors, influenced the selection of published local photos. Cassidy (2006) also argued that perceived routine level forces, such as the influences of peers and supervisors, exerted more influence than individual-level forces on the professional role conceptions of online and newspaper journalists.

Organizational level. The third level refers to the influence on news construction exerted by the organization, referring to factors such as an organization's size, structure, or orientation. Breed (1955) argued that journalists get socialized into the news organizations they belong to. This happens through organizational policy, which can either be explicit or often covert (Breed, 1955). Berkowitz (1990) advocated a move away from the individual-level focus of earlier gatekeeping studies to focus more on editorial decision-making as a "group process" constrained by organizational factors, such as an organization's newscast format. 
Beam (2003) found that newspapers with high market orientation tend to publish more lifestyle and sports stories, and fewer news items on government and public affairs, than newspapers with low market orientation. Though media corporations are criticized as being more susceptible to economic pressures, they are also more capable to withstand political influences because of their resources. For example, Rossman (2004) found that radio stations of larger chains were more likely to retain on their playlist songs from a group that had been criticized for making negative remarks against President Bush during a concert. Newsroom culture and even staffing arrangements also matter. For example, Hansen and colleagues (1998) found that journalists in a newsroom perceived a decline in journalistic quality when a team system, where journalists are assigned based on content areas, was introduced to replace the traditional beat system. Medium was also found to be related to content decisions (Maier, 2010; Singer, 2001).

Extra-media level. The fourth level refers to "influences on content from outside of media organizations" (Shoemaker \& Reese, 1996, p. 175). Shoemaker and Vos (2009) called this the social-institutional level of analysis, referring to factors such as the degree of market competition; pressure from sources, interest groups, public relations people, advertisers and the government; and the influence of the audience. For example, Yoon (2005) found that how journalists perceive the legitimacy of public relations organizations influenced coverage of those PR firms. Where news organizations are located can also influence news content. McCluskey and colleagues (2009) found that newspapers in less pluralistic communities tend to be more critical of protests than newspapers in high pluralistic communities. Newspapers in high pluralistic communities tend to quote protesters more frequently than do newspapers in low pluralistic 
communities (McCluskey, et al., 2009). Newspapers in communities that support the current President also tend to cover that President frequently (Eshbaugh-Soha, 2008). While characteristics of communities can be considered as extra-media influences, patterns that cut across communities, such as pluralism, can be considered as social system level influences.

Social system level. The fifth level refers to social system level influences. In the original hierarchy of influences model, Shoemaker and Reese (1996) identified the fifth level - the outermost of the concentric circles that represent influences on news content, thereby subsuming all the other levels - as ideology. For example, one of the filters that raw materials of news must pass through, according to the propaganda model of Herman and Chomsky (2002), is the anti-communism ideology prevalent in the US before the collapse of the Soviet Union.

But Shoemaker and Vos (2009) argued that the social system level of analysis involves more than the influence of ideology. They argued that this level refers to "society-level influences on news media content—-those influences include social structure, ideology, and culture" (Shoemaker \& Vos, 2009, p. 105). For example, Hanitzsch and Mellado (2011) compared survey responses of journalists in 18 countries and found that journalists in less democratic countries perceived stronger political influences on their news work than did journalists in democratic countries. A secondary analysis of data from journalists in China, Taiwan and the US found that political systems exerted a strong influence on journalists' role perceptions (Zhu, Weaver, Lo, Chen, \& $\mathrm{Wu}, 1997)$. A survey of Washington correspondents also found that journalists working for US-based organizations tend to enact the disseminator role while correspondents 
reporting for news organizations outside the US tend to enact the mobilizer and adversarial roles (Tandoc, et al., 2012). But while social systems have been traditionally defined as countries with specific boundaries, they can be smaller or bigger than nationstates, as long as scholars can argue how a specific social system is being studied holistically (Shoemaker \& Vos, 2009).

\section{A Hierarchy of Influences?}

Though initial work on the levels of influences on news content organized these levels in a hierarchy (Reese, 2001; Shoemaker \& Reese, 1996) — as we move from micro to macro levels, each one subsumes those that come before it-Shoemaker and Vos (2009) questioned whether these levels of influence were indeed nested in a hierarchy.

Conceptualizing influences as operating in a hierarchy is parallel to the news construction model of individual gatekeepers working in a hierarchical organization. The primary gatekeepers, in most instances reporters, are usually placed at the base of a pyramid structure, reporting under copy editors and senior editors, who report under managing and associate editors, who are under the editor-in-chief and the publisher. The hierarchical model is attractive for its simplicity and comprehensiveness, for it builds on and brings together otherwise isolated theories and assumptions in media sociology (Reese, 2001; Shoemaker \& Reese, 2013). It also accounts for the interaction between these different levels of influences, possibly influencing each other before exerting an effect on media content. For example, it provides an explanation for the influence of capitalist ideology on news content by specifying how a macro-level influence can trickle down into the micro-level of the individual media worker. Capitalist ideology translates into a particular government structure that privileges media autonomy, considering media 
organizations as private businesses supposedly governed by the market itself. Capitalism can also heighten competition and lead to media monopolies. This market structure can then influence a media organization fighting for survival to want a bigger slice of the revenue pie. This gets translated into explicit and implicit policies that shape media routines. For example, editors might privilege the news values of novelty and prominence over impact, socializing journalists into a newsroom that rewards sensational stories. This socialization process yields individual journalists oriented more toward these types of stories. It is possible that ethical considerations might make journalists wary of particular policies (e.g. Breed, 1955), but the pressure of getting stories published or aired, and the unwritten rules they have to play with, can override these tensions. This hypothetical example illustrates how the hierarchical model of influences can account for sensationalism in the news.

But while the hierarchy of influences model is both parsimonious and elegant, it is constrained by lack of empirical support. There is an issue how the different levels relate to one another. For example, in the second edition of their book, Shoemaker and Reese (1996) arranged their chapters from the individual level to the ideology level. But in the third edition of their book, they reversed the order of how they presented the five levels of influences, acknowledging that "the sequence of these levels can be approached in different directions, and we don't mean to single out any one level as more powerful than another" (Shoemaker \& Reese, 2013, p. 8). Only a few studies sought to test the hierarchical relationship among influences, even with the availability of sophisticated statistical tools. Studies have explored one or two levels at a time, limited by the challenges of empirical observation at multiple levels, only arguing which level exerted 
stronger influences and not exploring if these levels interact or mediate each other's effects. There is disagreement on which level exerts the most influence. Gans (1979) had argued that source considerations influence journalists the most. Bissell (2000) argued that routine forces were most influential in the selection of local photos to publish. Shoemaker and colleagues (2001) found that editors' preferences, not individual characteristics of reporters, were related to coverage of congressional bills. Cassidy (2006) also found that perceived routine level influences strongly predicted the role conceptions of American newspaper and online journalists. However, Kim (2010) also found that individual level factors were the most salient in explaining the perceptions of danger among Iraqi journalists.

But aside from the question of a hierarchical structure, another important point to ponder in this original model is how influences are directed at news content. These levels of influences are argued to influence news content, classifying the characteristics of individual journalists as the first level of influence (Reese, 2001; Shoemaker \& Reese, 1996; Shoemaker \& Vos, 2009). This important role of the individual in the gatekeeping process is bolstered even by studies that purportedly found other levels of influences to be stronger than the individual level. For example, studies that found routine level influences exerted stronger influences on content than other levels had operationalized routine influences as either based on the perception of journalists - individual-level perceptions (e.g. Cassidy, 2006; Hanitzsch \& Mellado, 2011), or as decisions made by editors-individual gatekeepers at a higher level in the organizational hierarchy (e.g. Shoemaker, et al., 2001). 
News values are routine level influences on news content, but they exert an effect only in so much as they are internalized and applied by individual gatekeepers. Shoemaker and Vos (2009) differentiated the concepts "gate" and "gatekeeper" in the gatekeeping process. Gates are the "decision or action points" while gatekeepers are the individuals responsible for making those decisions. Thus, gatekeepers do not only refer to journalists deployed in the field. Gatekeepers also include senior-level editors, the editorin-chief, and even the publisher, as long as they make themselves part of the gatekeeping process. News content—as gatekeeping studies have demonstrated—is directly constructed by gatekeepers manning gates in the gatekeeping process and gatekeepers mediate the effects of external influences on news content.

News gets influenced only in so far as the individuals who construct it get influenced; therefore I shall argue here that the focus should be on how gatekeepers get influenced rather than on how news content gets influenced. This focus on the individual gatekeeper in understanding how news gets constructed can easily fall into the trap of "methodological individualism" (Parsons, 2007). For methodological individualists, explanations ultimately rest on individuals, a drastic view that divorces supra-individual contexts from individual actions (Parsons, 2007). It will be easy to mistakenly criticize my proposed approach of focusing on individual gatekeepers in understanding influences on news construction as falling into this trap. However, my proposed approach does not seek to explain influences on news content based on the characteristics of individuals alone, which is a weakness of methodological individualism (Parsons, 2007). Instead, I am proposing that we cannot understand influences on news content per se, for news content cannot be divorced from those who constructed it. Therefore, what we should 
seek to explain is the influence on individual gatekeepers. I do not claim to reduce explanations to individuals, but rather I agree that "explanations must offer causal mechanisms, and the mechanisms must pass through individuals (but may not reduce to them) to connect to action" (Parsons, 2007, p. 25).

Whether or not the gatekeeper opens the gate depends on his or her personal characteristics, such as his preferences, beliefs and attitudes, among others (Shoemaker \& Reese, 1996; Shoemaker \& Vos, 2009). But among the important factors to consider are the gatekeeper's relative power compared with other gatekeepers and the nature of the gate he or she is in-charge of. Thus, individual characteristics can be shaped by routine, organizational, social-institutional and social system levels of influence, but they can also interact with these external influences.

The approach of categorizing individual-level characteristics as independent variables - among those that can influence news content—assumes that news content should be essentially value-free. A logical implication that can be deduced from the current hierarchy of influences model is that news is inherently value-free when it is protected from individual-level influences, such as when journalists can shield their outputs from the effects of their political orientation or personal history. However, I will argue that this is inconsistent with the basic assumption of media sociology, that news "gets constructed - by individuals — within a social occupational and occupation setting" (Reese \& Ballinger, 2001, p. 641), for this implication locates news content outside of the individual, instead of with the individual. Thus, a more realistic model will be to clarify "influences on news content" as "influences on gatekeepers" who facilitate or constrain the gatekeeping process. 


\section{A Missing Mechanism}

Scholars have outlined the different influences on gatekeepers (Gans, 1979; Hanitzsch, et al., 2010; Herman \& Chomsky, 2002) and how these can be grouped into levels of analysis (Reese, 2001; Shoemaker, 1991; Shoemaker \& Reese, 1996; Shoemaker \& Vos, 2009). For example, we know that politicians can directly and indirectly influence gatekeepers by either threatening to file a libel suit or offering bribes, or by just being friendly and accessible. However, theorizing on the mechanism with which this influence on gatekeepers comes about remains scarce. Because of this, a general impression from previous theorizing is that the media are always susceptible to influences, but journalists are also capable of resisting them. Specifying the mechanism of how journalists get influenced will lead to a more realistic representation of the gatekeeping process.

Sociologists have long stressed the importance of elaborating on mechanisms in theorizing (Elster, 1989; Hedström \& Swedberg, 1998a; Mahoney, 2003; Tilly, 2001). Situated between the positivistic search for encompassing laws and the narratives that characterize interpretivism (Elster, 1989; Tilly, 2001), mechanistic explanation "promises to add precision and depth to theories" (Weber, 2006, p. 120). Stinchcombe (1991) also argued that mechanisms increase "the suppleness, precision, complexity, elegance, or believability" of a theory (p. 367). For example, mechanistic explanation is proposed as an alternative to the so-called "black-box" explanation, where a particular variable is said to exert an effect on an outcome variable without explaining how and why the effect comes about (Hedström \& Swedberg, 1998a). Thus, “to explain we must always posit and seek evidence for causal mechanisms" (Parsons, 2007, p. 23). Theorizing and even 
empirical studies in gatekeeping have suffered from this omission. Studies would identify a level of influence as exerting effects on news content, but they would not identify how the influence comes about.

The problem with the discourse on mechanism is that different scholars have defined it in different ways (Norkus, 2005). For example, Elster (1998), one of the earliest proponents of mechanistic explanation, defined mechanisms as "frequently occurring and easily recognizable patterns that are triggered under generally unknown conditions or with indeterminate consequences" (italics in the original; Elster, 1998, p. 45). This definition argues that a mechanism refers to a pattern that can be applied across a range of situations (Mahoney, 2003), which increases the utility of mechanisms in general. However, this definition also restricts mechanisms only to those that are "easily recognizable" when some underlying mechanisms can be difficult to uncover (Hedström \& Ylikoski, 2010). Mahoney (2003) identified four ways in which mechanism had been defined: 1) as a cause of an outcome; 2) as an intervening process, event or variable; 3) as underspecified causal propositions that can be applied to a wide range of cases; and 4) as an unobserved entity that generates outcome (also summarized in Norkus, 2005). What appears to be common among these groups of definitions that initially might seem disparate is how mechanisms are ought to be uncovered if theorizing is to be meaningful. These definitions also acknowledge that mechanisms are difficult to observe.

A plausible reason for this difficulty in observing mechanisms is that they often operate at a lower level of analysis compared with units involved in the actual theorizing. Stinchcombe (1991) defined the function of mechanisms in a theory as "bits of theory about entities at a different level (e.g. individuals) than the main entities being theorized 
about (e.g. groups), which serve to make the higher-level theory more supple, more accurate, or more general" (p. 367). This is precisely my goal in theorizing a mechanism of influences on gatekeepers. While the gatekeeping process can be argued as a middlerange theory that encompasses a higher level of analysis (for example, the news organization), I propose to examine the mechanism of influences at the individual level of gatekeepers. Tilly (2001) differentiated processes from mechanisms. Mechanisms refer to "a delimited class of events that change relations among specified sets of elements in identical or closely similar ways over a variety of situations" (Tilly, 2001, p. 25). In contrast, processes are "frequently occurring combinations or sequences of mechanisms" (Tilly, 2001, p. 26). Thus, while gatekeeping is a process, the mechanism of influence is an event within this process of news construction that also needs an out-of-the-black-box approach.

Stinchcombe (1991) identified four units of analysis where mechanisms operate: social actors that can be considered individuals (such as organizations); situations; patterns of information; and individuals. Scholars who explicated the concept of mechanism identified individuals as the essential unit of analysis (Elster, 1989, 1998; Gambetta, 1998; Hernes, 1998; Stinchcombe, 1991). For example, Gambetta (1998) said mechanisms are "hypothetical causal models that make sense of individual behavior. They have the form, 'Given certain conditions $K$, an agent will do $x$ because of $M$ with probability $p^{\prime \prime \prime}$ (p. 102; italics in the original). Hedström and Ylikoski (2010) also said the focus on mechanisms "implies that explanations should refer to individuals, their relationships, and their actions" (p. 59). Tilly (2001) identified three types of mechanism: environmental (externally generated influences on social life), relational (those that alter 
people's connections and networks), and cognitive (or those that "operate through alterations of individual and collective perception") (p. 24). Cognitive mechanisms, operating at the individual level, have attracted the most attention in sociology (see this collection: Hedström \& Swedberg, 1998b). This is the same strand of research which contributes to my proposed framework.

But theorizing with mechanisms comes with dual traps (Stinchcombe, 1991). First, it comes with the risk of offering mechanisms as the only form of explanation, which might come at the expense of narratives in the qualitative realm (Norkus, 2005) or at the expense of external validity in quantitative approaches, for establishing causality requires some form of control. Second, mechanistic explanations risk too much focus on "input-output relationships, on linear chains of causality, and on building tightly knit models of arrows and boxes" (Weber, 2006, p. 120). I approach my theorizing mindful of these traps. In this study, I theorize a mechanism of influences as one of the mechanisms within the gatekeeping process. The mechanism complements - not replaces - the focus on understanding a holistic news construction process. I will borrow the concepts of economic and cultural capital from Bourdieu's $(1998,2005)$ field theory to argue a theory of the mechanism of influencing gatekeepers.

\section{Journalism as a Field}

News is constructed through a complicated process that operates under layers of forces and influences (Herman \& Chomsky, 2002; Shoemaker \& Reese, 1996; Shoemaker \& Vos, 2009). But a weakness in gatekeeping literature is the tendency to study the journalistic process in segments, as scholars are constrained by limited resources, the limitations of their chosen methodologies, and the still unresolved gaps in 
gatekeeping theory. However, the framework of field theory provides a more holistic analysis of this multi-layered gatekeeping process (Benson, 2004; Russell, 2007). Field theory seeks to study the journalistic field as a whole by accounting for not only the relationships between agents within the field but also the relationship of the journalistic field as a whole with other fields, such as the political and the economic fields. This is why scholars describe field theory as a relational theory (Benson \& Neveu, 2005; Siapera $\&$ Spyridou, 2012).

Field theory has its origins in the physical sciences, particularly in electromagnetism, and it crossed to sociology through the work of Kurt Lewin, referred to as the father of social psychology, who argued that behavior is the function of both the person and the environment (J. L. Martin, 2003). This holistic approach is retained as field theory reached journalism studies through the work of several other sociologists, such as Pierre Bourdieu and the researchers who adapted his conceptualization and linked it to journalism (Benson \& Neveu, 2005; Neveu, 2007). This focus on totality among the variations of field theory appears to have prompted Martin (2003) to argue that field theories are incompatible with mechanistic explanations. For example, Martin (2003), in a review of three main strands of field theory in sociology, said that "field theories are proposed, whether reluctantly or not, when no such mechanistic explanations currently offer promise: if there were a mechanism, there would be no need for a field theory" ( $\mathrm{p}$. 12). I will argue, however, that Bourdieu's discussion of forms of capital is an example of mechanistic explanation that could be adapted in understanding influences on gatekeepers. The holistic framework offered by field theory encompasses - not excludes—social mechanisms. 
The framework of field theory builds on four key concepts: field, capital, doxa, and habitus. The concept of a field has been used in numerous studies, conceptualizing as fields concepts such as politics, the arts (Bourdieu, 2005), organizations (Emirbayer \& Johnson, 2008), sports (Stempel, 2005), and journalism (Benson, 2006; Bourdieu, 1998, 2005; Handley \& Rutigliano, 2012). For Bourdieu, a field is a "field of forces" which agents struggle to either transform or preserve (Bourdieu, 1985, 2005). The journalistic field is an example, although journalism is often considered part of the more encompassing field of cultural production (Benson, 2006; Siapera \& Spyridou, 2012). The journalistic field, Bourdieu (1998) said, is a "microcosm with its own laws, defined by its own position in the world at large and by the attractions and repulsions to which it is subject from other such microcosms" (p. 39). For Bourdieu (2005), to exist in a field "is to differentiate oneself" (p. 39).

A field differentiates itself from other fields through an endemic system of rules that govern its own game. This is called the doxa, which refers to a " universe of tacit presuppositions' that organize action within the field" (Benson \& Neveu, 2005, p. 3). In short, it refers to the rules of the game. A specific doxa refers to a "system of presuppositions inherent in membership in a field" (Bourdieu, 2005, p. 37). When journalists enter the field, they accept particular conventions as part of the job. These are never questioned, for these have dominated the field for a long time and have been normalized. News values are examples of journalistic doxa - an enduring set of criteria of what makes something newsworthy (Willig, 2013). The principles that govern journalism, such as the problematic norm of objectivity or the normative idea of providing what the audience needs, are also examples of journalistic doxa. 
Norms dominate in part because of the individuals who perpetuate these normsagents within the journalistic field who play by the rules of the journalistic doxa. So while the field is differentiated by its own set of rules, the rules coalesce through the agents that enforce them. This link between the field and its agents, between the micro and the macro levels, is provided by the concept of habitus. The concept refers to dispositions, accumulated through an agent's experience over time, that generate "practices and perceptions" (R. Johnson, 1993, p. 5). In the journalistic field, the habitus "implies understanding the journalistic game" which allows an individual to master the rules (Willig, 2013, p. 8). In short, it refers to one's historical trajectory within the field, a collection of personal and professional experiences accumulated from various social positions - themselves partly determined by each preceding trajectory - that produces knowledge and understanding of the game. A case study of a media organization in the UK found the central role occupied by projections about the journalistic field in decisionmaking and day-to-day actions (Born, 2003). These projections are shaped not only by government and organizational structures, but also by the dispositions of journalists toward the field (Born, 2003). Bourdieu (1980) defined habitus as the:

...systems of durable, transposable dispositions, structured structures predisposed to function as structuring structures, that is, as principles which generate and organize practices and representations that can be objectively adapted to their outcomes without presupposing a conscious aiming at ends or an express mastery of the operations necessary in order to attain them. (p. 53)

The framework of field theory is therefore focused on both the field, with its own doxa, in relation to other fields; and the agents within the field, each with their habitus, in 
relation to one another. This makes it a meso-level concept (Sallaz \& Zavisca, 2007). Bourdieu (1998), for example, argued that the field of television had amassed enough meta-capital (see Couldry, 2003) to be able to exert influences on other fields, such as the political field, thereby transforming the struggles within these other fields. In the same vein, the journalistic field also finds itself influenced by other fields around it, such as the political and the economic fields that constantly challenge its already fragile autonomy. These external pressures influence how agents within the journalistic field participate in the struggle to either preserve or transform the field.

The question of autonomy is central to field theory. Fields are always confronted with oppositions between heteronomous, or external forces, and autonomous poles, or resources that differentiate a social space from other fields (Neveu, 2007). For instance, the journalistic field is torn between the pressure of selling ads and increasing circulation on the one hand, and the influence of the state on the other (Bourdieu, 2005; Neveu, 2007). Thus, Champagne (2005) observed: "The history of journalism could well be in large part the story of an impossible autonomy — or, to put it in the least pessimistic way, the unending story of an autonomy that must be re-won because it is always threatened" (p. 50). This is not unique to the journalistic field, for the social world in general is caught between two forms of power: economic and cultural capital (Benson, 2006).

The concept of capital refers to "the specific forms of agency and prestige within a given field" (Sterne, 2003, p. 375). It refers to various forms of resources, some more dominant than the others, but each being convertible into the other forms, depending on an agent's relative position within the field. These forms of capital enable agents to participate in the struggle (Handley \& Rutigliano, 2012), differentiating one agent from 
the other in terms of relative power based on accumulated capital. Thus, capital is also something that agents seek. Forms of capital are both "weapons" and "stakes" within a field (Emirbayer \& Johnson, 2008, p. 11). Field theory refers to two main forms of capital: economic and cultural (Benson, 2006; Benson \& Neveu, 2005), but field theory scholars also refer to social and symbolic capital (Sallaz \& Zavisca, 2007; Willig, 2013).

Economic capital refers to money or assets transformable into money (Benson, 2006) and is considered as the dominant capital in most fields. In journalism studies, it has been operationalized in terms of advertising revenues, circulation rates, television ratings, and audience size (Benson, 2004, 2006; Benson \& Neveu, 2005; Siapera \& Spyridou, 2012). An analysis of the online journalistic field, for example, measured its economic capital in terms of the number of online news users (Siapera \& Spyridou, 2012). But while economic capital is easily distinguished from the other three forms of capital, among the three the distinction is not as clear. Cultural capital refers to possession of competence in a socially valued area (Sallaz \& Zavisca, 2007), often operationalized as possession of journalistic excellence or quality as conferred by professional or academic groups, such as the Pulitzer Prize in the US (Benson, 2006; Benson \& Neveu, 2005). However, other scholars have defined it in terms of accumulated knowledge that can come in embodied, objectified, or institutionalized forms (Bourdieu, 1986; Siapera \& Spyridou, 2012). Skills and educational credentials of online journalists, for example, have been used to assess the cultural capital of the online journalistic field (Siapera \& Spyridou, 2012). Thus, cultural capital refers to "such things as educational credentials, technical expertise, general knowledge, verbal abilities, and artistic sensibilities" (Benson, 2006, p. 190). Social capital refers to "the sum of all those 
people one knows or groups to which one belongs" (Siapera \& Spyridou, 2012, p. 81). A journalist's social media network is a form of social capital. Finally, symbolic capital refers to prestige or status which legitimates dominance (Benson \& Neveu, 2005; R. Johnson, 1993; Siapera \& Spyridou, 2012), a form of socially misrecognized economic, cultural, or social capital that leads to recognition of legitimate competence (Bourdieu, 1986). For example, a wealthy family is high in economic capital, but the same wealth confers the family a particular social status that is subsequently equated with dominance and legitimacy. What further muddles the distinction between these forms of capital is the argument that essentially all forms of capital—economic, cultural, and social—are inherently symbolic, for while economic capital tends to be the dominant form, it is usually expressed and manifested in terms of cultural and social capital (Grenfell \& James, 2004). For example, a discussion about the concept of a journalistic capital referred to it as the symbolic capital of the journalistic field, only to refer to it again as "the specific, cultural capital of the journalistic field" (Willig, 2013, p. 9).

In this study, I will argue that in the journalistic field, economic and symbolic capital are the most important forms, consistent with the traditional normative wall of separation between editorial and business that is rooted in the belief that journalistic quality comes from editorial autonomy. It is true that many of the considered successful news organizations have accumulated both economic and symbolic capital. The New York Times, for example, is considered a reputable news organization and remains to be a profitable company, although it has had its own share of financial troubles in the last few years. But a more common profile is an organization that is high in one form of capital and low in the other. News organizations that have survived erosion of revenues have 
done so with celebrity news or cat videos. News organizations that were once considered paragons of quality investigative journalism are seeing their financial reports in the red. The field of cultural production is generally high in cultural and symbolic capital but low in economic capital, but compared with other forms of cultural production, the journalistic field arguably enjoys high economic capital but low cultural and symbolic capital, as journalism is produced for mass audiences (Siapera \& Spyridou, 2012).

Since they are the basic currencies that agents use in their struggles within the field, forms of capital are also used to amass more capital and elevate one's position in the field. For example, news organizations call attention to the awards they win, which is a form of symbolic capital, to attract more readers and increase circulation and their advertising figures, which are forms of economic capital. Symbolic capital refers to reputation and prestige (Benson \& Neveu, 2005; Bourdieu, 1986; Siapera \& Spyridou, 2012) that can be amassed, for example, through journalistic quality as accomplished by journalists with the necessary skills and knowhow—-forms of cultural capital. News organizations also use their economic capital to invest in investigative pieces with the hopes of gaining recognition from the field — or increasing their symbolic capital. Thus, Benson and Neveu (2005) argued: "Organizations who dominate the field are those successful in converting one form of capital into the other" (p. 4).

Field theory, in an oversimplified summary, locates an agent in the field as coming from a particular habitus that influences how one conceptualizes, enacts, and enforces the field's doxa; one's social position in the field; as well as how one understands and accumulates forms of capital. 


\section{Theorizing a Mechanism of Influences}

In this discussion, capital accumulation is considered a mechanism that is part of the struggle that characterizes the field as conceptualized by Bourdieu $(1977,1980$, 1984). Field theory theorizes at the level of holistic fields - for instance how the journalistic field relates to the political field (Bourdieu, 1998, 2005), but the mechanism of capital accumulation that allows agents to participate in the struggle to either preserve or transform the field is explained at the level of individual players. Martin (2003) argued that mechanisms, at least in practice, are commonly conceptualized "at a lower level of analysis than the theoretical units in question" (p. 11). This is precisely what field theory does. Bourdieu (1998) himself refers to "mechanisms" of the journalistic field, which he argued was "increasingly subject to market demands" that first affect journalists whose participation in the internal struggle then affect other fields of cultural production (p. 68).

Neither Benson (2006) nor Bourdieu (2005), in applying field theory to journalism, referred to individual journalists as accumulating these forms of capital, which is understandable given field theory's sociological focus on the entire field as a unit of analysis. And yet Benson (2006), in discussing how Bourdieu talked about both media production and reception, referred to members of the audience, composed of individuals, to be possessing both economic and cultural capital. For example, news organizations might have similar audiences in terms of the audiences' level of economic capital, and yet these audiences might still differ in their cultural capital (Benson, 2006). Following this line of conceptualization, individual gatekeepers, as agents within the journalistic field, also possess forms of economic, cultural, social, and symbolic capital (Siapera \& Spyridou, 2012; Willig, 2013). In order to maintain their position in the field, 
which locates them in the struggle to either transform or preserve the journalistic field, journalists as agents also need to amass different forms of capital, transforming one into the other when needed. This accumulation of capital can explain the mechanism of the influences on gatekeepers.

I will argue that as rational agents, journalists realize the required capital they need to survive and dominate the eternal struggle for control. They become susceptible to influences from various levels when they experience or perceive some form of instability in their capital accumulation. Instability can refer to either a perceived increase or decrease in capital. Thus, when journalists perceive some instability in either forms of their capital—for example, economic or symbolic — they become susceptible to influences. This mechanism can account for both organizational and individual responses to influences. For example, when a group of advertisers threaten a news organization with an ad boycott, that organization will experience a form of perceived instability in capital accumulation: a potential decrease in its economic capital. Being accused of biased coverage might also threaten — potentially decrease — the stability of an organization's symbolic capital. However, instability can also come in the form of an increase in economic or symbolic capital. Bribes can potentially increase a journalist's economic capital. A journalist wanting an exclusive story—a form of increasing one's symbolic capital—might also be more susceptible to the influences of his source. A journalist can also experience instability in both forms of capital either in the same or opposite direction. For example, winning an award can increase both one's economic and symbolic capital. Facing a libel suit might decrease one's economic capital because of 
litigation costs, but it can also increase one's social and symbolic capital by portraying the journalist as an active watchdog, garnering sympathy and support from the public.

The mechanism of capital accumulation can also explain how journalists resist influences. A way of standing up against pressure is when organizations or journalists can convert the decrease in one form of capital into an increase in the other, a process of capital offsetting. For example, an ad boycott might decrease economic capital, but refusing to bow to an advertiser can be converted into symbolic and social capital. Bourdieu (2005) argued that the relative power of players in the journalistic field depends on how well they can convert one form of capital into the other. Which form of instability makes journalists more susceptible to influences is an interesting question to explore in the future. This theory of the mechanism of influences is also particularly appropriate for a theory of influences on gatekeepers (instead of on news content).

\section{Theoretical Synthesis}

This study is guided by the theoretical intersection between gatekeeping and field theory in the study of news construction. Gatekeeping is a comprehensive framework that explains how news gets constructed under layers of influences. I argued, however, that consistent with the assumption of media sociology, the focus of gatekeeping research should be on influences on gatekeepers, rather than on news content, for one cannot understand news content separately from those who construct content. This focus on gatekeepers allows theorizing a mechanism of influence, something that has been missing in gatekeeping studies. Field theory's concept of capital offers a possible mechanistic explanation for influences on gatekeepers. In order to participate in the struggle to either transform or conserve the journalistic field, journalists accumulate forms of capital that 
define their relative position and power within the field. Thus, perceived capital instability - either a decrease or an increase — can make journalists vulnerable to influences. The degree of influence hinges on the extent of capital instability that a particular force can cause. A journalist, however, exists within a social and occupational setting (Reese \& Ballinger, 2001). Located within the journalistic field, a journalist comes from a particular habitus. The field itself is guided by a set of rules, the journalistic doxa. How a journalist responds to perceived capital instability— the mechanism of getting influenced - also depends on one's habitus and the field's doxa.

It is with this proposed theoretical framework that I am focusing on the audience as an influence on journalists. In the next chapter, I will demonstrate how much the audience for news, as well as the ways for journalists to track and understand them, has changed in the last few decades. I will also argue that these changes have increased the amount of influence the audience exerts on journalists. But this influence hinges on how journalists conceive of the audience as a form of capital, and how this conception is informed by the habitus and how it fits into other existing journalistic doxa. 


\section{The Audience as a Form of Capital}

The literature on influences on news content initially concluded that the relationship between journalists and their audiences exerted a relatively weaker influence on news work, especially when compared with other sources of influence, such as news sources or journalists' personal beliefs (Flegel \& Chaffee, 1971; Gans, 1979; Shoemaker \& Reese, 1996; White, 1950). This, however, no longer reflects the changing news media ecosystem. Shoemaker and Vos (2009) proposed a revision to gatekeeping theory to add what they called the "audience channel."

Gatekeeping is "the process of selecting, writing, editing, positioning, scheduling, repeating, and otherwise massaging information to become news" (Shoemaker, Vos, \& Reese, 2008, p. 73). Since journalists do not always have first-hand experiences of all events, they rely on sources for information. Initial work on gatekeeping therefore referred to source and media channels through which information flows from events to audiences (Shoemaker \& Vos, 2009). But as more and more members of the audience share news items and first-hand information online about events they encounter, audiences also become gatekeepers, providing a third channel for information flow.

"Therefore, we must conceptualize readers as having their own gate, and they send news items to others in the audience when the interaction between newsworthiness and personal relevance is strong enough" (Shoemaker \& Vos, 2009, p. 124). This has significant implications on how we understand gatekeeping, for it no longer culminates in 
publication of information. It also means that we have to reexamine how we understand the relationship between journalists and audiences.

Gatekeeping theory locates the audience at the social-institutional level of analysis of influences on news content (Shoemaker \& Vos, 2009). An example of the direct effect of the audience on news construction is what Herman and Chomsky (2002) referred to as "flak," a filter that shapes the news. Flak refers to negative feedback from the audience and other groups, such as criticisms or threats of boycotts - a way of "disciplining" the media (Herman \& Chomsky, 2002). The audience can also decide which types of content to patronize, and since audiences are not just consumers but also products that news organizations sell to advertisers (Loosen \& Schmidt, 2012; Webster \& Phalen, 1994), their preferences can influence editorial decisions. But the audience can also have indirect influences on news content, as when journalists are oriented to providing what they think the audience wants, even if this prediction does not match actual audience preferences. This orientation to the audience is an example of a routinelevel influence (Shoemaker \& Vos, 2009).

For the longest time, journalists ignored, if not rejected, feedback from the audience (Beam, 1995; Gans, 1979; Schlesinger, 1978). This apparently no longer holds true, as news editors increasingly find it no longer possible to disregard the audience (Anderson, 2011b; Lowrey \& Woo, 2010; MacGregor, 2007; McKenzie, et al., 2011). In many different ways, the audience is successfully wrestling for power.

\section{Rejecting Audience Feedback}

Journalists used to not know a lot about their audiences (Gans, 1979; Schlesinger, 1978; Wulfemeyer, 1984). In his observations in four newsrooms, Gans (1979) found that 
journalists had little knowledge of their actual audience. In many instances, journalists substituted their own preferences for those of their actual but "unknown" audience. Journalists also talked about an "invented audience" to justify editorial decisions (Gans, 1979). Not knowing the actual audience also meant not knowing what the audience really wanted. For their news judgment, journalists relied instead on their "known" audience composed of family, superiors and fellow journalists (Gans, 1979). This is plausibly an explanation for Baker's (2002) assumption that "the media cannot be expected to provide the audience what it wants" (p. 96). Baker (2002) outlined several reasons for this, such as the public good nature of media products that results in low production as well as media monopoly that leads to low diversity in content. But another plausible reason at the micro-level is that media content producers do not really know what the audience wants because, to begin with, they do not really know who their audience is (Gans, 1979).

Not only did journalists know little about who their audience was, but they also traditionally rejected the already limited feedback they got from their audiences (Beam, 1995; Gans, 1979). Feedback used to come in the form of letters to the editors or phone calls to the newsroom - forms of feedback that had to be volunteered by a few members of the audience (Schlesinger, 1978). They were, however, considered unrepresentative of the actual audience. As years passed, and even with newer audience measurement systems such as readership surveys and television ratings, journalists still relied on their supervisors, their peers, their relatives, and their personal preferences (Beam, 1995; Sumpter, 2000). And even with internet technology that allowed user-generated contributions, journalists still paid scant attention to what the audience had to say. A study of the online community created by a news organization in Denmark found that 
journalists "thought citizen contributors did not have the standards and skills required for professional news production" (Bechmann, 2011, p. 25).

The literature offers four plausible reasons for this institutional rejection of audience feedback. First, journalists have been found to dislike numbers and statistics (Curtin \& Maier, 2001; Gans, 1979), the form audience research most often takes. For example, readership surveys and broadcast ratings come in the form of statistics, offering information about audience size, and yet some journalists did not consider them useful at all (Beam, 1995; Schlesinger, 1978). Second, journalists and audiences have different preferences. Comparisons of story preferences of journalists and their audiences yielded contrasting results. In a study which asked 40 newspaper subscribers and 13 staff members to sort a list of stories, Atwood (1970) found "substantial agreement" between news preferences of newsmen and subscribers. The study noted, however, that "the editors were poorer predictors of the audience's preferences" (Atwood, 1970, p. 302). In contrast, a comparison of survey responses from 34 newspaper editors and a representative sample of residents in Wisconsin found that "editors to some extent accurately perceived the positions of their audience (regarding student demonstrations), and these positions influence them to a degree" (R. K. Martin, O'Keefe, \& Nayman, 1972, p. 468). In a survey of nine newspaper staff members and 107 of their readers, Jones (1993) found that news staff and reader story preferences were correlated, and, in contrast to Atwood's (1970) earlier finding, that the city editor was particularly accurate in predicting reader preferences. However, in a survey of television journalists and 250 television viewers, Wulfemeyer (1984) found divergent preferences. The journalists thought their viewers were more interested in sex, crime, and violence; the viewers 
reported they were more interested in economy, consumerism, and education (Wulfemeyer, 1984). A secondary analysis of representative surveys of news editors by the Associated Press and of audiences by the Pew Research Center combined with a content analysis of actual media coverage found a moderate correlation between "top news events of the year" judgments of editors and audiences (Tai \& Chang, 2002). But while judgments of editors were correlated with actual media coverage, audience judgments were not related to media coverage at all (Tai \& Chang, 2002). This difference between audience judgments and actual news media content apparently persists across countries. A study of news content, journalists, and audiences across 10 countries found that while audiences from different countries tend to agree on what is newsworthy, "people disagree with their newspapers about what should be covered most prominently" (Shoemaker \& Cohen, 2006, p. 337). Still, despite this inconsistency in earlier studies of audience and editorial preferences in traditional news media, recent studies of online news agree on the divergence in the preferences of journalists and audiences, with journalists preferring public affairs stories, and audiences viewing and sharing sports and entertainment stories the most (Boczkowski, 2010a; Boczkowski, Mitchelstein, \& Walter, 2011; Thorson, 2008).

Third, a vague notion of who the audience was, as well as the divergence in the preferences of journalists and their perceived audiences, could have led many journalists to have a pejorative view of the audience. For example, a survey of 489 editors and reporters across 10 newsrooms in 1981 found that journalists tend to have a "patronizing and unflattering view" of the audience, overestimating the audience's preference for superficial materials and underestimating preference for important content (Atkin, 
Burgoon, \& Burgoon, 1983). Though audience feedback also came not only in the form of cold statistics but also in conversations and interactions with some members of the audience, such as phone calls and letters to the editor, many journalists dismissed this feedback as coming from "cranks" and "idiosyncratic" members of the audience (Schlesinger, 1978). These forms of feedback were therefore not trusted and considered not representative of the actual audience.

Finally, a fundamental explanation for rejection of audience feedback among journalists lies in the journalistic norm of autonomy. Beam (1995) found that journalists feared incorporating results of readership surveys in editorial operations might erode journalistic quality. What journalists did not know about the audience, they filled with their own notion of professionalism by relying on traditional news standards that guide news content (Schlesinger, 1978). In short: "The conflict between researchers and journalists is over the priority of commercial versus professional considerations in story selection" (Gans, 1979, p. 233).

This dichotomy between professional and commercial considerations, between quantity of audiences and quality of journalistic work, is parallel to the opposing poles of economic and symbolic capital that marks the journalistic field. But new information technologies are offering new ways of interaction between audiences and messages, and the peculiar ways with which the audience is metamorphosing are making it harder for journalists to reject audience feedback the way they used to.

\section{The Changing Audience}

A common way of defining the audience is by its empirical components: "a collection of spectators; a group of individuals gathered together to attend to a 
performance and 'receive' a message 'sent' by another" (Ang, 1991, p. 33). This definition, however, is consistent with an unflattering view of a passive receiver (McQuail, 2010) that has given rise to conceptualizations of the audience as mere recipients, products, or commodities (Loosen \& Schmidt, 2012; Webster \& Phalen, 1994). A context to this conceptualization is how the audience is an institutional construction (Bermejo, 2007; Ettema \& Whitney, 1994; Napoli, 2011; Sullivan, 2013; Turow, 2005). For example, Butsch (2000) said: “The 'television audience' exists only with the text of a program. Beyond that, the audience does not exist; rather the individuals or households exist as entities unrelated to each other" (p. 289). An implication of the audience being "necessarily constructions" (Turow, 2005, p. 106) is that any attempts at understanding the concept must also account for the social and institutional context where the audience is situated. "There is no news consumer apart from the news" (Schudson, 2003, p. 168). Therefore, the audience "is always closely connected to the ways in which the audience is defined and by whom" (Sullivan, 2013, p. 16). Answering why the audience has been conceived of as passive receivers of information should lead us back to how the news media have come to this institutional abstraction of the audience as a passive and an unthinking mass: specifically the ways the news media have measured their audiences before.

In a period marked by a shift to a huge schism between public and private spaces in many democracies, institutions, such as the news media, had to face the absence of constant and close surveillance of citizens, forcing them to turn to indirect means of gathering input from audiences (Sullivan, 2013). Thus, audience measurement techniques, such as readership surveys commissioned by newspaper organizations and 
audience rating systems paid for by broadcast stations, sought to aggregate individual responses (Ang, 1991; Schlesinger, 1978). However, the process of aggregation leads to depersonalization (Ang, 1991). Reduced into numbers and detached from their personal contexts, members of the audience have been perceived as an object of management or manipulation by the media (McQuail, 2010). For example, television ratings are used as a form of currency for financial transactions between the media and their advertisers, instead of a measure of social behavior (Sullivan, 2013). Scholarly definitions of the audience are also mostly dictated by commercial considerations (Bermejo, 2007).

Understanding how the news media quantify their audiences is important because how the industry measures the audience can influence how much influence the audience exerts on news construction. Ettema and Whitney (1994) argued that "the measurement of audience behavior, not audience behavior per se, changes the media" (p. 78). The imagined audience, not the actual audience, influences news outputs (de Sola Pool \& Shulman, 1959). For example, Hardin (2005) found that sports editors selected content based on their own perceptions of what would interest the audience rather than the actual audience itself. A survey of health journalists also found that how health journalists conceive of their audiences influenced even the writing and argumentation techniques they employed in their stories (Hinnant, Len-Ríos, \& Oh, 2011).

But while the conceptualization of a passive, mass audience might have served traditional media institutions well, it no longer accurately reflects how much the audience has evolved. The audience is no longer composed of passive media consumers. Individuals, or whom Bruns (2003) called produsers, now consume and produce messages at the same time. Napoli (2011) outlined two important changes that challenge 
the traditional conceptualizations of the audience: audience fragmentation and audience autonomy. First, audience fragmentation that resulted from the exponential growth of media organizations and other sources of mediated messages challenges the traditional exposure-based approach of understanding the audience. Old audience measurement systems, such as readership surveys, just counted how many individuals were exposed to a particular content, when exposure is not a good predictor of audience behavior (Potter, 2009). Furthermore, exposure-based audience measurement techniques are no longer adequate in an information-saturated context. For example, readership surveys are skewed in favor of legacy media that have better name-recall among newspaper readers, when these viewers attend to other sources of similar content they cannot easily remember but they can easily search on Google (Napoli, 2011).

Second, audience autonomy, which refers to the increasing control that the audience now enjoys with respect to media content, allows new ways of interaction with content. This comes in the form of interactivity afforded by the internet, or even the ability to skip advertisements in television programs recorded in one's DVR (Napoli, 2011). The evolution of the audience should therefore be taken into account in audience measurement, for the internet is not only changing the nature of interaction between audiences and messages, but it is also a "powerful research tool, one that allows researchers to observe news reading behavior more reliably and less obtrusively than had been possible before" (Tewksbury, 2003, p. 695). Keeping up with the changing audience is a task that new forms of audience measurement, such as web analytics technology, have immediately caught up with (Kaushik, 2010). 


\section{Focusing on Feedback}

In dramatically changing the news media ecosystem, new information technologies have empowered the audience in two ways. First, these innovations now allow practically anyone with internet access to create and disseminate messages without having to go through the media gates, giving rise to what Castells (2007) called mass selfcommunication. Second, while traditional journalists remain protective of their once clearly dominant position in the flow of information, these innovations have increased the influence of the audience on journalistic decisions. In this study, I am particularly focused on the second approach to understanding how innovations in information technology are empowering the audience.

Twitter has allowed users to share details and photos of international events ahead of journalists just because these users happened to be on the scene (Hermida, 2010; Jewitt, 2009). The video-sharing site YouTube has this for its tagline: "Broadcast yourself." Bloggers wrote about issues that interested them, even if traditional journalists did not report about these issues, and some bloggers even used their blogs to criticize the mainstream news media (Domingo \& Heinonen, 2008; Ekdale, Namkoong, Fung, \& Perlmutter, 2010; Siapera, 2008; Vos, Craft, \& Ashley, 2011). These are forms of mass communication because of their potentially "global audience" and yet they are "selfgenerated in content, self-directed in emission, and self-selected in reception by many that communicate with many" (Castells, 2007, p. 248). Some of these mass selfcommunicators have been called citizen journalists (Gillmor, 2004). Clearly, journalists no longer have the monopoly of news. But journalists are not giving up either (Hermida, 2011). Many newsrooms have embraced blogging, and journalists have made their 
presence felt in social media (Lasorsa, Lewis, \& Holton, 2011; Singer, 2005). Threatened by the burgeoning of alternative sources of information, newsrooms have embraced new forms of audience feedback, catering to audience preferences to keep them from migrating to other sources, and finding themselves caught between audience considerations and editorial judgment.

From letters sent and phone calls made to newspaper and television newsrooms in the older days (Gans, 1979; Schlesinger, 1978), audience feedback now comes in the form of comments that appear after each online story (Braun \& Gillespie, 2011), posts in social media such as Twitter and Facebook (Hermida, 2010, 2012; Hermida, Fletcher, Korell, \& Logan, 2012), and real-time metrics through web analytics (Lee, et al., 2012; MacGregor, 2007). These new feedback mechanisms provide more clues about who the audience is. They represent an update from old ways of understanding the audience. For example, readership surveys and focus groups were considered problematic because audiences are not usually adept at reporting their own media habits (Tewksbury, 2003). In contrast, web analytics track audience behavior online based on actual behavior and without relying on self-reports. But initial research on how journalists approach new technologies generally found a process of normalization, where journalists adopt new technologies only to adapt it into traditional norms and routines, repurposing technology to suit their old practices instead of changing how they do their work (Lasorsa, et al., 2011; Singer, 2005).

A review of the growing literature on the changing interaction between audiences and journalists shows three major patterns of how audiences now figure in the journalistic news construction process. First, news audiences have provided journalists with tips, 
opinions, photos, videos, or even stories, which I will refer to as contributing content. This is different from online users functioning as the originators of content who function outside the gates controlled by journalists. Crowdsourcing has become a buzzword in journalism, referring to the process of obtaining ideas, pieces of information, or details from people (Akagi \& Linning, 2013; Poell \& Borra, 2012). Scholars also referred to user-generated content (J. Harrison, 2009; Singer \& Ashman, 2009; Wardle \& Williams, 2010; Williams, Wardle, \& Wahl-Jorgensen, 2010), something that has been embraced by news media giants such as $\mathrm{CNN}$ and $\mathrm{BBC}$ which encourage and devote web pages to contributions from the audience, such as photos and videos. Comments are also considered content contributions from the audience (Singer \& Ashman, 2009), and while user comments range from serious to hilarious, sometimes even resorting to personal attacks (Braun \& Gillespie, 2011), a growing number of people consider reading readers' comments as amusing and entertaining, and therefore comments also draw in some readers. But while collecting content from audiences can be looked at as free labor, journalists have to balance this with their traditional norms. "Journalists may worry that amateur-quality contributions from users will undercut the professional sheen of their own work; news organizations may find they must work harder to protect their brand as they incorporate user-generated content” (Braun \& Gillespie, 2011, p. 384).

Second, audiences have become key players in disseminating content. Lists of most emailed and most viewed stories have become standard elements in most news websites (Thorson, 2008). The same is true about sharing features that allow users to share a story through their social media accounts, such as on Twitter and Facebook (Hermida, et al., 2012). These website features have become a form of recommendation 
that other users employ as heuristics to decide which content to access (Thorson, 2008). Hermida and colleagues (2012) argued that "the traditional gatekeeping function of the media is weakened as a significant proportion of news consumers turn to family, friends, and acquaintances to alert them to items of interest" (p. 821). When users share particular articles they like, they also facilitate the audience channel through which these media content will reach other members of the audience (Shoemaker \& Vos, 2009). For example, a survey of 1,682 adults in Canada found that $45 \%$ received their news from friends and family on social networks such as Facebook (Hermida, et al., 2012).

Twitter is considered particularly suited to breaking news stories (Hermida, 2010; Jewitt, 2009) as shown in a string of international events first broken into a large audience through tweets from ordinary citizens who happened to be on the scene at that moment (Jewitt, 2009). Social media sharing has become "a form of cultural currency" (Hermida, 2012, p. 317), a terminology that leads me back to the core concept of capital from field theory, which I have borrowed to argue for a theory of mechanism of influences on journalists. If shares can be considered as cultural currencies, they can also contribute to the accumulation of cultural and symbolic capital. But while audiences help disseminate news content through their social media accounts and their emails, these audience activities actually pose threats to established media, which now find these interactions outside their websites and in third party applications that also compete for audience attention and subsequently advertising revenues (Hermida, 2012). In the language of my proposed theoretical framework, social media sharing might increase the cultural, social, and symbolic capital of a news organization, but it might also undermine its economic capital. 
Third, audiences have become important influences in tailoring content. This is different from the first pattern where audiences exert direct influences on what gets uploaded by uploading pieces of information themselves. Instead, audience preferences, communicated through new forms of feedback and quantified using new audience measurement systems, can affect journalistic decisions. This is where web analytics becomes central. Web analytics can inform newsrooms which stories are attracting a lot of clicks, where these clicks come from in terms of actual physical location and in terms of referrals online, and what readers do with the contents they access (e.g. share a story on social media, email it to a friend, etc.). Access to these metrics equips journalists with information on audience preferences that newsrooms might use to guide editorial decisions.

\section{Social Media and Web Analytics}

Many journalists have embraced social media, although the extent to which they integrate it in their news work varies (Lariscy, Avery, Sweetser, \& Howes, 2009). A study enumerated five uses of social media for the news organization News 24 in South Africa: to distribute information, to get feedback from users, to promote the news organization, to build a community of users, and as a source of story ideas and information (Stassen, 2010). It argued that social media "facilitates a type of journalism in which the audience is much more involved in the news-creation process, where feedback happens in real-time and users have the opportunity to interact with each other" (Stassen, 2010, p. 13). However, the study was based on email interviews with only four staff members. A survey of 200 business journalists in 2008 found that many journalists turned to social media "for inspiration, assistance, and information in doing their jobs" 
(Avery, Lariscy, \& Sweetser, 2010, p. 201). However, 32.5\% of these business journalists reported not spending time on social media in their daily professional lives (Lariscy, et al., 2009). They also "did not feel social media improved their work" (Lariscy, et al., 2009, p. 315).

A survey of 129 television news editors in 2010 found that $98 \%$ of respondents used Facebook and 97\% used Twitter (Lysak, Cremedas, \& Wolf, 2012), although about half of the respondents said they had separate professional and personal Facebook and Twitter accounts. The study also concluded that journalists have not really incorporated social media in their news gathering: "The survey results indicate there is less support for social media when it comes to the issue of its reliability as a tool in the actual newsgathering process, and how the information gathered through social media should be incorporated into reporting" (Lysak, et al., 2012, p. 203). Social media have the potential of generating traffic to news websites (Hong, 2012). A content analysis of tweets from 500 journalists found that $19.1 \%$ of these tweets were promotional in nature, merely tweeting links to their news websites (Lasorsa, et al., 2011). Journalists from elite media organizations also tend not to deviate from traditional journalistic norms and practices in their use of Twitter, limiting their personal opinions in their tweets which is consistent with the problematic norm of objectivity (Lasorsa, et al., 2011).

Newsrooms in the US have similarly embraced web analytics technology. Web analytics refers to "the measurement, collection, analysis and reporting of internet data for the purposes of understanding and optimizing web usage" ("Web analytics definitions," 2008, p. 3). To some extent, web analytics "examines both the quantity and quality of visitors to a site" (Miller, 2011, p. 108). Web analytics programs enable 
website owners to monitor how users of their respective websites behave online by providing metrics, which refer to "any quantitative measure of passive viewing or consumption of content by internet users" (Krall, 2009, p. 387). Having access to web metrics allows website developers to decide beyond their intuition (Duncan, 2010).

From providing hourly data, such as Google Analytics and Omniture, web analytics tools have evolved into being able to provide real-time data, such as Chartbeat and Newsbeat, to providing predictions of how a story will perform in terms of traffic, such as Visual Revenue (Sonderman, 2011). A growing number of studies have established how newsrooms have institutionalized tracking audience metrics (Anderson, 2011a; Boczkowski, 2010b; MacGregor, 2007). A survey of 178 editors in 2008 found that $61.2 \%$ of the respondents reported to monitoring metrics on online audiences daily, although only $7.8 \%$ said these metrics influenced editorial decisions (Lowrey \& Woo, 2010). The practice of monitoring metrics appears to have increased over time. News editors are now guided by web metrics in their decisions of where to place stories in the website (Anderson, 2011a, 2011b; Lee, et al., 2012). A phone survey of 529 newspaper editors in 2011 found that $90 \%$ of the respondents reported receiving web analytics reports about their news websites, with $49 \%$ of the respondents saying their newsrooms make decisions about what stories to cover based "at least partially" on web metrics (Mayer, 2011). McKenzie and colleagues (2011) found that publicly owned, sophisticated, and bigger news websites tend to track online audience feedback more frequently than did smaller websites.

In interviews with 19 online journalists, MacGregor (2007) found that: "Some admit now that they double-check their instinctive guesses with tracking data" (p. 294). 
An analysis of content in three online newspapers in the US and their lists of most viewed stories found that audience clicks, measured by most viewed stories, affected subsequent placement of stories in the homepage (Lee, et al., 2012). It is possible that these new forms of audience feedback also affect other types of editorial decisions in online newsrooms aside from story placement. But the extent of the effect depends on a lot of contextual factors. For example, a study of the Al Jazeera newsroom found that while journalists recognized the importance of web metrics, they "felt content to ignore metrics in what was perceived as the safe-space of the Al Jazeera newsroom" (Usher, 2013, p. 9). The news organization, anyway, was fully funded. The journalists were coming from a different habitus unlike journalists who have seen news organizations, including their own, suffer from declining revenues.

\section{Challenges in Audience Measurement}

The institutionalization of the audience for the purposes of the institutions that stand to benefit from such a process, namely advertisers and the media, culminates with the quantification of the audience (Bermejo, 2007). The measurement of the audience, no matter how imperfect, is a requisite to the institutionalization of the audience for business purposes (Bermejo, 2007; Ettema \& Whitney, 1994; Napoli, 2011). This is why readership surveys and broadcast rating systems have prevailed, setting standards on how the audience is supposed to be quantified. The internet, however, came with the initial belief that it would present itself as the most measurable medium (Bermejo, 2007). "However, this belief was soon shattered by a fundamental issue: the inability to link the collected information with individual users" (Bermejo, 2007, p. 225). 
While web analytics provides journalists with a wealth of information about audience behavior, it does not provide a complete picture (Wiggins, 2007). Web analytics data are based on "cookies" from websites that are deposited in a computer when a website is rendered by a web browser (Benkoil, 2010). But computer users can delete cookies before logging out. They can also choose private browsing with some web browsers. When these users $\log$ in on the same website again, they might be counted as a new user. On the other hand, when several people share the same computer, they might be counted as just one visitor. Online sites have considered user registration to address these issues with tracking visitors, but many users also get turned off by having to register (Bermejo, 2007). Some confusion also surrounds the selection of metrics to monitor, of what data constitute key performance indicators. The industry of web analytics has shifted its standard from hits, to page views, and to unique monthly visitors - each of which has inherent weaknesses in terms of accurately capturing what it is that journalists hope to learn from web analytics (Krall, 2009). Because of these issues, 'the possibility of carrying out a census-like measurement of users' online activities is clearly limited by the lack of a link between activity and user" (Bermejo, 2007, p. 225). These gaps in web analytics are filled by other audience information systems, such as surveys and customer databases (Wiggins, 2007), but they also leave wide spaces for editorial judgment. "Web analytics reveals what users do, but not why they do it" (Wiggins, 2007, p. 20). Shoemaker and Reese (2014) also argued that: “Audience research may give media workers ideas about the general interests of viewers, listeners, and readers, but it cannot help much in their daily choices" (p. 170). The need to fill these gaps in audience research rests on the shoulders of journalists, highlighting the tension 
between knowing what the audience wants and imposing one's news judgment—-the rules of the game, the prescriptions of the journalistic doxa, that journalists have to consider.

\section{Normalizing Technology}

Heinonen (2011) classified two journalistic roles in relation to the audience in the age of online news. The "conventional role" referred to protecting editorial autonomy from audience influence. The "dialogical role" referred to "a need to open up journalism to direction from users" (Heinonen, 2011, p. 49). The conventional role is consistent with the prevailing journalistic doxa of maintaining editorial independence. Though these roles were classified in the context of accommodating user-generated content, they remain strikingly relevant to understanding how journalists allow themselves to be influenced by audience preferences communicated in the new forms of audience feedback I have discussed. These are also parallel to what Gans (1979) found to be the root of the ambivalence among newsrooms regarding the use of audience research even during an era without the internet, social media, and web analytics: the conflict between commercial and professional considerations.

A survey of 239 journalists across 11 European countries in 2005 and 2006 found that in general, journalists are open to and comfortable with new technology (O'Sullivan \& Heinonen, 2008). However, newspaper journalists welcome the internet only "when it suits their existing professional ends, and are much less enthusiastic about, and unlikely to promote, radical change in news work" (O'Sullivan \& Heinonen, 2008, p. 368). This is parallel to the notion of how journalists normalize new information technologies (Singer, 2005). Studies of how journalists adopted blogging (Singer, 2005) and Twitter (Lasorsa, et al., 2011) have demonstrated how journalists used these technologies to fit into 
traditional routines and norms. For example, journalists who maintained political blogs retained "their traditional journalistic gatekeeping role by incorporating limited or no material from users, despite the inherently conversational and participatory nature of the format" (Singer, 2005, p. 189). The same pattern appeared to be true, at least to some extent, with how journalists initially used Twitter (Lasorsa, et al., 2011). But while “jtweeters appear to be normalizing microblogs to fit into their existing norms and practices," they were also "adjusting these professional norms and practices to the evolving norms and practices of Twitter" (Lasorsa, et al., 2011, p. 31)

It appears that the same process is happening with how newsrooms are using new audience information systems. Online journalists have slowly opened up to new forms of audience feedback that provide clear clues to what the audience wants. In his observations at online newsrooms, Anderson (2011a) found that journalists "now expect reader feedback, even if they do not like it, agree with it, or see it as enhancing their ultimate journalistic product" (p. 558). But journalists also remain loyal to journalistic norms that have dominated the journalistic field for decades. Interviews with journalists regarding user-generated content found that for "most journalism professionals, the public continues to be distinctively an audience for the media product—even if the relationship has more interactive features than before, enabling formerly passive audience members to be more directly present in the everyday work of journalists" (Heinonen, 2011, p. 52). This is similar to the term "active recipients" to refer to how journalists regard users of news (Hermida, 2011, p. 189), which demonstrates how the balance between maintaining traditional journalistic autonomy and keeping up with an audience that is constantly evolving with technology remains skewed toward the former. 
MacGregor (2007) found that while journalists started using web analytics, many

of them still did not want audience metrics to get in the way of traditional news values in guiding story selection. Thus, as Boczkowski $(2004,2005)$ found based on his case studies of three newsrooms that were starting an online presence between 1997 and 1999, adoption of technology does not lead to the same trajectory. Instead, organizational structures, work practices, and representation of audiences can influence how technological adoption will impact news organizations (Boczkowski, 2004; 2005). In this study, I am particularly interested in the impact of journalistic representation of audiences, which I shall refer to as journalists' conception of the audience.

\section{The Mechanism of Audience Influence}

Despite the availability of new audience information systems (Napoli, 2011) and audience feedback through social media (Hermida, 2012), journalists have still not devised a clear-cut formula for a news article that is guaranteed to attract the maximum number of article views and shares. First, these new audience information systems provide a rich, detailed, but still incomplete profile of audience preferences. Second, even with available data, some journalists still tend to shield editorial decisions from these detailed forms of audience feedback, arguing that it would be inconsistent with the normative roles of journalism to rely on audience preferences for editorial decisions. But this depends on how journalists conceive of their audiences. For example, this fear of journalistic autonomy being compromised by reliance on web metrics for content-related decisions assumes that audiences prefer fluff to substance (Boczkowski, 2010a; Boczkowski, et al., 2011; Thorson, 2008). 
A way to understand how journalists conceive of their audiences is to explicate the audience as a form of capital. But while we know that journalists seek to amasstherefore, in the language of the mechanism I am proposing, accumulate-audiences, a question is how journalists regard the audience as a form of capital: economic, cultural, social or symbolic? In the previous chapter I argued that in this study I shall focus on the tension between economic and symbolic capital in the journalistic field. In many journalism studies, audiences have been considered as both consumers of news content and commodities sold to advertisers (Butsch, 2011; Loosen \& Schmidt, 2012; Webster \& Phalen, 1994). This is consistent with the conceptualization of economic capital, which refers to money and other assets that can be converted into money. But audiences are also essential in understanding the normative roles of journalism (Siebert, Peterson, \& Schramm, 1963). For example, the press is considered the fourth estate, consistent with the ideal of serving the public (Schultz, 1998). In journalistic role conception literature, roles are oriented toward audiences. For example, the disseminator role refers to a passive role of providing information to the audience while the mobilizer role refers to the active role of shaping public opinion and mobilizing people (Tandoc, et al., 2012; Tandoc \& Takahashi, 2013; Weaver, Beam, Brownlee, Voakes, \& Wilhoit, 2007; Weaver \& Wilhoit, 1986, 1996). Indeed, the audience can be conceived of as a public, whose members are considered as citizens and not merely consumers or commodities (Butsch, 2011; Herbst \& Beniger, 1994). This is consistent with the conceptualization of symbolic capital, considering the audience as an informed public whose reliance on a particular news organization for information can be considered a stamp of public approval of journalistic quality. This also relates to professional autonomy-journalists considering 
their readers a public to whom they provide a necessary service. Forming and engaging with a community of loyal readers also provides news organizations and their journalists a network of people, a form of social capital. This is especially salient in this age of social media that is seeing more and more journalists establishing their networks of readers by engaging with them on sites such as Facebook and Twitter (Siapera \& Spyridou, 2012). Thus, the audience, or at least what journalists know about them, can be conceived of as either a form of economic, social, or symbolic capital (Siapera, 2008).

Field theory scholars have operationalized economic capital in various forms, which specifically includes the audience, quantified in circulation and rating figures. Benson (2006) specifically said: "Inside the journalistic field, economic capital is expressed via circulation, or advertising revenues, or audience ratings" (p. 190). This is consistent with most definitions of the audience as a passive and institutionally constructed group of spectators (Ettema \& Whitney, 1994; Napoli, 2011; Turow, 2005). For example, Ang (1991) referred to the conceptualization of the audience as a market. But the audience conceived as a group of citizens (Butsch, 2011) changes the argument. If the audience is composed of members of the public who must be empowered with accurate and complete information through responsible journalism, it can also be argued that the audience can be considered as a form of social capital. Social capital has been defined as the social networks or connections that people have (Putnam, 1995, 2000). An informed audience also speaks of the kind of journalism a news organization produces, a form of prestige that confers legitimacy, and therefore a form of symbolic capital. This conception of the audience is consistent with the prevailing doxa of the field and with the conventional journalistic role in relation to the audience (Heinonen, 2011). But despite 
these overlapping and possibly conflated forms of capital and their respective operationalization in field theory literature, what matters in the field is how journalists themselves conceive of their audiences, for this conception can determine the extent to which they open up the gates to audience influence.

\section{Theoretical Synthesis}

Let me summarize my assumptions. First, the audience can be conceived of as a form of capital. Second, as a form of capital, audience accumulation provides a mechanism that allows journalists to be susceptible to influences. Third, an agent's conception of the audience, not the audience per se, can affect perception of threats to capital stability. Thus, the extent to which the use of web analytics in online newsrooms can affect the news construction process depends on how journalists conceive of their audiences to begin with.

In the previous chapter, I proposed a theoretical framework based on gatekeeping and field theory to understand the mechanism with which journalists get influenced. In this chapter, I focused on the audience as an influence on gatekeepers. Scholarly attention on the audience as an influence on journalists is further made more pressing and important by new audience information systems that allow journalists to track more information about the news audience and its preferences. Newsrooms have adopted social media and web analytics, the audience feedback systems I am particularly interested in, and yet as Boczkowski $(2004,2005)$ found, adoption of technology does not directly affect journalistic routines. In this study, I am focusing on how journalists use audience feedback in their news work. This usage patterns, I argue, depends on how they conceptualize the audience as a form of capital. This conception however is rooted in a 
journalist's habitus. The extent to which one's conception of the audience as a form of capital affects news work also depends on how one balances the changing audience with the dominant journalistic doxa in the field (please see Appendix A).

The audience is an important layer of influence on the gatekeeping process. But the mechanism of capital accumulation in the journalistic field can explain how this influence comes about. This study is focused on explicating this mechanism through the concept of the habitus and how journalists conceive of the audience, a form of journalistic doxa. Therefore, my ethnographic case study of three online newsrooms, which I introduce in the next chapter, is structured around the following research questions:

RQ1. How do journalists conceive of their audience?

RQ2. How does their habitus affect their conception of the audience? RQ3. How do journalists use audience feedback in their news work? RQ4. How does their conception of the audience affect how they use audience feedback in their news work?

RQ5. What other factors affect how journalists use audience feedback in their news work? 


\section{Theory Development: Case Study}

This study is generally interested in the influence of the audience in the online gatekeeping process. Specifically, it is focused on understanding how audience feedback communicated through new audience information systems — social media and web analytics — affects editorial decisions. This influence of the audience, however, has to be balanced with journalistic norms that guide news work.

This study will be divided into two phases, each largely defined by its particular research goals and the data-gathering methods appropriate to fulfill them. The first part focuses on theory development. In my review of the literature, I argued for a need to clarify that influences on news content are influences on gatekeepers who construct the news. I also proposed a mechanism of influence based on capital accumulation. These are both aimed at contributing to a clarification of gatekeeping theory as well as to developing a theory of how audiences influence journalists in a changing media ecosystem. Focusing on mechanisms moves theorizing away from black-box explanations characteristic of quantitative research that highlight relationships between variables without explaining why and how such relationships exist (Hedström \& Swedberg, 1998a; Tilly, 2001). The first phase, therefore, requires close, careful, and holistic observations: a case study of an online newsroom. But while case study research illuminates complex causal mechanisms with the goal of finding relationships that might be applicable to other cases (Creswell, 2007), it is criticized to have weak external validity. An attempt to uncover patterns and relationships across cases-for example, 
how journalists in the US are using web analytics in their news work-requires a quantitative approach that allows generalization, such as the survey method (Shoemaker $\&$ McCombs, 2003). The second phase of this study, therefore, is a survey of online editors in the US, providing a form of theory testing, particularly of the theoretical mechanisms developed based on the first phase of the study. In short, this dissertation is a mixed methods study (Creswell \& Plano Clark, 2011; Greene, 2008; R. B. Johnson, Onwuegbuzie, \& Turner, 2007).

Mixed methods research has been proposed as a methodological paradigm on its own (Greene, 2008), situated between the extremes of quantitative and qualitative paradigms and marked by its philosophical assumption of pragmatism (R. B. Johnson, et al., 2007). Social phenomena are inherently complex and researchers can benefit from using multiple ways of knowing (Greene, 2008). An increasing number of researchers are recognizing that many investigations warrant a combination of research methods (Creswell \& Plano Clark, 2011; R. B. Johnson, et al., 2007) even if it puts a lot of demands on the researcher in terms of the required expertise (Yin, 2011). A review of scholarship on mixed methods research offered the following definition:

Mixed methods research is the type of research in which a researcher or team of researchers combines elements of qualitative and quantitative research approaches (e.g., use of qualitative and quantitative viewpoints, data collection, analysis, inference techniques) for the broad purposes of breadth and depth of understanding and corroboration. (R. B. Johnson, et al., 2007, p. 123) This dissertation employs an exploratory sequential mixed methods design (Creswell \& Plano Clark, 2011) which is also referred to as a quantitative follow-up 
design (Morgan, 1998). A common purpose of this design is evaluating and interpreting results from a "principally qualitative study" with a "smaller quantitative study" (Morgan, 1998, p. 368). It begins with a qualitative study with a goal of developing something as general as a theoretical framework or something as specific as an instrument or a scale using a qualitative method (Creswell \& Plano Clark, 2011). The framework or instrument is then tested using a quantitative method (Creswell \& Plano Clark, 2011). These methods must be within a single study for the study to be considered mixed methods research (Yin, 2011). Thus, while the study uses two or more different data-gathering methods, the results of which might be analyzed separately as well, the results are interpreted together leading into the study's main conclusion (Creswell \& Plano Clark, 2011; Morgan, 1998; Yin, 2011). This is exactly how I designed my dissertation research. I started with a multiple case study involving three online newsrooms. Based on the case studies, I developed a theoretical framework that I subsequently tested and refined using a survey of online editors (please see Appendix A). However, while the case studies were conducted before the survey, I did not consider the former as the priority over the latter. Instead, I consider my research design as a coordinated approach (see for example Stecher \& Borko, 2002), for I originally and purposely designed this dissertation as a mixed methods study, with each methodological component considered an important piece in completing the puzzle (see Appendix B).

\section{Case Study}

The case study approach is employed across a range of fields, from sociology, to political science, to mass communication. It is particularly appealing to scholars interested in examining complicated causal links. Hammersley and colleagues (2000) 
recognized the theoretical value of the case study approach for "it can uncover the causal processes linking inputs and outputs within a system" (p. 234). Scholars disagree, however, in how to define what constitutes a case study. Some say a case study is defined by the case selected for analysis; others argue it is a method comparable to surveys or experiments; while others refer to it as a methodology with its own philosophical assumptions (Creswell, 2007; Hammersley \& Gomm, 2000; Yin, 2009).

I argue that case study is a methodology with an epistemology that emphasizes the need to understand cases holistically instead of dissecting a case into decontextualized segments. It relies on a range of methods to achieve this purpose of understanding a case or cases in depth (Eisenhardt, 1989). As a research methodology, case study "focuses on understanding the dynamics present within single settings" (Eisenhardt, 1989, p. 534). This approach has been used in multiple studies involving journalists (e.g. Atton \& Wickenden, 2005; Boczkowski, 2005; Maier, 2003; Sue Robinson, 2009). While a survey involves a relatively large number of cases but gathers a small number of features per case, a case study usually focuses on a relatively small number of cases - sometimes even just on a single case - but gathers a large number of features about each naturally occurring case (Hammersley \& Gomm, 2000). What makes the case study approach holistic is its recognition that a case cannot be divorced from its context. Yin (2009) defined case study as an "empirical inquiry that 1 ) investigates a contemporary phenomenon in depth and within its real-life context, especially when 2) the boundaries between phenomenon and context are not clearly evident" (p. 18). In contrast to quantitative studies, such as surveys or experiments, where the narrative is that a variable "does something" while cases - or the individuals that contain or exhibit those 
variables - are written out of the analysis (Abbott, 1992), case study research examines individual agency within a context, which serves the purpose of my study, particularly my initial goal of theory development (Eisenhardt, 1989).

Case study research "involves the study of an issue explored through one or more cases within a bounded system" (Creswell, 2007, p. 73). For example, an instrumental case study starts with an issue and then locates a bounded system that illustrates the issue (Creswell, 2007). Thus, an important question in case study research is how a case is determined. How does one determine the boundaries of a system? Ragin (1992) referred to "casing" or the process of making something into a case. This is done by matching ideas and evidence (Ragin, 1992). This process "creates objects that researchers can manipulate to refine theory" (Ragin, 1992, p. 221). Abbott (1992) used the term "case" in the sense of "instance." Thus, something can be an instance of a population or an instance of a conceptual class, such that "the conceptual class has some property and the cases exemplify that property" (Abbott, 1992, p. 53).

\section{The Three Cases}

This study involves three cases - instances of the phenomenon I sought to study_following a replication logic (Eisenhardt, 1989; Yin, 2009). I used theoretical sampling in selecting the cases. "Theoretical sampling simply means that cases are selected because they are particularly suitable for illuminating and extending relationships and logic among constructs" (Eisenhardt \& Graebner, 2007, p. 27). Since I

am generally interested in understanding how audience feedback affects news work, I had to select online newsrooms that used social media and web analytics. 
Sampling for multiple case studies, however, is also influenced by opportunities for research access (Eisenhardt \& Graebner, 2007). I initially sent requests to five different online newsrooms. Three of these requests were approved. Compared with a single case study, "theory building from multiple cases typically yields more robust, generalizable and testable theory" (Eisenhardt \& Graebner, 2007, p. 27). I consider these three cases as theoretical units of the same phenomenon, similar to the logic of "literal replication" (Yin, 2009, p. 54) or "pure replication" (Swanborn, 2010, p. 104).

This focus on theory building across multiple cases also requires a narrative that spans across the three cases, as how my next two chapters are structured, for unlike in a single case study, "presenting a relatively complete and unbroken narrative of each case is infeasible for multiple-case research" (Eisenhardt \& Graebner, 2007, p. 29). My access to these online newsrooms and the project approval from the University of Missouri's Institutional Review Board (IRB) came with the promise of anonymity.

The websites of the three online newsrooms included in this study are among the 50 biggest news sites in the US based on traffic. The main website of the first newsroom claims to have about 3 million unique monthly visitors. The website of the second newsroom claims to have about 3.9 million while the third newsroom claims to have about 3.8 million. These newsrooms all have newspaper products, also among the 50 biggest newspapers in the US based on circulation. Thus, the online desks are located in newsrooms converged with the editorial desks of their respective newspapers. So while I focused on the operations of the online desks, their operations are closely intertwined with the editorial operations for their respective newspapers. These news organizations all have a long history, with their newspapers all founded before 1900 . 


\section{Research Methods}

The methodology of case study employs a range of methods, such as document research, observation, and interview (Yin, 2009). Some case studies also use survey and content analysis (Creswell, 2007; Hammersley \& Gomm, 2000; Yin, 2009). In this study, I used participant observation and interview methods, considered ethnographic methods. The use of ethnographic methods is appropriate to the goals and assumptions of my multiple case study, an argument for referring to my approach as an ethnographic case study (see for example Boczkowski, 2005). Paterson (2008) argued that only ethnographic methodologies "can come close to providing an adequate description of the culture and practice of media production, and the mindset of media producers" (p. 2).

Participant observation. Observations are consistent with the assumption of case study as involving naturally occurring cases (Yin, 2009). This method allowed me to observe the actors in their actual environment while also allowing me to gain some experience of their routines. I assumed the observer-as-participant role (Lindlof \& Taylor, 2010) as observation was my priority but it did not preclude me from interacting with the editors I observed. This stance allowed me to take notes during my observations and to establish good rapport with many of the editors I interacted with (Tracy, 2013). I attended daily budget meetings in each of my three cases. Outside these meetings, I sat in the online desks observing web editors do their work—checking emails, writing and editing stories and photo galleries, tweeting, using Facebook, taking phone calls, and talking to reporters and other editors. I took down notes using a small brown notebook that had the logo of the University of Missouri. It was small enough not to call attention to itself. I wrote my formal field notes every day, right after I left the newsroom. I also 
posted my field notes on a private blog. This encouraged me to write them as soon as possible and guaranteed that my entries were fresh and accurate.

I spent a total of about 150 hours of observation across the three newsrooms, spread out in the months of March and May 2013. I spent the longest time in the first newsroom, with about 110 hours of observation spread in 12 consecutive days, from March 5-16. There, I was assigned my own work station next to a web editor and two cubicles away from the managing editor who oversaw the daily operations of the online desk. For my first replication, I went to a second newsroom where I spent about 10 hours of observation spread in three days from March 18-20 as my point person was wary of allowing me longer access. In the limited number of hours that I was in the second newsroom, I sat next to whoever was the designated homepage editor. I also attended budget meetings and I was able to observe an entire news cycle on my first day. Finally, I spent 30 hours in the third newsroom for four consecutive days, from May 28-31. There, I sat on a chair between the two web editors who took turns in updating the homepage. They shared a long desk and their workstations where on the opposite ends of the desk. They allowed me to sit between them, which gave me a good view of both their workstations.

Respondent interviews. Interviews enable people to provide stories, accounts and explanations (Lindlof \& Taylor, 2010). This method is appropriate for studies that seek to understand "the social actor's experience, knowledge, and worldviews" (Lindlof \& Taylor, 2010, p. 173). It is also consistent with the assumption of naturalistic research (Rubin \& Rubin, 2005). An advantage of the interview method is the "wealth of detail that it provides" (Wimmer \& Dominick, 2011, p. 139). 
Interviews with journalists are important in understanding not only what they do but also the outputs they produce (e.g. Boczkowski, 2005; Gans, 1979; Tuchman, 1978). Their work provides them a unique access to a wide range of information (Besley \& Roberts, 2009). Thus, they can provide a lot of insights about the gatekeeping process. For example, Yang (2004) conducted phone interviews with six environmental journalists to explore constraints on environmental news production. Avraham and colleagues (2002; 2000) conducted interviews to explore influences on the coverage, or lack thereof, of minorities in Israel. Journalists, however, are a peculiar group for interviews. Their busy routines makes coordination — and convincing them to spend a long period of time to participate in the study—challenging (Attfield \& Dowell, 2003). They are also used to interviewing people instead of being interviewed.

I experienced these challenges during my interviews. This is why I decided to conduct semi-structured interviews (Lindlof \& Taylor, 2010; Plooy, 2004). I prepared a three-page interview protocol but I also allowed myself to be flexible during the actual interviews (please see Appendix C). A few editors initially just gave one-sentence answers. I had to ask numerous probes and follow-up questions to make them elaborate on their short answers (Rubin \& Rubin, 2005; Tracy, 2013). But a few other editors also talked a lot. For example, I asked my first question to an editor that got him to start talking. I looked at my recorder and he was still talking about the first question after eight minutes. This is when I deviated from recommendations that qualitative interviews refrain as much as possible from asking closed-ended questions (Lindlof \& Taylor, 2010; Tracy, 2013). I found that asking closed-ended questions, a form of directive questions (Tracy, 2013), could help keep an interviewee from digressing. I realized that certain 
types of interviewees would automatically elaborate on their answers even if they were asked with a closed-ended question. Not only did this save me some time, but it also helped me keep the interviews on the right track.

I engaged in ethnographic interviews, or informal conversations that occurred during the course of my observations, and respondent interviews, or sitting down with an editor at a specified time usually after their work hours (Tracy, 2013). I tried maximum variation sampling by requesting interviews with editors at different levels of the newsroom hierarchy (Tracy, 2013). In the end, I managed to conduct interviews with a publisher, a general manager, an editor-in-chief, a managing editor, two assistant managing editors, and a couple of web editors from the three newsrooms. I interviewed a total of 30 people: 15 from the first newsroom, 8 from the second newsroom, and 8 from the third newsroom. In total, my respondent interviews added up to about 668 minutes (please see Appendix D).

\section{Data Analysis}

I used a constant comparative approach to my data analysis. It is a common analytical strategy in grounded theory, a methodology that has seen different iterations from its inception (e.g. Corbin \& Strauss, 1990; Glaser, 1965). Grounded theory, as it was originally conceived, is an inductive approach, where theory emerges from the data. But constant comparison as an analytical strategy has also been used in studies that did not use grounded theory as methodology (Creswell, 2007; Tracy, 2013). I am borrowing this analytical approach. But I also employed it using an iterative strategy. "An iterative analysis alternates between emic, or emergent, readings of the data and an etic use of existing models, explanations, and theories" (Tracy, 2013, p. 184). Thus, while I 
approached the data with the sensitizing concepts from my initial theoretical framework (Blumer, 1954; Christians \& Carey, 1989), my iterative strategy also allowed me to identify emerging concepts and relationships. Corbin and Strauss (1990) argued that the goal of constant comparison in grounded theory is not generalization but theoretical explanation, and as such what is required is representativeness of concepts, not of persons. This is consistent with the assumptions of case study. The process of constant comparison does not only refer to constantly comparing a code with another code within a set of data as many studies using this analytical approach had pointed out, but also comparing old data with a new set of data. Thus, constant comparison begins after the first set of data is collected, not after all the data has been gathered (Tracy, 2013). I started writing analytic memos right after my first day of observation. I continued this process as I went along in my data gathering — jotting down emerging patterns and then comparing them with new observations and interviews as they came along.

I used NVivo, a computer assisted qualitative data analysis software (CAQDAS), to organize and code my data. I formatted my field notes and interview transcripts as word documents and stored them in NVivo. The software helped me organize my data based on each case. It also helped keep my coding process organized. Since I used an iterative coding process, I started developing codes based on my first field note. The software allowed me to save the codes from the first document with my own memos and descriptions attached to each code. Thus, when I coded my second field note, I was able to easily refer to my existing codes as well as create new codes as they emerged. NVivo uses the term "nodes" to refer to codes. 
Primary-cycle coding. Tracy (2013) recommended the process of fracturing, or breaking down data into smaller pieces, during the primary-cycle coding stage, or the first stage of coding, also called open coding (Glaser \& Strauss, 1967; Saldaña, 2009). Fracturing, and then lumping related codes at a later stage, should save a researcher from missing important links (Tracy, 2013). I discovered, however, that it is not always possible to engage in fracturing, especially at this initial stage. I will argue that the iterative process is also true regarding fracturing and lumping at this initial stage of coding. Some codes naturally came from the theoretical framework I proposed. But a few of these concepts still retained some abstraction in my initial coding (e.g. using analytics) that I had to fracture them later on. This, however, did not keep me from seeing emerging relationships. Rather, switching back and forth from fracturing and lumping allowed me to refine each concept and each relationship based on my evolving theoretical framework. This stage yielded me with 135 codes.

Secondary-cycle coding. The advantage of NVivo is the ease of storing and retrieving codes. For example, to determine whether an existing code is appropriate for a chunk of data I was looking at, I just clicked on that particular code and saw all the passages I have coded the same way-I was comparing new data with old data, consistent with the constant comparison approach. This process also allowed me to recode old data in light of new codes that emerged from the current data. However, I also experienced the limitations of the software (Tracy, 2013), particularly as I moved into secondary-cycle coding, or the stage that is marked by "classifying, prioritizing, integrating, synthesizing, abstracting, conceptualizing, and theory-building" (Saldaña, 2009, p. 45). This was the stage when I started categorizing the codes identified in the 
primary-cycle stage and noting the emerging relationships between them (Tracy, 2013). NVivo allowed me to draw a conceptual model using its model building function. But I found it difficult to visualize the relationships between the codes.

I decided to switch to manual coding. I printed out all my codes, cut them into pieces, and started sorting them manually. This made me more connected with my data. It allowed me to easily explore patterns and relationships by manually moving around pieces of paper without the confines of my computer's 15 -inch screen. I grouped my codes into conceptual bins by pasting the cut-out pieces into color-coded cardboards that each represented a main concept. Then, I started composing a qualitative report.

Writing is a form of interpretation. As we write, we engage in a cognitive process that helps us identify patterns and relationships. As I wrote my qualitative report, composing a narrative surrounding each conceptual bin, relationships began to develop. As I wrote about each conceptual bin, I found myself going back to my data, looking for exemplars and vignettes that best represented each of the main concepts (Tracy, 2013). This process was facilitated by the data organization allowed by NVivo.

Rakow (2011) argued that saturation — the point when a researcher can decide to stop collecting new data—does not only refer to the point when no new information emerges, but also to the point when the concepts are fully developed. In the next two chapters, I present the results of my analysis, demonstrating the full development of each of my main concepts. 


\section{Journalists and their Audiences}

The door swung open after long, silent minutes of people going in and out of the room speaking in hushed tones. A tall man, probably in his late 50s, emerged out of the room, his face flushed red, his eyes wet, his voice cracking. "Thank you all," the veteran journalist said, addressing a newsroom of about 30 people, most of them confused about what was going on. The first newsroom that I observed had just been renovated as part of a move to centralize operations to go "digital first." A few workstations-narrow tables juxtaposed in such a way that everyone can see everyone without having to stand upwere still empty. The four television monitors hovering right on top of the digital desk located in front of the newsroom were switched on but barely audible. Normal chatter ceased and gave way to a respectful applause from those who understood what was going on. "Thank you," the man said again after almost two minutes of applause. "This newsroom has been my family for 23 years."

Then, the man, a videographer per his most current job description, made an informal salute and left. A web editor — she had been here for about six months so farwas left speechless, her jaw wide open. Another web editor, who also came in just a few months ago, covered his mouth with both of his hands. Layoffs have been ordinary in this newsroom in the last year or so. But nobody gets used to seeing people go.

\section{Change or Die}

It is painful to see these layoffs happen, but older editors in the upper echelons of the newsroom are no longer surprised. Many of them started their careers at a time when 
newspapers flourished and they rose to the ranks of the newsroom hierarchy as the industry continually declined. The newsroom's deputy managing editor for digital finished college in 1996, a period when, she said, "everybody can get a job." Then she and her contemporaries witnessed how everything changed. The company filed for bankruptcy in 2009. The new editor-in-chief, who has spent most of his life as a journalist, now finds himself having to make decisions on which among his staff members will go jobless next. "The day is coming very quickly," he told me in one of our conversations during my observation. "The day is coming very quickly that the printed paper will go away."

The editor-in-chief spoke to his employees a few hours after the photographer he had just fired had left. Standing in the middle of the rectangular newsroom with sad, confused, and angry staff members surrounding him, the editor-in-chief reminded his employees of the dismal conditions of the market. He reminded them they were no longer a newspaper company, that there would be more changes to introduce new products and find new avenues for advertisements. "I hope I can stand here in front of you and say there would be no more layoffs," he told a quiet crowd. "But that is not the case."

In this chapter I will focus on the journalistic habitus and demonstrate the ways that journalists' perception of the trajectory that the journalistic field has taken provides the context to understand how news work is changing. It can explain the adoption of new communication technologies as well as how some norms, part of the journalistic doxa, are being renegotiated. For the editors that I spoke with and observed, this understanding of the journalistic field's trajectory comes from their experience of being in the field and their own practice of journalism. This perception is part of the journalistic habitus, which 
consists of "bodily knowledge which is based on practice and experience" (Willig, 2013, p. 8). This focus on editors' experiences as part of the habitus is important for the "habitus also links past fields to present fields through the individual actors who move from one to the next," (Emirbayer \& Johnson, 2008, p. 4). To a large extent the habitus is an "understanding of the journalistic game" (Willig, 2013, p. 8). It includes seeing journalism change and thinking of ways to keep pace with this evolution through niche journalism and going digital.

Seeing journalism change. The editor-in-chief had worked for this company many years ago, after which he started doing rounds of numerous news organizations, ending up in a couple of online-only newsrooms, and coming back to this newsroom whose glory days in terms of revenues have long passed. "The landscape changed very quickly," he said, reflecting on what he had witnessed. "Lots of journalists lost their jobs. It meant smaller newsrooms had to do more with less. Editors had to do more with less. And it was kind of, you know, either change or die."

In the three newsrooms where I observed, many of the older editors shared the same experience: of starting their jobs when newspapers flourished and having to witness them perish in some form or another. The American Society of News Editors (ASNE) estimated that about 2,600 full-time newspaper jobs disappeared in 2012, and the total number of newspaper jobs had shrunk from more than 52,000 in 2007 to 38,000 in 2012 (Edmonds, 2013). The assistant managing editor for online at the third newsroom where I observed feels lucky to have lived during the "heyday of journalism when the staff was twice as big and it felt like the public in general held journalism in higher regard." Things are different now, she told me during our interview. "We're not dying. We're changing a 
lot. But I don't know whether journalism will ever regain the status it once had. To me that is sad."

This appreciation of how much the journalistic field has changed does not only come from the editors' own experiences as journalists but also from what they personally witnessed from their own children. The publisher of the second newsroom I visited has three children: aged 26, 23, and 19. He said: "The chances of migrating them to replace me, when I'm no longer reading a print product, I think is very, very slim to no chance." The general manager for the website of the third newsroom where I observed also said: "My son has very little use for a newspaper other than once in a while when he is looking for a movie listing, but most of his stuff is done on his phone." A 2012 survey by the Pew Project in Excellence in Journalism found that half of the respondents got their news digitally compared with only less than a third who still read newspapers (Beaujon, 2012). For the traditional newspaper, losing readers equals losing advertising revenues.

Some editors pointed to how much the audience for news had changed. The managing editor of the first newsroom said that a lot of people had become "distrustful of the media." In my observations during their budget meetings, when stories are decided upon particularly for print, the editors never talked about favoring one politician over the other, and yet the managing editor believes that a lot of people perceive them as having a "political agenda." His deputy managing editor for digital also referred to how often and quickly technology changes, citing social media sites such as Facebook, Twitter, and more recently Instagram, which also change how news gets disseminated not only by journalists themselves but also by members of the audience. "The user's appetite for news and information has changed," she said. "They have more outlets for it. They are 
also going to different platforms." For the second newsroom's social media manager, journalists should just look at what happened to the music industry to realize how much things have changed.

The first, second, and third newsrooms where I observed and conducted interviews are well-known newspapers listed as among the biggest newspapers in the country in terms of newspaper circulation. This is why dwindling circulation hits the bottom line. The field of print journalism is seeing a shrinking economic capital. Though they have long started their own news websites, revenue from both pay wall fees and online advertising remains insufficient to finance the scale of operations these news organizations have been used to. They may not agree when exactly it will happen, but for the top-level editors in these three newsrooms, the extinction of the newspaper medium is clearly no longer a question of if, but a matter of when.

This appreciation of how journalism is morphing is communicated to the rest of the news organization in numerous ways. It can be as general as the editor-in-chief's memorandum, issued as soon as he stepped in as the new editor of the first newsroom I visited, that declared: "We are no longer a newspaper company." It can also be as specific and jolting as firing employees, like what happened to the videographer I met at the first newsroom, whom a lot of people thought would be safe considering that his job was that of a videographer, something that was thought to be important for a multi-media news website. The editor-in-chief who fired him said:

It's hard to change directions. It's hard to convince people that the old way of doing things that was successful for a long time is now out of step, and you know, I think it takes things, unfortunately, like what we had last week - a layoff. Not a 
lot of people, but people we have to say goodbye to. And until that, sometimes, until that happens, people don't understand how tough the business has become..."

Keeping it focused. Layoffs have been frequently jolting the journalistic field that journalists have started to find ways to try to live with the reality of shrinking newsrooms. A smaller pool of reporters means having fewer resources. Casting a wide net is no longer practical. This reality of the field is particularly most felt at the first newsroom. "Since 2008, we've been having constant layoffs and it's never stopped," a reporter who also works as an editor during the weekends told me during one of our conversations. "We think we can't layoff anybody else, then another person gets laid off. So you're working a lot more."

Her newsroom has apparently become more cognizant of the need to keep news coverage focused. "Do we report about every fire?" her editor-in-chief asked rhetorically. "Probably not—but do we focus more heavily on politics and city hall because people in this town like that?" One of his web editors said they have been trying to keep their coverage as local as they could - people could go to CNN if they wanted national stories. But even at the second newsroom, editors are becoming conscious about eliminating costs, a reflection of the shrinking economic capital for print journalism. "I think that what we've done a good job [here] doing is cutting down on the money that we spend on journalism that isn't advancing our vision," the vice president for digital said. "So, you know, we are more investigative journalists today than we did five years ago." He asked me to think about articles on gardening as well as movie reviews. He pointed out that a lot of bloggers offer these types of contents for free, and social media users have become 
movie critics as well, that a newsroom's resources are better off devoted to investigative stories. "Spend money on what matters," he said. This consciousness of keeping news coverage focused amid a shrinking pool of resources has become more salient as newsrooms also seek solutions by focusing on digital initiatives.

Turning to digital for survival. The first newsroom was still being renovated when I started my observation. It is located on the ninth floor of a skyscraper in the middle of the city. They gave me my own workspace, a small cubicle that was still missing a landline phone and a computer just like a few other still empty workspaces, as the editors supposed to occupy them have not relocated yet. This is the digital desk, where the managing editor and his two web editors, along with other editors tasked to help edit and upload stories to the website, work. The digital desk sits in the middle of the newsroom, surrounded by the metro, business, and arts desks. The workspaces devoted to the digital desk are arranged in a horizontal row that is perpendicular to the rest of the workspaces that are, in contrast to the digital desk, arranged in vertical rows. Only a few weeks ago, the digital and metro desks were located on separate floors.

The third newsroom was also relatively recently renovated when I came for my observations. It is located on the third floor of an old building. It is a huge newsroom, whose size is betrayed by the old and narrow staircase leading to it. A wooden door opens into the middle of the newsroom and anyone who enters will be directly staring at a workspace at the center, composed of two desks facing each other. This is where the assistant managing editor for digital sits from 9 a.m. to 3 p.m. as she directs the daily operations of the website. Behind her, immediately to the right after the main door, is a workspace where two homepage editors are stationed. A third homepage editor is seated 
in the sports desk, which is in the opposite side. The homepage and the sports desks are arranged diagonally, looking like opposite parts of a hexagon surrounding the assistant managing editor's workspace at the center, so that, according to one of the two homepage editors: "[She] is at the center of the universe."

The layout of these two newsrooms speaks of the central role of digital operations in how these previously newspaper-only news organizations do their journalism. For the first newsroom, the managing editor said the makeover of the office layout was aimed at facilitating easier conversations between different news desks. But in my observations, I also found that locating the digital desk in the middle of the newsroom also allowed an easier diffusion of news-related technology: An editor would come to ask for help on how to tweet, a columnist would come to ask how his article is doing in terms of traffic, a reporter would come to ask for hashtag suggestions for Twitter. These physical changes in the newsroom layout also serve as concrete and constant reminders of how much the journalistic field has changed.

Choosing survival means changing and trying a lot of new things. Since the new owners brought him in just a year ago, the first newsroom's editor-in-chief has been trying to emphasize how the newsroom should think of itself as a digital company. This entails pursuing new ways of interacting with the audience, delivering content, and accessing data. He said:

The great part about this period that we are in now is that there's a lot of experimentation. There's a lot of room to fail successfully — try something else. When things were great, ironically, it was not a great period for experimentation, because why would you rock the boat? 
Not rocking the boat meant newspapers existed as if things would never change, and when they finally started putting out content online, they realized they never had time to prepare. Newspapers initially provided online content for free. But while their websites were not earning a lot of money, their papers were bleeding red. More and more newsrooms started putting up a pay wall, but by that time online news consumers were already used to getting their news online for free. The second newsroom's social media manager shares the same sentiment, for while their company remains ahead of the competition, it has also seen its revenues dwindle, even filing for bankruptcy in 2008. "I think that what got us in trouble in the first place is the inability to consider a new way," she told me in our interview. "We were unwilling to accept evolution in the industry and that is what got us off-track in the first place."

This realization of how much journalism has changed has left journalists, even those who were once averse to change, with no other options but to go with the flow. "The market is changing every day and if we don't change at the same rate, we fall behind," the publisher of the second newsroom said. "You either go forward or fall behind in this world — and standing still means you really fall behind."

So how are journalists changing in response to the changing market, to the realization of a shrinking economic capital for the print journalistic field? In this study, I am focusing on the intersection of two important factors in this evolution-news audiences and the technologies to understand them—-and how they are re-shaping journalistic norms and routines. 


\section{Tracking the Audience}

Technology is an important force behind the jolts in the journalistic field. The decline of the newspaper medium is blamed, to some extent, on the ease of getting information, often for free, online. A few newsrooms have also phased out their photo departments, arguing that journalists themselves can take photos using their mobile phones (Romenesko, 2013). "Technology in many ways hasn't been a friend to the industry," the assistant managing editor for digital at the third newsroom told me during our interview. "It has made things easier, but it has devalued some of the skills that journalists have." But journalists also acknowledge that technology cannot be undone. The social media manager at the second newsroom said. "Once a new way exists, it exists. It's always going to disrupt."

What journalists have been good at —although the field itself is criticized to have been consistently snail-paced in responding to technological shifts-is normalizing technology, adapting it to suit traditional norms and routines. The deputy managing editor for digital at the first newsroom talked about using "technology to your advantage." In turning to digital for survival, journalists are also balancing their traditional journalistic norms and routines with the rules of the online game they have started to play.

In September 2009, Adobe, one of the world's leading software makers, spent $\$ 1.8$ billion to buy Omniture, a company that offered products allowing clients to monitor how people use their websites (B. Johnson, 2009). In the online world, information about the audience is precious, and news organizations have realized this. Surveys of editors and news managers found that a big majority of newsrooms in the US have been using web analytics software, including Omniture (Lowrey \& Woo, 2010; McKenzie, et al., 
2011; Tandoc \& Jenner, 2013). Collecting information about the audience is not new. In the old days, numbers came in the form of readership surveys for newspapers and news magazines and rating systems for television and radio networks (Gans, 1979; Schlesinger, 1978). These numbers took some time to collect and were based on non-representative samples of audiences. But new audience information systems — new technology—are now able to provide numbers on audiences and audience behaviors in real time. The managing editor at the first newsroom said:

I mean with print, we really don't have much idea how people are using it except for letters to the editor. That's somewhat useful, but it only goes so far. With digital, which is where we have three or more times more eyeball everyday than we do in print, we know exactly what they're reading and for how long and where they're coming from.

In the first newsroom where I observed, most of the editors I spoke with did not have formal training in the use of web analytics. The editor-in-chief only referred to his experience working in an online-only newsroom prior to him coming to his present newsroom. His deputy managing editor for digital said her husband was a marketing analyst who knew how to crunch all these numbers from web analytics. The managing editor also said he learned the tricks in the newsroom, being personally interested in new technologies. The first shift web editor said most of what she knew about web analytics was self-taught.

The same pattern is true across the three newsrooms, although one afternoon when I was staying at the third newsroom, I came across one of the two web editors on a phone conference for more than 45 minutes. The company had scheduled the editors to 
join a webinar on the use of a new version of Omniture, which the company would be rolling out the following week across all its newsrooms. In general, however, training on web analytics is not formalized in most newsrooms - either a young editor is expected to know it prior to working into the newsroom or an old editor being moved to digital is expected to learn the technology by using it. In the three newsrooms where I observed, these four analytics programs are used to track the audience: Chartbeat, Visual Revenue, Omniture, and Comscore.

Chartbeat. I sat with a web editor at the second newsroom on my first hour of observation there. The first things I noticed were his two office-issued computer monitors next to his personal Macbook computer and an office-issued iPad. In the bigger monitor, he had his email account, the company's news website, and his Tweetdeck open. The smaller monitor was solely devoted to Chartbeat, where he would glance once in a while, checking how much traffic stories were getting. The New York City-based Chartbeat was launched in 2009 and serves more than 150 news organizations (N. Yang, 2012), including both the first two newsrooms. Chartbeat provides a list of the top performing stories on the site based on page views and this information is updated in real-time. It also displays top sources of traffic. For example, one time a story by the first newsroom was linked by Drudge Report, sending a lot of traffic to the website. Chartbeat claims to being used by $80 \%$ of the top publishers in the US (Haile, 2013).

One of the first few things that editors in the second newsroom did in their budget meetings was look at Chartbeat being projected on a monitor in the middle of the meeting room. Their web editors also use a heat map, a service included in Chartbeat. Incorporated into a view of the homepage, the heat map shows how a story placed on a 
particular spot, say as the main story on the homepage, is performing compared to previous stories placed on the same spot. A bubble turns green if the story is outperforming the average for its spot and turns red if it is underperforming. In the first and second newsrooms, web editors looked at Chartbeat multiple times a day. "I use Chartbeat as the instant gratification kind of thing — understanding the trends and things like that," the first newsroom's deputy managing editor for digital said. "The newsroom uses that as part of their arsenal of tools every single day to help them, you know, figure which content places well on the homepage or other sections, and things like that. That's what I call the daily operations."

Visual Revenue. They do not use Chartbeat at the third newsroom, but when I started my observations there the newsroom had just started using Visual Revenue, an analytics program very similar to Chartbeat. One of the web editors started talking to me about Visual Revenue when I sat next to him on my first day of observation. I immediately sensed his excitement about the program, which the newsroom started using only in October 2012. Visual Revenue has four main tabs. First, the front page shows how content elements in the homepage are performing - articles, photo galleries, and videos. It gives not only the average page views per hour, but also how a story is performing in a particular position compared to the average performance of previous stories in that same position, similar to Chartbeat's heat maps. Second, the content tab ranks the top contents on the website. It also shows where clicks are coming from, or how users are landing into the site: the homepage, direct access, through aggregators, through social media, or through search engines. What makes Visual Revenue slightly different from Chartbeat is its social tab and placement recommendations - although Chartbeat has 
released a new version that includes recommendations as well. The third tab, the social tab, works with the website's Twitter account and tells how many times per hour a story gets retweeted. Finally, the recommendation tab provides suggestions on which of the uploaded stories could be moved to which position. It also provides an estimated number of page views the site will generate for following each suggestion. Visual Revenue also allows headline testing. A web editor can write two headlines for the same story, upload them on the website so that half of those who view the story gets to read one headline, the other half gets the other version. The editor can then choose which of the headlines to retain. These suggestions are based on a formula built into the system using several criteria, Visual Revenue's founder Dennis Mortensen told me during a web analytics conference in September 2013. These criteria include an analysis of how previous stories and headlines performed in the past and a set of instructions from the subscribing newsroom which Visual Revenue tries to incorporate in the system.

Visual Revenue was founded in 2010 and was acquired by Outbrain, a contentrecommendation startup, in 2012 (Lynley, 2013; N. Yang, 2012). "With Visual Revenue we're looking at real time analytics constantly, doing headline tests," the assistant managing editor for digital told me. "And this just gives us a fantastic opportunity to change things on the fly versus trying to guess and maybe changing things every couple of hours." One of her web editors said that even the publisher looked at Visual Revenue "all the time." One time, the assistant managing editor for digital tried to get a sense of how much web editors were using the program and she found that the three of them- the assistant managing editor herself and her two web editors - were the top users. The surprising thing was their publisher was not far behind. 
Omniture. Top-level editors who needed to monitor and report to the management long-term trends use Adobe Site Catalyst, more popularly known as Omniture. The deputy managing editor at the first newsroom described Omniture as a "big beast." Omniture was launched in 2004 and was acquired by Adobe in 2009 (N. Yang, 2012). Newsrooms use it to examine traffic data for longer periods of time. For example, on my first day at my third newsroom, one of the web editors showed me the website's total number of views for the previous week. He was surprised that they did much better last week in terms of total views: On one particular day alone-Tuesday— the website got 1.4 million views. He asked his fellow web editor, the one seated next to him, what happened on Tuesday. The other editor said the tornado story and gallery must have attracted a lot of views. So he went into Omniture to be sure, and discovered that much traffic came from the Barbara Walters gallery they uploaded. It got 950,000 views. "Who would have predicted that?" the web editor exclaimed.

Omniture, used in the three newsrooms where I observed, allows comparison of a wide selection of data: page views, unique visitors, traffic sources, and even views per type of device, such as via web, tablet or mobile phone. Omniture claims to be serving more than 100 media publishers in the US (N. Yang, 2012). "That is what we use for more long-term, like the next day, or several days later or that kind of thing," one of the two web editors at the first newsroom said. "So that's more to review over the last month or over the last year for longer trends." At the third newsroom, the assistant managing editor for digital checked Omniture all the time. 
Every day I'm looking at our page views from the previous day and I'm looking at how they are trending for the current day. So if I'm watching them looking a little low, we start being a little more aggressive.

Comscore. The use of Comscore came up in my interviews at the first and third newsrooms. It is not exactly a web analytics program, for it is a mixture of data from online surveys and actual web visits (Beleaga \& Geary, 2012). Comscore claims to have a panel of two million internet uses around the world, half of whom are in the US, who opt in to have their data collected and shared (Delo, 2011). Unlike the other three services I have described, Comscore does not provide detailed real-time data about a particular website. However, it provides data about a lot of other websites, allowing clients to compare their own websites with others, something akin to Nielsen's television rating service. "Comscore does not have as much detail about our website," the marketing analyst at the third newsroom told me while I was observing him at work. "However, in addition to [our website], it also is ranking other websites, such as the local TV websites, and that allows me to say how did we do compared with other local media websites." This information is particularly important for advertisers. In her work at the first newsroom, the deputy managing editor for digital would always switch back and forth between Omniture, Chartbeat, and Comscore: "So we get a nice hybrid model of, you know, sample data versus what is actually happening. That kind of paints a much more picture to advertisers and people outside of our system understand what's going on."

Social Media. Numbers can only tell so much, however. In traditional newsrooms, feedback about audience attitudes came in the form of mails and phone calls. But journalists seldom took these seriously, dismissing them as unrepresentative of the 
total audience, paying attention to a few of them only when they point out glaring factual errors (see Gans, 1979). Online newsrooms, however, now find it harder to ignore audience feedback. Online journalists can still ignore emails or delete comments posted on their websites, but comments posted on social media, such as Twitter and Facebook, are more difficult to gatekeep. These posts can also go viral beyond the control of journalists. Social media have been normalized in the newsroom. The social media manager at the second newsroom said social media skills were now expected of any journalist. "In all honesty I have no idea why a news organization would hire a journalist right now that doesn't know social media. That person seems like a liability to me." Social media provide newsrooms with a wealth of information about how people respond toward content. There are the easily quantifiable indicators, such as the number of "likes" and "shares" on Facebook and number of "retweets" and "favorites" on Twitter. The number of followers on both social media sites also indicates, to some extent, the size of following a news organization has compared with other news organizations with social media presence. There is also the more qualitative indicator of audience response. Some of the web editors I interviewed use social media to monitor what readers are saying about particular stories on the website. For example, a web editor at the first newsroom said: "You are just constantly looking at what people are saying about you and seeing how you can improve it, how you can capture their attention, whether information needs to be sent that people maybe are finding out on their own." She uses both her personal Facebook and Twitter accounts as well as the newsroom's official accounts to monitor people's reactions to their stories. But not everyone uses both their personal and organizational social media accounts for work. For example, at the 
third newsroom, I saw one of the two web editors check his personal Facebook account only once. He told me he used it for purely personal purposes. I noticed he only had photos of his family there. I asked him what he thought about social media, and he said: "My personal opinion is that I don't like Twitter, but it is important to the job and I think we're getting a lot more traffic that way than through Facebook."

In my observations, I also noticed that web editors pay attention to user comments on Facebook and Twitter more than to reader comments on their actual websites. I asked another web editor at the first newsroom about this.

I think it's just easier to keep track [of social media] than to read the comments on the actual stories themselves, because, you know, I think there's just less of a flow... Like Twitter, you're up scanning stuff on Twitter and it's really easy to kinda scan the last couple of replies there. And Facebook, you know, you're going in to check how many people liked this and how many people shared it, you can just kinda skim the comments. Sometimes, it's a lot easier to monitor that kind of stuff than it is the comments section.

At one point, he asked his fellow web editor and their managing editor how he could disable the commenting function on the website. It turned out that he got annoyed with a regular commenter, someone who the other web editor told me later would comment on almost every story on the site. She had blocked the commenter a couple of times, but on each occasion, the commenter just created a new account. This struck me as particularly interesting, that web editors paid attention to comments on social media more than on comments posted on their websites' own comments section. The managing editor explained to me during one of our conversations that social media sites were third-party 
platforms that operated outside the system of the news organization. So while they are helpful in promoting the brand and helping journalists interact with their audiences, in terms of actual revenues social media do not directly convert into page views that will make the news site more attractive to advertisers. To me this was puzzling, that web editors were more likely to interact with commenters outside their territory—within a third-party platform — than within their own journalistic space. It might be that, at least as far as commenting goes, the web editors remain protective of their own territory, their own sacred editorial space, preferring instead to pay some, but not much, attention to comments that are posted outside their news websites. Interacting with commenters legitimizes them to some extent by acknowledging their contribution to the news construction process. In engaging in this acknowledgement process in a third-party platform, editors accommodate audience feedback while still clearly separating audiencegenerated content from the editorial content on their own websites.

In the three newsrooms where I observed, web editors used Twitter and Facebook most of the time, although at the first newsroom I saw the web editors upload photos on Instagram, while at the second newsroom, the social media manager spoke to me about Google+ while her social media editor showed me how he used Pinterest to upload front pages of the newspaper from a century ago.

Social media and web analytics provide journalists with more information about their audiences than ever before. This has implications on how journalists do- or are redoing - their news work. But having access to a wealth of information about the audience also shapes how journalists conceive of the audience, a conception that, as I will argue in 
the next chapter, affects how journalists balance what they know about the audience with the journalistic norms they still hold dear.

\section{Conceptualizing the Audience}

It was a quiet afternoon. The three main people at the digital desk at the first newsroom were all present, each of them staring at their own computer screens, incessantly clicking on their keyboards. Then the managing editor shouted:

“Unbelievable!" He was exasperated. His two web editors stared at him, puzzled, waiting for some explanation. It turned out that the managing editor had been reading comments on the newsroom's Facebook page. In one of the posts - the story about a girl who was shot dead a few days ago - a reader commented that there should have been a concealed carry law in the city, in effect implying that the girl's father could have defended her from their shooter if he had a gun and if that was allowed. "Someone on our Facebook page said there should be a concealed carry law," the managing editor said. One of his web editors flatly responded: "What do you expect?"

What do journalists expect from their audiences? On one hand, the literature says not much, as journalists who value their editorial autonomy tend to ignore, if not reject, feedback from the audience. Thus, they also have an unflattering view of the audience. On the other hand, the audience is an important influence on the gatekeeping process, for why would news organizations disseminate news if no one is attending to their messages? In my observations and interviews, editors tend to segment their audiences, usually knowing the type of audience they want but still not sure which audiences they are reaching. 
The imagined audience. Journalists used to rely on the imagined audience whose preferences they reconstructed based on their own preferences and those of their peers and superiors. But with the amount of information online journalists can now access about their online audiences, they should have more clues about the actual, instead of the imagined, audience. However, while most of the editors I spoke with offered descriptions of who they thought their audience was, their descriptions varied. Let me focus on the third newsroom. One of the web editors told me the online audience was a bit younger than the newspaper audience, but the website's general manager told me the online audience was not as young as everyone thought, because "everybody has gotten access to computers, including your grandmother and everyone else.” The assistant managing editor told me the age range for the website audience would be between early 20 s and 60s. "I would actually like to have a study of our readers," she said. "I would like to know who our readers are compared to our print readers. I don't know that." Though they deal with information from their actual audiences all the time, through the metrics they get from web analytics, these editors still constructed their imaginary audience.

When I was asking a web editor about the audience for the third newsroom's website, he said he could examine some demographic data from Omniture—information volunteered through their pay wall registration — but he said he would have to "dig around to find that." The general manager, when he offered me his description of an online audience getting older, said "that is kind of my gut feeling." The other web editor, who is also exposed daily to web metrics, said he thought the audience was "collegeeducated, probably professional." I asked where this picture of the audience came from. 
He said: "Nothing scientific. Anecdotal... I just build that imaginary person from people who I talk to who tell me that."

The unwanted audience. Knowing more about the audience does not always lead to liking the audience more. This is particularly true among editors who directly deal with audiences on social media. For example: One of the two web editors at the first newsroom is in his early $30 \mathrm{~s}$. He is funny, he talks a lot, and he does not mince his words. In our interview, I asked him if he encountered audience feedback in his routine as a digital editor. He laughed. Then he said:

Yes. Umm, 95\% is bullshit. I don't know if you've ever bothered to read the comments sections on any of our stories on the main site. It will make you sad for humanity. Just the worst of the worst are usually who comment. And we have just a different breed. We're just one of those papers, and there are other papers out there like us, we just attract somehow awful, awful people. A little less awful on Facebook - some of that is because people have their names attached to it. But you'd be surprised by what people are still willing to say with their name and avatar right there.

He acknowledged that sometimes they get valuable feedback, but usually more so from social media than in the comments sections of the website, so he and his fellow web editor would still skim the social media comments once in a while. "Maybe it's not as rare as I think," he later clarified. "It just feels like it because you have to sift through so much garbage to get to that good stuff."

The adjectives some of the other editors used to describe the audience speak of how they think about a segment of their audiences: The social media manager at the 
second newsroom refers to audiences as a "crowd;" a reporter-cum-editor at the first newsroom referred to some commenters as "ignorant;" and an audience development staff member at the first newsroom referred to a need to distinguish between preferred people and "people we don't want—just garbage people."

So which audience do they want?

The preferred audience. An advantage of online sites is how they can transcend geographic boundaries, promising a wider reach than a physical newspaper. But not everyone that visits the website is a target audience. Traffic on the web is not treated equally. For example, in April 2013, only about 39\% of the total traffic to the website of the third newsroom I visited was considered local traffic — or those that came from its designated market area (DMA), a terminology that originated from Nielsen's classification of areas in the US as television media markets. The marketing analyst for the company told me that advertisers were not after total traffic. Advertisers, particularly local ones, target local audiences, something that top-level editors are apparently aware of. The editor-in-chief at the first newsroom said that while a story about Lindsay Lohan would attract traffic, "that's not necessarily the kind of audience you may want."

The erection of membership programs and pay walls, though initially doubted to be effective in starting a subscription revenue stream for online journalism, has made it easier for newsrooms to identify the audience that they want—-the engaged audience. For example, the first newsroom has a soft pay wall. Readers can access 20 articles in a month for free, but they will have to sign up for membership first. This membership comes with email news alerts, and news digests in the morning and in the evening. Readers can also sign-up for full membership for a fee. Someone registering or paying a 
subscription fee is someone who likes the product. "That was much harder to tell if you didn't have a membership program, and people [are] coming in and out of your website but not staying very long," the editor-in-chief said. "Here they are taking the time to fill out membership." An engaged audience is an audience that comes back to the website for more, an audience that will be marketable to advertisers. The deputy managing editor said: "Agencies and advertisers are really going to be focusing on engaged people, people who are going to engage with their ads." Thus, she described an engaged audience as a "powerful audience."

The second newsroom's website also has a pay wall, but readers who come across a story through Google search or through social media can access that particular story for free, because these readers are engaged readers. "The conversations people are having about our journalism matter," the newsroom's social media manager said. "If some just random person with no stake in it is going to Tweet or post our information, I think [we should] give them access."

The audience as capital. It is easy to understand how journalists have such ambivalent attitudes toward their audiences, for the audience has occupied such varied roles in the journalistic field. From the point of view of journalists, the audience can be considered as customers to be pleased, a conceptualization that was appropriate for the traditional newspaper model that relied, to some extent, on circulation revenue. The audience can also be considered as products sold to advertisers, a conceptualization that was appropriate for free television whose business model relied heavily on advertising revenues. But with new technologies such as blogging and social media, the audience can 
also be conceptualized as producer of content, thereby increasing, and also confusing, its role as a stakeholder in the journalistic field.

The bottom line is that the audience is important, and for many editors I spoke with, this is because of the bottom line- the online audience translates into advertising revenues that translate into their paychecks. "We write stories to engage people, to inform people - the audience is critical. These are the people who pay the bill," the metro editor at the first newsroom said. I also asked the deputy editor for digital at the third newsroom why the audience is important, and this is how our conversation went:

Edson: How important is the audience?

Editor: It's everything.

Edson: Could you elaborate on that?

Editor: Well, without audience we don't have, if nobody is looking at the site, we're screwed.

Edson: Why are these numbers important?

Editor: That's revenue. That's money.

This is not breaking news, for it is the same business model that has sustained the now seemingly unsustainable newspaper industry, a news medium that is seeing its once stable economic capital shrink. "It's no different than what we did in the newspaper," the general manager of the third newsroom's website said. "We tried to increase circulation all the time. We did stories to increase circulation and that meant revenue. I don't think we're doing anything differently now. We're just doing it smarter."

What is different now is how journalists in these online newsrooms can no longer ignore the audience. It used to be that news editors did not have to think about how many 
people are attending to their news content, consistent with the wall of separation erected between the editorial department that protects its journalistic autonomy on one hand, and the business department—circulation, marketing, and advertising — taking care of thinking about audience and revenue on the other. This was one of the prevailing norms during the time when traditional media felt financially secure. "There was such an aversion by some newsrooms, many newsrooms, to the web... and even at the beginning they didn't really want to hear from their audience," the editor-in-chief at the first newsroom said. "But now it's crucial for their survival to listen to the audience." With some shifts in the capital within the journalistic field, things are changing.

First, how the online journalistic field has developed is now putting on journalists some part of the task of content dissemination and promotion through social media because of the affordances of these new technologies. There are no newspaper delivery trucks to rely on. Online, and through social media, everyone can be a content distributor. Online metrics have also become omnipresent in many newsrooms that it is almost impossible to ignore the numbers. "In print you don't have to worry about revenue - that job is in a different department," a web editor in the third newsroom said. "Here that is more of the equation — revenue comes from ad dollars; ad dollars come from page views." Second, this conception of the audience as a form of economic capital critical for journalism to survive is influenced by how much traditional journalism has changed and how its future, even in digital form, remains uncertain, at least from the perspective of editors who directly deal with content and traffic. I asked one of the web editors at the third newsroom how he felt about what journalism critics claim to be a dichotomy between quality journalism and the goal to draw web traffic into the site. He said: "I 
don't think that we have the luxury of thinking that way because if the company's not making money then I might get laid off. I mean, that's just the way it is.”

The reality, however, is that while online revenue is slowly increasing, it still pales into comparison with the declining traditional media revenues. A study by the Newspaper Association of America found that in 2012, digital advertising accounted for only $11 \%$ of total revenue for newspaper companies with digital platforms (NAA, 2013). In the three newsrooms where I observed, the newspaper remains to be the bigger earner, and yet in all of them there is a great push for going digital. The mantra of going digital first is more than just rhetoric: The first newsroom, for example, already uploads as early as Saturday morning stories that are still scheduled to be published on its Sunday paper. "Yes, the printed paper is still bringing a lot of revenue and will for some time," the newsroom's editor-in-chief said. "But your audience growth is much bigger on the web. So you're managing decline through the printed paper but you're gaining readers."

The declining print revenue and the increasing online readership come with the hope that digital revenue will, in the immediate future, be able to sustain journalism. This can explain why the editors I spoke with conceive of the online audience as economic capital even if online revenues remain marginal in terms of revenue generation for their organizations: Their conceptualization is based on the traditional business model that has supported traditional media for quite some time as well as on the hope that the same business model, or at least a version of it, will bring revenues in the immediate future. To some extent, this is defining economic capital based on how it functioned in recent history and how it is expected to function in the years to come. In the meantime, the editors I spoke with are also conscious about treating the audience as a form of symbolic 
capital. Organizing readers as a community—keeping them engaged and loyal, at least until a feasible business model comes to sustain online newsrooms - is a form of accumulating symbolic capital in the anticipation that it can be converted into economic capital when the time comes. A web editor at the third newsroom told me: "I think we can be the source of [the city's] news and be credible and solid and authoritative on that, and through that have good numbers."

The conception of the audience as a form of capital in the journalistic field offers a theoretical explanation to why audiences matter to journalists. How much influence the audience exerts on the news construction process depends on a multitude of factors, including how journalists conceive of their audience and how this conception fits into the changing realities of the journalistic field that journalists inhabit. While web analytics and social media have made audience preferences almost impossible to ignore, journalists have long been governed by traditional norms that have dominated the journalistic field. For example, how does the conception of the online audience as economic capital fit into the journalistic doxa of editorial autonomy? How does conceiving of the audience as economic capital fit into the conventional journalistic role of providing the audience what it needs more than what it wants (Heinonen, 2011)? In the next chapter, as I discuss the impact of audience information systems on the different aspects of online news work, I will demonstrate how in using these new tools, journalists are witnessing a renegotiation of some of the norms - the journalistic doxa —of the field as manifested in the decisions they make in their day-to-day news work. 


\section{Analytics, Social Media, and the Journalistic Doxa}

Their conception of the actual audience remains hazy, but through new audience information systems, particularly web analytics and social media, journalists now have a clearer picture of what the actual audience wants. The preferences of the audience are now quantifiable in the form of number of unique visitors, number of page views, and time spent on a page, among other metrics. These metrics, along with feedback from social media, such as comments, retweets, and likes, have allowed journalists to typify the audience into those they want and those they do not. But what do journalists do with these pieces of information?

Layoffs meant smaller newsrooms. I asked a reporter at the first newsroom I observed who was also working as a desk editor on weekends how many reporters they have. "That's a good question," she said. She paused for a few seconds. Then, she started counting with her fingers. They probably have about four general assignment reporters, and between five and seven beat reporters, she said, much lower than before. That surprised me, considering how big the city is in terms of land area and population. "When you have fewer resources, you cannot be a paper for everybody," her editor-in-chief told me during an interview. "So what it's going to do is help determine where we focus our reporting efforts." This means journalists will have to determine what the preferred audience - the engaged audience - wants. Not only do they have to discriminate between audience preferences and their news judgment, but they also have to discriminate between the actual audience and the audience they want. 
In the middle of an evolving journalistic field, journalists are witnessing a reworking of their norms, of their journalistic doxa. This concept refers to a "'universe of tacit presuppositions' that organize action within the field" (Benson \& Neveu, 2005, p. 3). In simpler terms, it refers to the rules of the game. In this section, I will demonstrate how the rules of the game are being renegotiated, as journalists find themselves needing to balance their journalistic autonomy with the increasing influence of the audience, and how this balancing act shapes the specific ways that journalists do their work.

\section{Shifts and Routines}

The first shift for the digital desk begins between 6 a.m. and 7 a.m. A web editor arrives in the office and starts to share stories on the website through social media. The web editor then looks for stories uploaded in other sections that can be placed in the homepage. The web editor also rummages through wire services to find stories that can be used for the website. Stories that have been getting good traffic in the morning are moved to more prominent places on the homepage. The morning shift is importantpeople who are commuting to work usually read the news on their phones. Those who get to the office will then browse news sites after logging onto their office computers. In both the second and third newsrooms that I visited, an informal meeting for the digital desk starts at 9 a.m. In the meeting, the web editor sits with representatives from the different sections of the newsroom to find out stories these sections are working on that could be used online. The assistant managing editor for digital at the third newsroom makes it a point to attend the informal meeting. An hour later, she attends the budget meeting for the newspaper. 
The newspaper budget meetings start at 10 a.m. for both the first and third newsrooms. It starts at 11 a.m. at the second newsroom. Section editors meet with the managing editor and the editor-in-chief to discuss stories their respective reporters are working on. They exchange ideas on how to develop a particular story or if it is worth developing at all. For the second and third newsrooms, the priority during the morning budget meeting is to plan coverage for the newspaper. For the first newsroom, the morning meeting serves both the paper and the website. For example, at the first newsroom, the managing editor usually refers to stories that will potentially draw traffic, asking editors who pitch stories during the budget meeting if those stories come with photos or videos for the site. For the second newsroom, the budget meeting usually starts with an editor hooking up Chartbeat into a monitor that allows editors to see the numbers from the website; it ends with the managing editor asking the social media manager about trending topics on social media. The web editors rarely attend these meetings as they are already busy editing and uploading stories in the morning.

The assistant managing editor for digital at the third newsroom keeps an eye on stories from news sections that she might want to use online. Sometimes, she would ask the metro desk for a particular local story, asking if she could have it by noon, the peak hour in terms of online traffic. The digital desk has one online reporter who writes stories for the website; otherwise the desk depends on wire stories and articles from the other sections in the newsroom - metro, business, entertainment, sports, among others-which are used to the newspaper deadline. Coordination remains challenging, the assistant managing editor told me. 
The setup has caused some tensions in the newsroom. For example, web editors at the third newsroom are fond of a particular reporter assigned to cover local businesses. Her stories usually draw a lot of traffic that during the online budget meetings the web editor would always ask the business editor what stories the local business reporter was working on. The reporter herself knows how much traffic her stories make. One time while I was observing I saw her pass by the digital desk to pitch a story she was putting together. The assistant managing editor introduced me to the reporter, describing her as someone "very good in driving traffic." This has caused some stir in the newsroom, something the reporter was aware of, as she said people might get jealous if she starts talking how much traffic her stories are drawing in. In one of the budget meetings that I attended, I heard the assistant managing editor tell the editor-in-chief: "We are very happy with [the local business reporter]. She gets so much traffic. Retail, restaurants, boom!"

The increasing influence of the digital desk is also being accepted begrudgingly at the first newsroom because of the changes the "digital first" mantra is causing. One time editors sent a young photographer to secure a copy of a photo of a girl who was critically wounded in a drive-by shooting. The instruction to her was clear: send the photo as soon as possible. The assistant managing editor for visuals was waiting for the photo for the newspaper's front page. A couple of hours later, the photo editor on duty phoned the young photographer, asking for the photo. Based on what I was hearing, the photographer was having a difficult time sending the photo through the system, but she had apparently already emailed it to the managing editor leading the digital desk. The photo was actually already being uploaded on the website. Then, the photo editor saw the email from the 
managing editor forwarding a copy of the photo the photographer had emailed to the digital desk. I saw the photo editor roll his eyes, obviously annoyed, for he should have received the photo first, going by the traditional workflow.

Stories that are published in the paper version are all uploaded online, and in the case of the first newsroom, the stories on tomorrow's paper get uploaded today. Since they layout the Sunday paper on Friday night, I got to read the Sunday paper's banner story on a Saturday that I observed. I was surprised when I realized that the main story on the Sunday paper was the main story on the homepage on that Saturday morning. I later asked the editor-in-chief about it, and he said, at least for now, that the print reader and the online reader are totally different readers. Readers get more content online, including stories that were rejected for, or were mentioned only briefly on, print. For example, I heard the managing editor several times comment how they might not have print space for a story, but that the same story would get a lot of traction online. One particular story stood out to me during my observations. One Friday afternoon, I saw that a web editor had tweeted a story about a carjacking. The tweet read: "Teen allegedly tells carjack victim: 'I'm Denzel Washington bitch, now drive!' The tweet got several retweets and a lot of replies, with one of them saying: "That carjack story is awesome!" The reporter of the story also knew her story would be popular. "I knew it was going to get retweeted," the reporter told me when we finally met, "but it did not even get in the paper." Not even as news brief.

A second web editor comes in for the second work shift that has significant overlap with the first shift. At the third newsroom, the second web editor comes in at 9 a.m. At the first newsroom, the second web editor comes in at noon, and the first shift 
editor leaves ideally at 2 p.m. Section editors - those who head the metro, business, sports, and entertainment desks, among others - have access to their own pages on the website so that they can upload their own stories anytime, but only the web editors have access to the homepage. Only one editor can access the homepage at a given time. At the first newsroom, they just yell at one another when someone is going into the homepage. At the second newsroom, they have a pink bowling pin that stands on top of the cubicle of whichever editor is taking charge of the homepage at that particular moment. At the third newsroom, where the two main web editors sit side by side, they just tell each other.

Sometimes, a section editor alerts a home page editor about a possible story for the homepage. One time, at the third newsroom, I saw an entertainment editor come to the digital desk to show the web editors the layout for the movie review page for tomorrow's paper. She said the movie review was already uploaded in the section's webpage, and that the web editors might want to consider it for the homepage because it might get good traffic. But sometimes, too, a homepage editor gets surprised to find a story performing well from one of the section pages, and decides to include it on the homepage.

The section editors meet again at 2 p.m. to finalize the lineup of stories for the paper. In this meeting, the head of the digital desk would update the editors on which stories are getting good traffic so far. But online traffic rarely affects decision-making for print. Some editors said online traffic would be more influential in the decision-making process for print in the near future. I did not see this happening yet in the budget meetings I observed. What I noticed though was how the selection and prioritization of stories for the homepage was almost an individual-level decision, unlike the process for selecting 
the banner story for the paper. A web editor at the first newsroom told me that choosing the main story on the homepage was a "group decision." I asked him to elaborate, and he said sometimes he decides, sometimes it's the other web editor, and sometimes it's the managing editor. It is basically who is working on the homepage and whether or not he or she feels like changing the main story. I asked him what if there were disagreements on which should be the main story. It rarely happens, he said. The selection of which stories to tweet about or share on Facebook is also made without any discussion, turning it into almost an individual activity_almost devoid of the multiple layers of gatekeeping that had filtered what pieces of information got disseminated by traditional media.

\section{Watchdogs and Entertainers}

The rejection of audience feedback by many traditional journalists was consistent with the dominant journalistic roles at that time. As a disseminator of information, the journalist was tasked to primarily report about issues and events that were deemed important by the journalist. As a watchdog keeping an eye on the government, the journalist was expected to act on behalf of the interest of the public, but again this largely depended on the judgment of the journalist. "The model for the longest time is that journalism—newspapers, news organizations - are the gatekeeper. We take in lots of information, we pare it down, and then we say to you: 'This is what's important,", the managing editor at the first newsroom told me. But while there is still a need for some of that gatekeeping function, he acknowledged that the "big gated community that is news has been broken down." Blogging has given rise to citizen journalists who gather and disseminate information outside traditional news media. Social media have allowed anyone with internet access and an account to upload photos and videos from anywhere, 
even beyond the reach of traditional news media. Journalists can decide something is important, but audiences can also now decide on their own, even create their own messages, and communicate what is important to them through new forms of audience feedback. Part of a journalist's role now is to listen to what the audience says.

Many of the editors I interviewed said the roles of journalists in society remain the same. A web editor from the first newsroom talked about keeping people informed. A web editor from the third newsroom talked about being a watchdog on the government. Another web editor from the third newsroom even said there was no need to speak of a role for online journalists, for "it is just the same as it always was." And yet everyone acknowledged how news sites such as theirs now have to compete with a lot of other sources of information online. This complicates the role of the journalist even more. "The audience - these are the people we have to inform, we have to educate," the metro editor at the first newsroom said. "Maybe we have to tell them something important, maybe a little complicated, maybe we have to boil it down, tell them that it's interesting, you know." The role of informing people might still be the same, but the way of enacting it is becoming more challenging and different. The ways of carrying out traditional journalistic roles are evolving. I asked one of the web editors at the third newsroom what he thought his role as a journalist was. He said: "Give people the news they want. Also serve as a watchdog — there is still that —a watchdog on people in power. But also we seek to entertain...."

\section{Spinach and Cotton Candy}

Journalists and their audiences have divergent preferences when it comes to news, as numerous previous studies have established (e.g. Boczkowski, 2010a; Boczkowski, et 
al., 2011; Lee, et al., 2012; Shoemaker \& Cohen, 2006; Tai \& Chang, 2002; Wulfemeyer, 1984). This is something that journalists have been aware of, and this has not stopped them from substituting their own preferences for those of their imagined audience, for this is also consistent with the norm of editorial autonomy. Studies found that while journalists prioritized public affairs pieces, audiences read stories on entertainment and sports the most (Boczkowski, 2010a; Boczkowski, et al., 2011). On one hand, journalists believe it is their role to provide the public with the information it needs, consistent with the conventional journalistic role (see Heinonen, 2011), part of the journalistic doxa. On the other hand, news organizations need to attract an audience to survive. "I think our value to readers still is telling them what is news and what should be news, what are the important stories," the editor-in-chief at the first newsroom said. "But we have to listen to the audience more than we have in the past." Journalists used to have a hunch on what readers would like. Now they have quantifiable metrics to compare that hunch with. When editors talked about story lineups for the newspaper as well as for the website during the budget meetings I attended at the first newsroom, the managing editor would often comment on how he thought a particular story would get a lot of online traffic. For example, when an editor spoke over the phone about a story on newborn lambs in a farm, stressing as well that she had lots of photos of baby lambs to go with the story, the managing editor asked the group of editors gathered in the room: "Anyone want to bet that that will be the most popular feature in our website?" In one of our conversations during my stay, the managing editor told me that his news judgment and that of the audience sometimes clash, and that as an editor he had to balance these sometimes contradictory preferences: 
We have an idea of what the important stories of the day are. Our readers have a much different idea of them. You know, we need to give them the spinach newswhat's going on with the welfare reform—but we also need to make sure that we give them something they'll actually click on.

Part of offering the audience some spinach is encouraging them consume it, too. How do you make readers view on a story on welfare reform, for example? The metro editor said journalists have to make an important but boring issue more interesting and more relatable to the audience. It is part of their role as journalists. "So the spinach," the metro editor said, "you dress it up with a little lemon or a little garlic, you know?" A human interest angle, a photo gallery, or an infographic might do the trick.

The editors usually have a hunch on whether a story will get a lot of clicks or not. These are based on their own beliefs about what the audience wants as well as what they have seen in their website numbers of what stories have done well in the past. When I was observing at the third newsroom, the assistant managing editor came to the digital desk and mentioned a story about a pinball artwork in France, created based on a controversial remark by senatorial candidate Todd Akin about rape. The artwork was "generating a lot of buzz and it might drive some traffic," the assistant managing editor said. One of the web editors quickly exclaimed: "Click-bait!"

"I know when I'm working on the web, there will be click-baits and that sometimes feels like cotton candy," the other web editor at the third newsroom said. "But sometimes you have to hold your nose." Holding your nose is in keeping with the reality that news sites need to generate traffic. It is an unspoken rule at the first and second newsrooms; it is an explicit instruction at the third newsroom, where the publisher set a 
goal of increasing traffic by $10 \%$ from that of the previous year. The goal to generate traffic is consistent with the conceptualization of the audience as a form of capital, specifically a form of symbolic capital that news organizations expect to be able to soon convert into economic capital. "I think now you have to sit down on the table and have an honest conversation about what the goals are," the deputy managing editor for digital at the first newsroom said, "and knowing that having the money and being a respected journalist, organization, you know, you have to strike a balance."

Balancing the spinach and the cotton candy is not an easy task, but bringing the cotton candy onto the table is already a form of compromise on the part of these editors. One of the web editors at the third newsroom said that for the homepage, "what we try to do is mix those things that we know are going to get a lot of clicks with serious news stories." But the metro editor of the first newsroom argued that sometimes the audience does not know what it wants. The vice president for digital of the second newsroom said readers would not know whether or not they like a particular story until they know what the story is about: "I mean you can't really judge people's feedback about a subject they don't know much about because the big bright light hasn't been shown on it." In effect, he said readers get to pick and choose on a given set of choices that are pre-determined by journalists. That pre-determination was still necessary, for how can you know that readers will not click on a story about problems with social security benefits if readers have no idea what it is about? But another problem is how different the composition of the total audience is. The assistant managing editor of the third newsroom said the audiences for their website, their e-paper edition, their tablet edition, and their mobile 
apps were very diverse: "It is a very splintered audience. I feel like we're serving all different types of people and different reading habits."

So how does one balance the spinach and cotton-candy for a group of audiences that want different things amid the reality of having to work with limited resources that is making focused coverage more practical? This boils down to the preferred audience. Click-baits will generate a lot of traffic, but this might not be the kind of traffic that represents the symbolic capital a news organization seeks to accumulate. For example, the first newsroom' editor-in-chief said:

You can take a look at a certain set of analytics, and something sensational, like a

Lindsay Lohan story, will obviously do well. But that's not necessarily the kind of audience you may want... So you can't let analytics completely take over your news report. You are really not serving the reader, especially the local reader.

\section{Sex, Drugs, and Online Traffic}

Web analytics software, even if they now offer recommendations for story placement and headlines, cannot do the balancing act that is required between journalistic autonomy and listening to the audience. So the editors I spoke with and observed still view their roles as central in the news construction process while audience information systems are viewed as tools. The metro editor at the first newsroom described audience feedback as “an inspiration, but it's not something that's determining whether you do a story or not." In effect, when editors consider the audience in their news judgment, they do not necessarily see it as an influence of the audience on the news construction process per se, but rather they see the decision-making as an exercise of their news judgment that is being reworked to be cognizant of an omnipresent audience feedback. They think they 
still retain control, consciously incorporating audience preferences in their news judgment only when they see it useful.

When I first sat down with the online senior editor at the second newsroom, I saw him going through the sports page. He told me he was looking for a sports story that he could place on the homepage. "It's a sports town," he told me when I asked why he was looking for a sports story instead of a different topic. "Any time there is an injury story, a story that is related to injury, or any updates on who plays, usually it's worth getting it out there." He said he had gotten to know this by working with the website for a while. He acquired this knowledge through his experience as a journalist. "That is important, to have a long memory of what types of stories that people are interested in, that have done well in the past," he said. The exposure to web metrics and other forms of audience feedback is adding new forms of information to the stockpile of knowledge and expertise that journalists have accumulated over years of experience — part of an agent's habitus in the journalistic field. But this knowledge about the audience is also reworking some of the journalistic doxa - the rules of the game.

News judgment now functions somehow different from when journalists rejected audience feedback. For example, the metro editor at the first newsroom told me about how a particular story did well online the previous day. The following day, a reporter pitched a follow up. The metro editor said:

When the city hall reporter pitched me a follow up I was-I would be enthusiastic anyway about it, because it is an interesting story and it is something-our core readers are city workers and cops so I knew it's gonna be good for that. But also it did well online, so that has added into my enthusiasm for the story. 
Traditional news values are still invoked. In my observations of the budget meetings across the three newsrooms, news elements such as prominence, timeliness, proximity, and impact were always brought up when assessing which stories to pursue and prioritize. A web editor at the third newsroom also referred to "sex, drugs, and rock and roll." Online traffic, however, appears to have become an important element of what makes something newsworthy. Of course human interest has been a traditional news element (see Shoemaker \& Reese, 2013), but it was usually viewed from the perspective of the journalists themselves, of what they thought would be interesting for the imagined audience. The omnipresence of quantifiable and immediate audience feedback has made the discussion of online traffic a staple in budget meetings. In one of the meetings I attended at the second newsroom, I saw how at the end of the meeting, after each section had presented their story lineups for the day, the managing editor turned to the social media manager and asked: "Which story is going to be big tomorrow in social media?" The social media manager responded, saying that based on topics currently trending, it would be the story on the super bug and the story about the Republican Party. The managing editor then turned to the editor-in-chief and asked: "Which do you like better?" In effect, metrics are being used to narrow down choices for journalists, but in the end the journalist and her news judgment becomes the final arbiter. The journalist retains control. Metrics are adapted to fit into traditional norms and processes, an example of journalistic normalization. The important role of a journalist's news judgment can be seen in how the second newsroom, just a month before I started my observations there, changed the rule on the list of breaking news stories on the homepage. It used to be that the latest stories appeared on the list, consistent with the idea of breaking news. But the 
website has since switched to a different model. The senior digital editor said the new model had worked well: stories that appear on the breaking news tab are now being determined not by how current they are but by the news judgment of the home page editor. "Metrics, you can't really overthink them and be obsessed with them," the senior digital editor told me. "We are paid for exercising our news judgment and for our experience."

However, reworking news judgment to fit into the balancing act that journalists now find themselves having to engage in is a complicated task. The newspaper has a particular deadline when pages are supposed to be ready for printing. That gives editors some time to reflect on their editorial decisions. The budget meetings, for example, are an avenue to discuss and agree on how the newspaper will prioritize particular stories: which stories will go to the front page, which stories will end up in the trash bin. Online editors do not have this luxury. There is no deadline so to speak, because every second is a deadline. The website is an ever-changing platform and editors are mindful about keeping it fresh. So while in my conversations with the web editors they all talked about how their news judgment reigns supreme in their news work, I did not see or hear them refer to particular news elements or personal criteria when they chose which stories from the wire to upload and which stories in the website to highlight on the homepage. The only consideration routinely invoked is the metrics displayed in the web analytics software splashed on their computer monitors all day. "You have the dessert but you also have the nutrient. It's always like that; you have to have a balanced plate and hope it works," a web editor at the third newsroom told me during our interview, referring to an ideally 
conscious balancing act of mixing spinach and some cotton candy. But then, he said: "I couldn't consciously do that."

Having to attend to multiple tasks that come with the territory of being digital, web editors do not have the luxury of time to pause and consciously reflect on every editorial decision they make.

\section{Hats Too Many}

When the editor-in-chief spoke in the middle of the newsroom a few hours after the videographer he had just fired had left, a few people in the newsroom, obviously upset, asked him a lot of questions. A female editor stood up and asked: "Why fire a videographer?" That job was consistent with the shift to doing multi-media reporting on the digital front. Why layoff someone who does video? The editor-in-chief appeared calm. He said he had just created a video team. Why did he fire the videographer? It was because every reporter would become one. "Every reporter will be and should be equipped with a phone to take videos," he told his employees during that impromptu meeting.

But reporters are not the only ones seeing their job descriptions evolve. The official job designation of the first shift web editor at the first newsroom was "digital editor." She was tasked to edit and upload stories to the website. But she also had to tweet breaking stories, post on the newsroom's Facebook account, and attend to numerous questions on social media from editors and reporters. On my first day of observation, I sat next to her and saw her browser with five tabs open: She was checking her email while also on Facebook, Twitter, Bitly, and the newsroom's website. It turned out she had another window open, and in that window she had numerous tabs open too 
many for me to even count. That same day, I observed how a lot of people would go to the digital desk, particularly to her, to ask for help, that she had to leave her desk multiple times: an editor wanted to tweet about the Dow Jones closing on a record high; a photographer wanted to use Vine on her phone to upload photos; a transportation reporter asked help for her Twitter account just as the digital editor was preparing to call it a day. That was already 40 minutes past 2 p.m. when her shift was supposed to end. She had been in the newsroom since 6 a.m. It was her fellow web editor who told the managing editor later how she had been feeling worn out because of the many other things she had to attend to aside from her main tasks. In one of our conversations, the first shift web editor recalled how at one time she posted the wrong information on Facebook about a breaking story. It was about a court verdict on a high-profile case. The court had just found the defendant guilty.

In the rush to get it out so fast, you know, I end up doing a lot—everything, pretty much — so I'm writing the story as I'm trying to send out a tweet, and a Facebook post, and an e-mail and some text. And in the process of sending out one of those, I was typing so fast, and I accidentally typed 'not guilty' instead of 'guilty'. Thank God it was on Facebook, because on Facebook you can edit it.

She is not alone, as the web editors I spoke with, those tasked to directly work on the homepage, also experience having to wear too many hats, as digital desks continue to make sense of how the workflow should look like as news organizations embrace the digital-first mantra. For example, I asked a web editor at the third newsroom to describe to me what his typical day looked like. His description is particularly noteworthy for 
while he worded his first two sentences sequentially, the tasks following the second sentence were all mixed temporally—a classic case of multi-tasking:

We have our morning meeting at 9 a.m. and plan out what is coming from all the departments. Then, it is posting stories, editing, changing headlines, photos, and photo galleries - all those kinds of things really all day. And also mixed in there would be sending alerts. We send text alerts to phones, email alerts. We also have newsletters that we send... We monitor traffic_-both Omniture and Visual Revenue that helps us make decisions where we place things. We have an assortment of little things too like a press release area that we have to go in and approve... There is monitoring of people's comments, stories, blacklisting them sometimes. I'm probably forgetting some of it.

The responsibilities that come with higher positions in the newsroom hierarchy have changed as well. The editor-in-chief at the first newsroom said that about $80 \%$ of his job is more strategic than journalistic. "The editor is always seen as the person who's running the newspaper, maybe running the website," he said. "Now it's about developing new products on the digital side that will, you know, take the resources we have in the newsroom, use them in a different way to produce products so that people who have iPads, tablets can access our information." The publisher of the second newsroom also described his editor-in-chief to me as "a great journalist, a great leader, and he is also a great marketer." The description of an editor-in-chief as a marketer struck me as markedly different from the old system that celebrated the wall of separation between a news organization's editorial side and its marketing side, a separation that was normatively thought to protect editorial autonomy. The second newsroom's vice 
president for digital also came from another paper as a long-time sports editor. He clearly identified himself as a journalist with many, many years of editorial experience, and yet he now finds himself overseeing all that is related to digital—including the "shopping team;" the digital services team "that sells social media services to advertisers;" and even the "advertising" team for their digital platforms. The assistant managing editor at the third newsroom said her work spanned everything on the digital platform — the website as well as apps for tablets and mobile phones: "So basically I am responsible for what we put on the site and also growing traffic..."

In a newsroom where staff sizes continue to shrink, roles continue to evolve, and tasks continue to pile up, journalists do not have the time to engage in a personal reflection to match their belief of a need to balance editorial autonomy and audience influence with the specific day-to-day actions they undertake. Clearly, journalists have incorporated web analytics and social media into their routines and news judgment, but whether they are considering metrics and feedback as tools or as goals, as means or as ends in themselves, is another question.

\section{Using Web Analytics}

In one of my conversations with the managing editor of the first newsroom, he compared using web analytics with getting hooked on drugs. "It's like crack," he told me, grinning. "You can sit here and watch it, popping all night." The numbers on the dashboard would change all the time, as analytics programs such as Chartbeat and Visual Revenue would report metrics in real-time. It will be easy to get drowned in the numbers and be amused by the patterns they show. "It can be all consuming," the newsroom's deputy managing editor for digital warned me. "I call it like the editorial crack, right? 
You sit there and you can see what people are doing, you know, instantly." The metaphor is funny, but it also has deeper implications. Drug addiction is bad for one's health. The reason illegal drugs are outlawed is because a drugged person might pose danger to herself and to others as she loses control and becomes unable to function normally. How much personal control does an editor retain when she is using web analytics, when she is using the editorial crack? In this section, I shall enumerate the various ways in which the editors I observed used information from web analytics in their news work.

Selection. The first main use of web metrics is in the selection of story elements. In the budget meetings I attended in the first newsroom, the managing editor would take note of story pitches that he thought would get good traffic. Stories that had gotten good traffic would also get updates and follow-ups. To some extent, this affects decisions on what types of stories are covered. Topics that have done well in the past tend to get assigned more. But web metrics also affect selections of photos, videos, and graphics. For example, at the second newsroom, one of the web editors was updating a news story about a homicide when he suddenly came up with an idea. Having the suspect's photo next to a story is common, he told me, but readers would also want to see the photo of the victim. So he thought of putting the two photos side by side. "I kind of favor that," he said. "We need her face [the victim's] out there for it to perform well so I'm gonna talk to photo." He walked toward the photo section and when he came back to his workstation, he looked at me and said: "So they're producing that."

Photo galleries have also become staples in news sites. For example, during the 9 a.m. digital desk meeting that I attended at the second newsroom, another online editor proposed an idea for a photo gallery. "There's a lot of interest over the weekend about the 
Pope being a 'regular' guy," she said, adding that stories on the new Pope did well on Chartbeat. "It was really resonating over the weekend." So she proposed a photo gallery of the new Pope for the website. These additional elements to the story, such as photos and photo galleries, are called assets. One time while I was sitting in the digital desk at the third newsroom, I overheard the assistant managing editor tell one of her newer web editors: "You should always have assets on the stories that are trending." The use of this metaphor to describe elements added to a story is consistent with the language of capital accumulation. In the field of economics, this is one way the concept has been defined:

An asset is an entity from which the economic owner can derive a benefit or series of benefits in future accounting periods by holding or using the entity over a period of time, or from which the economic owner has derived a benefit in past periods and is still receiving a benefit in the current period. Because it represents a stock of future benefits, an asset can be regarded as a store of value. (A. Harrison, 2006, p. 3)

The addition of these assets to a story is rooted on the belief that they would attract more traffic, a form of capital that is of value to the newsroom. This belief is also based on how assets have performed in the past. Photos, videos, and infographics have no direct market value, but in the newsroom they are regarded as entities which the website can benefit from, a way to accumulate more capital.

Placement. It is correct that a news website has more space than the limited pages of a newspaper, so that selection of stories to be published is less problematic for online than for print. However, only a limited number of stories are placed on the homepage. Limiting the number of stories on the homepage ensures it does not get cluttered and 
readers can easily navigate the site. For example, the website of the third newsroom had layout space for only 17 main stories - those that include short blurbs, usually the story lead - and 13 headlines under the tab "latest news." But this limited number of homepage stories is compounded by the need to keep the website fresh by adding new stories and elements regularly. Keeping the same main story for an entire day is a death sentence online-readers are not expected to come back if they will just find the same set of stories over and over again. When numbers start to dip, web editors take that as being the right time to update the homepage by moving around stories or adding new ones to replace those that have stagnated in terms of traffic.

The homepage then is the prime space for a news site and it is where homepage editors exercise a lot of judgment in terms of story placement. This judgment is often based on web metrics. For example, I was seated next to a web editor at the second newsroom when he decided to place a new story as the third main story on the website. That meant he had to take one story out. Since he still needed to tweet about the new story and edit more stories in the pipeline, he just looked at Chartbeat and made a quick decision. He relegated the story he chose as one of the headlines listed under breaking news. I asked him why he chose to move down that particular story. He looked at me and said: "It wasn’t doing well."

I saw many instances of this across the three newsrooms. One time, a web editor at the first newsroom was routinely checking numbers from Chartbeat when he saw that an opinion piece was getting a lot of traffic even if it was not on the homepage. So he put the piece on the homepage, replacing the story that was getting the least traffic. Sometimes, the recommendations are made by the algorithms in the software, as Visual 
Revenue, which the third newsroom uses, provides such placement recommendations. The recommendations even come with estimated number of unique visitors that following each suggestion would bring to the site. In one of my conversations with a web editor, he told me about a story that quoted a football player saying "bad barbecue makes me want to fight." The article was a blog post buried in the sports page and had gone unnoticed by the homepage editors. But then, out of the blue, Visual Revenue recommended putting it on the homepage. The web editor followed the recommendation, and the story ended up being the day's most viewed story.

One time, at the second newsroom, a web editor took out a business story from the homepage to give way to a new sports story that he was sure would get a lot of traffic, the locality being "a sports town." However, when he checked Chartbeat again, the business story he took out was actually the eighth most viewed story so far, so he decided to put it back. Instead, he took out a story on a girl who was shot dead. "If it doesn't get any traction in 20-30 minutes, we usually pull it out," the web editor told me.

Headlines. The goal of attracting traffic has also made editors conscious of how they write headlines, because creative titles that were celebrated in the traditional newspaper-only newsroom no longer works with search engines. A way to bring traffic into the site is making sure that your articles show up when a reader searches for related keywords on search engines such as Google. This is why websites have also devoted resources to search engine optimization (SEO) efforts (Dick, 2011). For the web editors I observed, their SEO work is focused on writing headlines. The assistant managing editor at the third newsroom said online headlines should be more straightforward and less clever than newspaper headlines. For example, one of her web editors came across a 
sports story while reading a printed copy of the day's paper. The story was already online, specifically in the sports page, but it was not getting any traffic. The web editor surmised it was because of its three-word headline that was written apparently to fit space constraints on the newspaper layout. The web editor wrote a new headline that included names of the baseball teams involved in the story and the city where they were playing. A web editor at the first newsroom also told me how simply adding the word "watch" to the headline of a video post could improve traffic. He said that instead of saying " 10 best Super Bowl ads," he would write "Watch Super Bowl ads." He said: “Just by adding something like 'watch' will make the traffic double easily."

The web editors at the third newsroom had put words such as "bra" and "vagina" on their headlines during the time I was there. "There is no way in hell I would put that in print ever," one of the web editors told me, referring to the word "vagina" which they used the day before. The story was about the New York City police denying actress Amanda Bynes' allegation that her arresting officers had slapped her privates. The web editors exchanged ideas on how to write the headline. In the end, one of them decided to use the word vagina on the headline. The story attracted a lot of traffic as expected and was turning up in search engine searches for that specific story.

Sometimes, when a web editor would be dilly-dallying on how to write the headline, he would just use Visual Revenue's headline testing service. I saw one of the web editors at the third newsroom do a headline test one time. He wrote two headlines for the same story. Visual Revenue randomly exposed readers to one of two headlines. His first version got a $9 \%$ rating while his second version got $42 \%$. The ratings were based on how readers who saw the respective headlines responded to each of them in the form of 
viewing the story, among others. He decided to go with the second headline based on Visual Revenue's report.

Judgment. Since the decisions that a web editor makes is almost always an individual decision, even when it comes to story selection and placement, sometimes web editors just need "something to bounce an idea off," a web editor at the third newsroom told me. In his newsroom, this comes in the form of Visual Revenue, which provides placement suggestions and even headline testing. The machine, however, does not always prevail. "Sometimes I will reject them because it's just not appropriate," he told me. For example, Visual Revenue recommended that he make the Amanda Bynes article with the vagina headline as the main story on the homepage. It was guaranteed to attract a lot of traffic, the software reported. It was already generating good traffic. Seeing this recommendation, his fellow web editor clicked "decline," turned to me and said: "You see why we don't let the machines do it?"

Not letting the machines do it means retaining editorial control and exercising news judgment. This might explain a growing trend of taking out lists of most popular stories that were used to be automatically populated based on page views. For example, I remember noticing a most viewed box on the website of my first newsroom when I was still preparing for my actual case study. But when I started my observations, an editor at the digital desk pointed out to me that the box was no longer there. It was instead replaced by a box of “editor's picks." I realized, based on my observations and interviews, that there were two main reasons for this. First, lists of most popular stories tend to be static: an initial list functions as a guide to other readers who would view the articles listed, hence keeping them in the most popular list. A static list, however, does 
not encourage repeat visits. Second, relying on algorithms that populate the list based on page views takes the control out of the journalist.

In the instances when the news day was slow, I saw how web editors got the chance to discuss editorial decisions. For example, it was a stormy week when I started my observations at the third newsroom. There was one day when not a lot of things were happening except for a stream of updates about the weather. In the afternoon, after the usual peak of traffic between noon and 1 p.m. had passed, one of web editors looked at the website, and told his colleague: "I feel bad that we have Amanda [Bynes] and Beyonce both in the latest news." The web editor finally decided to move the Amanda Bynes story down. I realized how these pauses for reflection, almost impossible in a typical fast-paced, information-overloaded news cycle, allow journalists to reassess their actions based on what they believe is their "responsibility," as what another web editor from the first newsroom said:

There's a responsibility on our end, just to say: OK, this Justin Bieber post got a thousand views in an hour, and this post on violence in [the neighborhood] got 50. Well, that doesn't mean that we should only cover Bieber and not cover violence. What it means is we need to check back. It could be any number of things: the way we present the story, it could just be an anomaly...

There is also an effort to provide a good mix of stories on the homepage that represent content from different sections, something that requires exercising editorial judgment. Some editors also voiced out the need to provide a balance of click-baits and serious stories, of cotton candy and spinach. For example, a web editor at the third newsroom said during our interview: 
We try to get all the departments represented on the homepage, especially up on the top of the page... But at the same time, traffic is the number one thing. So if something is not getting traffic we're probably going to move it off of there, even if some editor thinks it's really great.

\section{Using Social Media}

Social media sites, similar to web analytics programs, provide audience feedback to journalists in the form of numbers such as number of likes and retweets, and also in the form of comments that may reflect attitudes toward stories, issues, or the news organization itself. Social media sites, unlike web analytics programs, are usually free. They also allow direct interactions between journalists and social media users providing feedback. When I set out to conduct my case studies, I decided to focus on how newsrooms use the audience feedback they get from audience information technologies such as social media, but in this section I will also present other uses of social media for the newsrooms I observed, arguing that these other uses of social media have become part of a web of routines set in motion by having more clues about what audiences want. The main uses of social media in the newsrooms I observed can be grouped into these three categories: monitoring, interacting, and promoting.

Monitoring. The editors I observed and spoke with used social media for monitoring news from other news media, from traditional news sources such as the government, and from typical social media users. They also monitor comments about their stories in particular and their news organizations in general. They also monitor social media for topics that are trending or being talked about.

First, the editors use social media to monitor news from a variety of sources. For 
example, a reporter who is also working as a desk editor on weekends told me how she would keep her personal Twitter account open to monitor breaking stories from other news organizations. This is rooted in her acknowledgment that their newsroom is understaffed in terms of reporters, and during the weekends, when some of them take days off, there is a big chance they might miss something. The web editors also subscribe to tweets from government agencies. For example, during one of my observation periods at the first newsroom, a web editor alerted me about a tweet he read from the city's police scanner. There was fire on a major street, already on second alarm. He alerted another editor, who started making phone calls and writing a few paragraphs while the web editor looked it up on the wires, pulled the story he found, edited it, and then uploaded the story with an accompanying map.

Second, the editors also monitored comments on their newsroom's social media accounts. When the web editors at the third newsroom decided to write a headline that referred to Amanda Bynes' vagina, one of them started monitoring tweets about the story. A tweet said: "Headline of the year." That remark made the web editors laugh. I realized that to some extent, the web editors looked at Twitter for confirmation of their hunch that the story — and the headline-would get some traction. A few other tweets commented how hilarious the headline was, but then one tweet from the audience said: "Don't confuse page views with news." The web editor stopped reading the tweets on his Tweetdeck.

Some web editors also look at tweets outside their accounts, searching for their organization's name on Twitter for example. "I am constantly looking at our mentions in social media, just to see what people are saying about our stories, to make sure we are not 
overlooking anything." Social media have also apparently become easier channels for readers to complain—passwords not working, paper not delivered, among other things. Thus, at the second newsroom, the social media manager said sometimes she would also put on the hat of a customer service manager. In fact, she created two positions that just monitored the news organization's social media accounts for complaints such as these.

Finally, the editors also monitored trending topics on social media. Twitter, for example, has a list of trending topics. In the budget meetings I attended at the second and third newsrooms, the managing editors would always ask the social media manager or the assistant managing editor for digital what topics were being discussed on social media. Sometimes, these trending topics are considered in planning stories for the website and the paper. For example, when I arrived for the morning budget meeting for the digital desk at the third newsroom, I heard the public editor, who was also tasked to do social engagement through social media, tell the assistant managing editor for digital about the story of a mammoth carcass still with liquid blood that was discovered in Russia. He said the story had been trending in social media. The assistant managing editor responded that she also saw the story and had already uploaded it precisely because it was trending.

Interacting. The use of social media to interact with the audience comes in many forms and degrees. It can be something as simple as responding to tweets and mentions on social media to actively soliciting information about news events from social media users. For example, a web editor that I observed at the first newsroom responded to a tweet that praised the paper's front-page layout, saying it was better than the competing paper's. The editor tweeted back: “Thanks for the feedback! We won't tell the [competing paper] you said that." She later told me that whenever possible, she would 
respond to tweets like that because it helps foster brand loyalty among their readers. I also observed the same editor actively solicit information from social media users. For example, when a popular bridge was closed for renovation, she sent a tweet asking for people to share their experiences. Her tweet went: "How was your morning commute? Were you affected by the [bridge] closure? Share your stories, photos with \#[hashtag]." She later put together a Storify post that included tweets and photos shared by social media users who used the hashtag she started. The managing editor at the first newsroom also recalled how he got started using Twitter when he and a colleague was covering the Democratic National Convention in 2008. They heard about Twitter and started playing around with it:

We got a lot of engagement_- people asking us questions and people asking for stuff — and it just struck us both: social media is a pretty powerful tool... It's a way to find sources. It's a way to find different viewpoints. It's a way to have a conversation with your community and your readers. It's not just me-'I send links out, and then I'm done.' It's social media. It's an interaction.

The assistant managing editor at the third newsroom also recalled how during one big snowstorm even before she came to the newsroom the web editors created a tool on the website that allowed people to report how much snow they got in their backyards. Then, the web editors put together a map based on the crowd-sourced information. She said: "There is no way that a newspaper staff could go out and measure all of those places but by having people do it, you got a great sampling of the area... that you wouldn't be able to get on your own." To some extent, this can be interpreted as traditional journalists opening the gates for the audience to take part in the news construction process. This 
particular use of social media, unlike the passive monitoring of comments, is beyond just normalizing technology. To some extent it also shows a reworking of norms to factor in affordances by new technology that can contribute to more efficient journalistic practices (see Lasorsa, et al., 2011). However, in the end it is still about the journalist retaining control. The assistant managing editor told me:

Well, now there is a lot of reader-submitted journalism coming in, whether that is pictures or blog posts or commentary. I just think that there is a lot more interaction because it used to be sort of a one-way street and now it is open to be more like this. It probably will increase. Again, I think the social media platform is changing all of that. I think that is important. But you still have to have an editor that filters all of that.

Promoting. Finally — and based on my observations, the most common useeditors use social media for content delivery and promotion. For higher-level editors, those who oversee operations instead of directly dealing with content and users, social media provide an avenue for content promotion and dissemination. For example, when I asked the first newsroom's deputy managing editor for digital what they use social media for, she said: "Well, we use it a lot for content syndication. We also use it for marketing and promotion.” Indeed, when I was observing there during the Papal Conclave in March, a web editor was monitoring the news on television and she already had a tweet ready to be sent out using the newsroom's account. She had drafted the initial text and she was just waiting for the name of the new Pope. When the name of the new Pope was announced — she and the rest of the newsroom were watching $\mathrm{CNN}$ - she sent the tweet right away. She sent a second tweet a few minutes later, this time containing a link to a 
breaking news story she had uploaded on the website from the wires.

This is also where the use of web analytics and social media intersect. Though editors use analytics to determine popular stories, the same metrics also show them the underperforming stories. Knowing which stories are not getting a lot of traffic leaves an editor with two choices: take it out of the homepage and replace it with a click-bait, or keep it on the homepage, especially if it is something editorially determined as important and help it gain more traffic by placing it more prominently on the homepage, updating it, adding story assets to it, or by promoting it on social media. For example, when the newsroom's managing editor sat down with me to show me how he used Chartbeat, he decided to do an "experiment" so I could see how Chartbeat worked. He shared a link to a story about a girl who had been shot. He used both his personal Facebook account and the newsroom's account. Then, he pointed out to me how the page views to the story as measured by Chartbeat increased in just a matter of minutes. This is another example of normalizing technology—using web analytics and social media consistent with the conventional journalistic role of giving the audience the spinach that it needs. This type of promotion, however, was not very common in the three newsrooms I observed. Most of the time, promotion on social media was done to drive traffic to the site, so that stories that are expected to be click-baits are the ones promoted most often.

There was an unwritten rule at the first newsroom to get editors and journalists on social media. I sat in a meeting between the managing editor and his web editor, and three of their columnists who wanted to talk to them about improving their social media presence. One of the columnists was complaining how columnists from the competing paper were more visible on social media. One of them also asked about the difference 
between tweeting from an official account of the editorial section and tweeting from his personal account. He was thinking that Twitter followers would want to read tweets that were more personal. The managing editor agreed, saying that: "people want to identify with a person." But this also presents a problem. "We have a sheer scaling issue at this point," the deputy managing editor told me later. "It's like: Oh my God! We have 40 newspaper.coms, 40 different Twitter accounts minimum, 40 different Facebook accounts minimum, 40 Pinterest accounts minimum, 40 Google-plus accounts.”

There were also efforts to manage social media use across the three newsrooms. For example, at the second newsroom, the social media editor showed me a copy of what they called their "social media assets" which he would email to all their employees every day. The email contains suggested tweets and shares-already composed, edited for word limits, and complete with the corresponding links to the website - that employees can just copy and paste on their personal social media accounts every morning if they wanted to. It was not mandatory, but the practice was encouraged, a testament to how social media are looked at as platforms to promote content and drive traffic to the website. The social media manager referred to having social media presence as having a "microphone" that she considers it a requirement for every journalist. She even holds half-an-hour trainings on social media for their journalists and editors, emphasizing the need for social media presence particularly for SEO purposes. Google searches social media sites, and even if Google + has not taken off compared with Facebook or Twitter in terms of number of users, having a Google+ account ensures placing prominently on Google searches. The social media manager said: 
When I teach journalists social media, I always say: This thing I'm asking you is playing; don't think about it as extra work. Think about it as 'this is yours for the taking.' You have earned this. Take everything you have coming to you and more. Get all the credit you are due. Why would you not? Like why would you not put your byline on a story? Right? Take the credit that Google is going to give you for doing this extra stuff. Don't think about it as extra work. Think about it as 'I am claiming what's mine.'

The focus on social media and the convergence of platforms within the backdrop of shrinking newsroom staff have given rise to new routines. Since tweeting can help position the website on Google, the social media manager at the second newsroom advocated for a new policy: Once a big story is confirmed, the reporter is expected to tweet about it first, even before writing the story. After the story is written and is published online, then the reporter can tweet again about the story, this time including the link to the story. "That way, Google gets that subject, Google gets that link fast." The web editor at the first newsroom also works the same way. If there is a big breaking story, she would tweet something out without any links to the story. Then she would quickly write a paragraph or two about it, and then tweet again with a link to the initial story. Finally, when the full story has been uploaded on the site, she can tweet the update: “'Hey, remember how three seconds ago I told you this breaking news? Well here's the story,' and then link to it.” This is noteworthy considering, as I argued in the earlier chapter, social media are third-party platforms that do not bring any direct revenues to the news organization. But they are also free sites where the newsroom can promote its brand, drive traffic to the site, and hopefully be able to turn that traffic into advertising or 
pay wall revenues. Social media function as platforms for journalists to accumulate symbolic capital that they might be able to convert into economic capital.

The journalist now needs to promote her own content in order to survive in a crowded online space where, according to the managing editor of the first newsroom, it is now more difficult to be heard amid all the noise. This idea challenges the traditional notion of what constitutes newsworthiness. It used to be that the journalist reports about something newsworthy based on traditional news values, and that was all that was expected of her. The newspaper delivery truck takes care of dissemination. Now, part of the expectations of a journalist includes delivering and promoting your content. "We are moving away from just reporting the news to actually like controlling the distribution as well," the deputy managing editor at the first newsroom said. "Now, the editorial folks are actually taking some ownership in the distribution process."

\section{'Doing Well'}

In any type of game, an important purpose of having rules is to differentiate between what is acceptable and what is not. The rules also function, to some extent, as a way to evaluate a particular play, not only to assess it as being within or outside the rules but also to gauge whether it was a good play or not. In the evolving online journalistic field, where a few of the rules have somehow changed to accommodate the increasing influence of the changing audience, how do journalists define what a good story is? How do they know if they are playing the game well?

The editor-in-chief at the first newsroom has been a journalist for almost three decades and has seen some of the rules of the field evolve. He started in a traditional newsroom and moved up in management ranks around different news organizations, 
including an online-only platform immediately prior to moving to his current newsroom. There, he was exposed to the uses of web analytics: "It's a different way of looking at, you know, what is considered successful in terms of reaching readers and how you are measuring it." But when I pressed him for how he would define good journalism now, he said that the story itself still mattered. "We are still great reporters who just want to do really good journalism. We think that's the value we are giving to the readers. That's what means [to be] successful."

The day-to-day operations I observed showed otherwise. A phrase that I often heard in the newsroom is "doing well." An editor who phoned in during a budget meeting at the first newsroom was talking about a video she had posted on the site when I heard the managing editor tell her: "Did you see my note on that? The video did very well." A web editor at the second newsroom told me when we chanced upon a story about drones while looking at a news site: "The drones stuff has done well for us in the past." When a section editor praised an online reporter for a "cool" story he wrote, I heard the assistant managing editor for digital jump in and said: "Yeah, it did pretty well."

What does doing well mean? It means getting good numbers. It means getting a lot of traffic. It means that old measures of whether or not a newspaper story did wellpicked up by other media, got the attention of government officials, talked about by a lot of people, influenced policy, won an award—have given way to easily quantifiable assessments: number of hits, page views, unique visitors, shares. A sold-out newspaper issue might have had a good banner story, and yet the other stories included might have also done well—it was impossible to assess the attention each story got. Now, web 
analytics programs have been particularly good at quantifying metrics for each element on the website, comparing a story with another story, a headline with another headline.

But while web analytics has been particularly good at counting the numbers and measuring what people are looking at, there are still no metrics that can measure why people are clicking and viewing those that they click and view to begin with. "I mean the numbers are the most detailed and probably the most objective," the first newsroom's metro editor said. "But I mean you just get a look, you just get a sense of what they're looking at as opposed to what they're thinking about." Social media posts offer clues about what people think about, but the argument of whether or not they are representative of the public sentiment is another thing.

Pinpointing what makes a story do well remains an editorial guesswork, albeit supported by a wealth of audience metrics. But when audience metrics become the ends, the measure of a story doing well; when journalists believe in the norm of balancing spinach and cotton candy but get too swamped by the requirements of their ever-evolving job descriptions and by the wealth of data they get from the editorial crack that is web analytics to pause and reflect on actual decisions they make, then who prevails in the daily grind, who gets to impose the rules on the day-to-day game - the man or the machine?

\section{A Synthesis}

I started my case studies with a simple question: How do journalists incorporate new forms of audience feedback in their news work? The answer, however, was complicated, for in order to understand how agents engage in particular actions in the struggle within the journalistic field, we cannot simply focus on what they do. We need 
to understand the context within which journalistic decisions are made and how this context intersects with individual agency. For while it is true that actions cannot be divorced from the agents that enact them, agents do not exist in a vacuum. It is through these theoretical assumptions that I presented what I found in the field in the last two chapters. The agents participate in the struggle to either transform or preserve the field having come from a particular habitus. This habitus structures how forms of capital are valued and how rules, the journalistic doxa, are created, re-created, invoked, or changed. The doxa provides an explanation to how agents manage their editorial decisions, but specific actions are also shaped by the occupational setting agents are in, consistent with the assumption of media sociology that news gets constructed-by individuals - who exist within a social and occupational setting (Reese \& Ballinger, 2001). How much of the journalistic doxa is reflected on the particular day-to-day actions in the newsroom depends on this occupational setting, itself structured, but mostly unnoticed by journalists themselves, by the habitus they come with.

The narrative in the last two chapters is built around the research questions that guided me in my case studies across the three newsrooms. The results that emerged from my analysis of my field notes and interviews transcripts and from my personal experience during my field work have addressed each of these research questions, reflecting many of the concepts that comprised the theoretical framework I offered in Chapters 2 and 3. But the results also expanded my original theoretical framework (please see Appendix A) as they illuminated interesting linkages and patterns (please see Appendix E). In this section, I shall revisit my research questions and summarize the results for each. But I 
will also highlight the results that emerged outside these research questions that have further developed the theoretical framework I have initially offered.

RQ1 asked about how journalists conceive of their audience. The results showed that journalists still imagined their audience despite the wealth of data offered by web analytics and social media. Top-level editors also identified a preferred audience, but day-to-day operations at the online news desks still appealed to the audience that generated the most clicks. This is because the editors conceived of their audience as a form of capital, particularly as economic capital. RQ2 asked about how journalists' habitus influenced this conception of the audience. The results showed that the editors recognized the decreasing economic capital for the print medium that made the shift to digital more pressing and the adoption of new technologies inevitable. This awareness is leading editors to turn to the online audience as a form of economic capital, or at least a form of symbolic capital that can be converted to economic capital in the immediate future, to offset what is happening to the print medium. But another important factor for this conception of the audience is the capability of web analytics to quantify the audience.

RQ3 asked how journalists used audience feedback in their news work. To a large extent, the editors I observed used audience feedback to inform strategies on how to further increase web traffic. They used web analytics to monitor stories that were doing well, so these can be placed more prominently on the homepage. Backed by web metrics, editors predicted which topics, headlines, and story assets were more likely to generate traffic. They also used social media to promote stories to drive traffic to the site. Thus, to some extent, the use of social media is also driven by the use of web analytics. This is rooted, in response to RQ4, in their conception of the online audience as a form of 
economic capital. To some extent, however, the editors I observed also normalized both social media and web analytics, adapting them to fit existing norms and routines. Web analytics were used to spot important but underperforming stories and social media were used to promote these stories. This is consistent with the conventional role of a journalist. In response to RQ5, this also highlights the journalistic balancing act that editors engage in, for aside from their conception of the audience, traditional journalistic norms also influence, to some extent, their use of audience feedback. However, because of their demanding routines and evolving job descriptions, editors do not have the luxury to reflect on their decisions, so that the balancing act usually tips away from the spinach and toward cotton candies. 


\section{Testing Theory: Survey}

The results of my case study focused on the mechanism of how the audience potentially influences the gatekeeping process through new audience information systems. This mechanism centers on the interplay between perceptions of the habitus, conceptions of audience as forms of capital, and the journalistic doxa. The following conceptual links are grounded in my qualitative data: One's perception of the journalistic field, rooted in experience, determines the extent of one's adoption of new audience information systems. These, both within the realm of one's habitus, lead to particular conceptions of the audience as a form of capital. This conceptualization, within the realm of the journalistic doxa, shapes how editors use audience information from web analytics and social media in their news work (please see Appendix F).

\section{Complementing Case Study}

The case study approach seeks to understand a phenomenon based on how it unfolds within a bounded system or systems, with the theoretical aim of being able to come up with explanations that could be applicable to other cases (Creswell, 2007). This is an example of the importance of representativeness of concepts - not of persons - in qualitative studies (Corbin \& Strauss, 1990). The applicability of theoretical explanations across cases - or in quantitative terms, generalization - may not be the immediate goal of case study research. But it is also an equally worthwhile pursuit particularly in theory testing that can be served by survey research. Combining case studies and surveys in studying the same phenomenon is not new. Several studies have employed mixed 
methods research using both case study and survey across a diverse range of fields, such as marketing (Woodside, 2010), management accounting (Modell, 2005) and educational reforms (Stecher \& Borko, 2002). Survey research “may improve our understanding of the incidence of a particular phenomenon and/or the form and strength of conceptual relationships observed in case studies" (Modell, 2005, p. 233). This is precisely my goal in combining these two in a sequential approach.

Survey research "collects information by asking people questions" (Shoemaker \& McCombs, 2003, p. 231). The collected information is recorded in numerical forms that can be analyzed statistically. In this study, I am using a cross-sectional design that is appropriate in capturing a "snapshot of the population" during this period of evolution in audience information systems. The use of surveys in journalism research is common not only among studies of national samples of journalists (e.g. Cassidy, 2006; Johnstone, Slawski, \& Bowman, 1972; Weaver, et al., 2007; Weaver \& Wilhoit, 1986, 1996) but also of journalists from specific areas of specialization (e.g. Tandoc, et al., 2012; Tandoc \& Takahashi, 2013) and of journalists across several countries (e.g. Hanitzsch, 2008, 2011; Hanitzsch, et al., 2010; Hanitzsch \& Mellado, 2011).

\section{Web Survey}

This study used a web-based survey, an approach that dates back to 1996 (Couper \& Miller, 2008). Web surveys themselves are another manifestation of the changing relationship between message producers and audiences: Survey platforms, many of which offer access for free, have allowed practically anyone with internet access to create a survey, collect data, and report findings (Couper \& Miller, 2008). Web surveys are cheaper than traditional mail and telephone surveys (Wright, 2005). Other advantages 
include a quick turnaround from participants and the ease of preparing recorded data into a format suitable for statistical analysis (Shoemaker \& McCombs, 2003; Wright, 2005). Web surveys are self-administered, just like most mail surveys and unlike telephone surveys (Shoemaker \& McCombs, 2003). In general, self-administered surveys have lower response rates than interviewer-assisted surveys (Shoemaker \& McCombs, 2003).

A study involving more than 19,000 university students conducted both mail and web surveys and found that "web survey application achieved a comparable response rate to a mail hard copy questionnaire when both were preceded by an advance mail notification" (Kaplowitz, Hadlock, \& Levine, 2004, p. 100). Another study that involved 1,000 adults who received a mail survey and another 1,000 adults who received a web survey link found that the web survey had a lower response rate (Kwak \& Radler, 2002). But the web survey also had a lower item nonresponse rate and longer open-ended answers than the mail survey (Kwak \& Radler, 2002). Web survey respondents also rated themselves as more proficient in advanced computer technology and spent more time online than did mail survey respondents (Kwak \& Radler, 2002). Finally, a study with a sample of 300 university professors found that web surveys had "significant advantages" over mail and fax surveys (Cobanoglu, Warde, \& Moreo, 2001). The web survey was also the cheapest of the three and had the highest response rate (Cobanoglu, et al., 2001).

What these studies show is how web surveys can be the most practical and most appropriate approach based on the population being studied. The high response rate from the study involving university professors might be explained by the fact that the sample was composed of professors who had internet access and who routinely checked their emails (Cobanoglu, et al., 2001). The finding that web survey respondents tend to be 
internet savvy (Kwak \& Radler, 2002) is particularly salient for studies involving populations that can be considered digital natives, such as studies of social media users or even online journalists.

\section{Sampling Strategy}

The web survey approach is therefore particularly appropriate to this study's population composed of online editors across newsrooms in the US. These editors are online most of the time considering the demands of their work. Since my goal is to test the framework I developed from observing and interviewing editors from three newsrooms, I decided to limit the quantitative part of this study only to editors involved in online operations at their newsrooms. Thus, reporters, photographers, videographers, columnists, among others, were excluded. I drew my population from the database provided by CisionPoint, a software solution that offers a list of media contacts across several countries, primarily the US. The list is based on voluntary participation of media organizations, but surveys of journalists have used the database, considered the most comprehensive list of media contacts that also now includes bloggers (Lewis \& Zhong, 2013; Telecomworldwire, 2011). CisionPoint allows users to filter through the database using different categories, such as location, medium, position, among others. I created a population of editors working for online newsrooms in the US that deal with local, national, or international news. These filters included editors from a range of editorial positions - from web editors up to editors in chief. They also excluded editors working for online newsrooms not listed under the news category, such as gardening or beauty blogs. This process yielded a total of 3,697 online editors, excluding those who were 
listed multiple times (e.g. an editor with a particular email address listed for two different news organizations).

From this population, I randomly selected 1,103 editors to invite to participate in the survey using an online random digit generator. I hosted my questionnaire on the survey program Qualtrics which allowed me to send invitations and reminders containing individual links to the survey. This allowed the system to monitor those who had completed the survey so that subsequent reminders were sent out only to those who had not yet taken or finished the survey. I sent the survey on September 18, 2013 and kept the links active for a month. In between, I sent four reminders. I also offered a $\$ 10$ gift card for either Amazon or Starbucks, with the approval of the University of Missouri's Institutional Review Board. Since my sample is composed of journalists who have jobs, the amount was not expected to influence their decision to participate but was considered as an ethical act to express appreciation for participation. I closed the survey on October 18,2013 with 276 responses or a response rate of about $24 \%$, which is typical of web surveys (Cobanoglu, et al., 2001; Kwak \& Radler, 2002). However, only 206 of these were completed surveys, for a completion rate of about $19 \%$. A total of 56 editors opted out of the survey, for an active refusal rate of about $5 \%$. An a priori statistical analysis using G-Power software showed the study required a minimum of 68 respondents to have a sufficient statistical power of .80 to detect small effect sizes of .15 using multiple regression analyses.

\section{Final Sample}

The average age in the sample was 44.5 years ( $\mathrm{SD}=11.41$ years). The youngest was 23 and the oldest was 68 . Some $67 \%$ were males. The sample also represented 
editors from every level of the newsroom hierarchy. Some $32 \%$ were web editors while some $25 \%$ were editors-in-chief. Online newsrooms of different sizes based on traffic were also represented in the sample. The average number of unique monthly visitors was 4.08 million with a huge standard deviation of 18.7 million. This is because popular news sites, including one with some 197 million unique monthly visitors, were also included in the sample. The median value was 3.5 million unique monthly visitors. Some $44.2 \%$ reported working for news organizations that also publish a daily newspaper, $20.4 \%$ with a weekly paper, and $9.2 \%$ with a television station.

\section{Data Analysis}

I used structural equation modeling (SEM) with maximum likelihood estimation to simultaneously test my hypotheses in an operational framework (see Appendix F). SEM is particularly appropriate for studying variables that are not directly observable (Byrne, 2010; Schreiber, Nora, Stage, Barlow, \& King, 2006) - the kinds of variables that researchers deal with most of the time in media sociology. Path analysis and regression assume no measurement error, but most variables in social science research are latent constructs that require estimation of measurement error (Schreiber, et al., 2006). This is addressed by SEM, which some scholars consider as a combination of multiple regression and confirmatory factor analysis (Schreiber, et al., 2006). In summary:

The term structural equation modeling conveys two important aspects of the procedure: (a) that the causal processes under study are represented by a series of structural (i.e., regression) equations, and (b) that these structural relations can be modeled pictorially to enable a clearer conceptualization of the theory under study. The hypothesized model can then be tested statistically in a simultaneous 
analysis of the entire system of variables to determine the extent to which it is consistent with the data. (Byrne, 2010, p. 3).

SEM has become a popular analytical technique in social science. One reason for this is the awareness in the research community of the need to study multiple variables to account for a phenomenon (Schumacker \& Lomax, 2004). Researchers have also become more careful about issues of validity and reliability (Schumacker \& Lomax, 2004), which SEM addresses by estimating measurement error. In general, SEM is a priori and as such it leads researchers to approach studies based on theoretical models (Kline, 1998). "But a priori does not mean exclusively confirmatory. Many applications of SEM are a blend of exploratory and confirmatory analyses" (Kline, 1998, p. 8). I evaluated the models I tested based on recommended goodness of fit measures (Hu \& Bentler, 1999; Schreiber,

et al., 2006). Though many consider the chi-square statistics $\left(\chi^{2}\right)$ as a basic measure of fit, it is considered an unreliable measure on its own as it is affected by sample size, among other factors (Byrne, 2010; Hu \& Bentler, 1999). It is useful, however, when comparing models (Byrne, 2010). Thus, in the next chapter, I will also report other goodness of fit measures. Finally, I used IBM SPSS AMOS 21 software to run my SEM analyses.

\section{Questionnaire}

I developed a questionnaire based on the literature on web analytics and social media as well as on my empirical observations at three newsrooms for my case studies. I also conducted a pretest of the questionnaire among five journalism professors - three of them teach web analytics courses - and five journalists, with two of them actually from one of the newsrooms I had observed. The feedback from the pretest resulted in a few revisions. The pretest involving the two journalists from a newsroom I observed also 
served as a form of member check to validate that the items I included in the survey based on my empirical observations captured the concepts they were supposed to measure. The consultation with these two editors generated positive feedback that allowed me to proceed with conducting the actual survey.

The online questionnaire on Qualtrics took about 10-15 minutes to complete. It asked editors to answer a variety of questions: from demographic information, to information about their organization, to questions specific to the concepts pertinent to this study. The questions and the items under each of these were mostly based on my qualitative results, but I also compared them with scales developed by previous studies.

\section{Variables, Hypotheses and Research Questions}

In the next chapter, I am focusing on testing the mechanism I proposed to explain audience influence on news work - the extent to which audience feedback in the form of audience metrics and social media posts get embedded into the news construction process. This survey of online editors in the US is consistent with my argument that gatekeeping influences should be examined as influences on gatekeepers, for the mechanism of influence operates at the individual level based on capital accumulation. The results in the preceding chapters allowed me to test the following hypotheses, largely based on my proposed framework but also building on previous research on web analytics and social media. I will start with the general patterns of how journalists conceive of the audience and how they integrate web analytics and social media in their news work. I will discuss how these variables are measured, which will subsequently allow me to offer the rest of my hypotheses. 
H1. Online editors conceive of the audience as economic and symbolic capital, but more so the former rather than the latter.

RQ1. What are the general patterns with which online editors integrate web analytics in their news work?

RQ2. What are the general patterns with which online editors integrate social media in their news work?

Conception of the audience as capital. In my qualitative results, I found that while editors clearly conceive of the audience as a form of economic capital, they also speak of the online audience as a form of symbolic capital that can be converted into economic capital in the immediate future. Thus, in the survey, I also asked the participants to rate their level of agreement with each of six statements about the audience. They used a 5-point Likert scale from strongly agree to strongly disagree. They were asked: "How would you describe your level of agreement with each of the following statements about the importance of the audience?" The items were mostly based on my respondent interviews (see Appendix G). An exploratory factor analysis (principal axis factoring) using oblique rotation (oblimin) found two underlying factors of how the participants conceived of the audience, explaining $78 \%$ of the variance, $K M O=$ .75, Bartlett's Test of Sphericity, $X^{2}(15)=734.39, p<.001$. The first factor had three items and referred to the conception of the audience as symbolic capital (eigenvalue $=$ 3.42 , accounting for $57.07 \%$ of the variance). This was measured by statements that described the audience as important because a bigger audience meant a) more credibility for the company $(\bar{x}=3.51, S D=.91), \mathrm{b})$ higher trust $(\bar{x}=3.26, S D=.82)$, and c) better reputation $(\bar{x}=3.46, S D=.87)$. These statements formed a reliable scale, Cronbach's 
alpha $=.88$. The second factor had two items and referred to economic capital (eigenvalue $=1.28$, accounting for $21.27 \%$ of the variance). This was measured by statements that described the audience as important because a bigger audience meant a) more advertisers $(\bar{x}=3.91, S D=.87)$, and $\mathrm{b})$ higher advertising revenues $(\bar{x}=3.85, S D=$ .85). These two statements were strongly correlated, $r(206)=.85, p<.001$.

These two forms of conception of the audience are moderately correlated, $r$ (206) $=.44, p<.001$. Online editors rated the audience as economic capital $(\bar{x}=4.06, S D$ $=.65)$ higher than they did the audience as symbolic capital $(\bar{x}=3.57, S D=.70), t(205)$ $=.98, p<.001 . \mathrm{H} 1$ is therefore supported (please see Appendix G).

Patterns of web analytics use. To answer RQ1, I turn to the web analytics use items in the questionnaire. The participants rated how frequently they engaged in 16 different uses of web analytics. I also ran an exploratory factor analysis (principal axis factoring) using oblique rotation (oblimin) to examine the underlying patterns of use, $K M O=.90$, Bartlett's Test of Sphericity, $X^{2}(120)=1425.89, p<.001$. Three factors emerged, accounting for $67 \%$ of the variance. The first factor includes three items (eigenvalue $=7.54$, accounting for $47.15 \%$ of the variance). I will call it site-oriented use, Cronbach's alpha $=.81$. Site-oriented use refers to using web analytics to make sure the website is running smoothly, measured by the following items: to monitor if the site is working properly $(\bar{x}=3.16, S D=1.23)$; to help design the website $(\bar{x}=2.68, S D=$ 1.16); and to improve user experience $(\bar{x}=3.11, S D=1.15)$.

The second factor includes five items (eigenvalue $=1.65$, accounting for $10.34 \%$ of the variance). I will call it content-oriented use. Content-oriented use refers to using metrics for editorial decisions, measured by the following items: to decide which stories 
to cover $(\bar{x}=2.47, S D=1.01)$; to determine what stories to do follow ups on $(\bar{x}=2.96$, $S D=1.13)$; to determine how to cover a story $(\bar{x}=2.17, S D=1.04)$; to plan deployment of reporters $(\bar{x}=2.20, S D=.97)$; and to know which topic areas to increase coverage in $(\bar{x}=3.03, S D=1.06)$. The items formed a reliable scale, Cronbach's alpha $=.90$.

Finally, the third factor includes two items (eigenvalue $=1.10$, accounting for $6.84 \%$ of the variance). I will call it traffic-oriented use. Traffic-oriented use refers to using the site to monitor traffic and is based on the following items: to determine which stories are doing well $(\bar{x}=4.26, S D=1.00)$, and to determine which stories are not doing well $(\bar{x}=$ 3.82, $S D=1.21), r(206)=.74, p<.001$. The participants rated using analytics for monitoring traffic the highest (please see Appendix H). Thus, in response to RQ1, online editors integrate web analytics in their news work in three general patterns: site-oriented, traffic-oriented, and content-oriented (please see Appendix H).

Patterns of social media use. To answer RQ2, I will now turn to the items that measured social media use in news work. The participants rated how frequently they engaged in each of 12 different uses of social media using a 5-point scale, from 1 (never) to 5 (very frequently). Since based on my observations, Facebook and Twitter were the most commonly used social media platforms, I specifically asked for usage patterns for each of these two sites. First, I asked how the participants used their newsroom's official Facebook and Twitter accounts. If they did not use their newsroom's accounts, I then asked for how they used their personal accounts in their news work. For the $6.9 \%$ who did not use or did not have a newsroom Facebook account and the $10.7 \%$ who did not use or did not have a newsroom Twitter account, I proceeded to use their responses for how they used their personal accounts in their news work. This is appropriate considering my 
purpose of understanding how editors are using social media in news construction. Furthermore, I also decided to analyze Facebook and Twitter uses separately after paired samples t-tests showed that editors' use of the two sites differed across a few particular items.

I ran an exploratory factor analysis (principal axis factoring) using oblique rotation (oblimin) for Facebook use and found two factors, $K M O=.88$, Bartlett's Test of Sphericity, $X^{2}(66)=1069.85, p<.001$. These factors accounted for $55.76 \%$ of the variance. The first factor has seven items (eigenvalue $=5.38$, accounting for $44.81 \%$ of the variance). I will call it engagement-oriented use, referring to using Facebook to interact with other Facebook users. This was measured by the following items: to get suggestions from followers $(\bar{x}=3.31, S D=.98)$; to read what people are saying about a story $(\bar{x}=3.93, S D=1.02)$; to see what issues are trending $(\bar{x}=3.61, S D=1.13)$; to communicate with followers $(\bar{x}=3.86, S D=1.00)$; to find sources $(\bar{x}=3.06, S D=.97)$; to find different viewpoints $(\bar{x}=2.98, S D=1.04)$; and to get information from followers about events they witnessed $(\bar{x}=3.09, S D=.99)$. The items formed a reliable scale, Cronbach's alpha $=.87$.

The second factor has two items (eigenvalue $=1.31$, accounting for $10.95 \%$ of the variance). I will call it promotion-oriented use, referring to using Facebook to promote the organization (see Appendix I). This was measured by these two items: to promote a story $(\bar{x}=4.53, S D=.82)$, and to direct readers to the site $(\bar{x}=4.44, S D=.86), r(206)=$ $.69, p<.001$. The items measuring traffic-oriented use were rated the highest. They also had the smallest variance, indicating agreement among the participants (see Appendix I). 
In terms of integrating Twitter in the news construction process, the same patterns emerged from the exploratory factor analysis (principal axis factoring) using oblique rotation (oblimin). Two factors accounted for $62.52 \%$ of the variance, $K M O=.90$, Bartlett's Test of Sphericity, $X^{2}(66)=1381.77, p<.001$. The first factor has eight items (eigenvalue $=6.14$, accounting for $51.19 \%$ of the variance). It is consistent with the engagement-oriented use as measured by the following items: to get suggestions from followers $(\bar{x}=3.08, S D=1.00)$; to read what people are saying about a story $(\bar{x}=3.39$, $S D=1.11)$; to see what issues are trending $(\bar{x}=3.68, S D=1.15)$; to communicate with followers $(\bar{x}=3.64, S D=1.07)$; to determine how popular a story is $(\bar{x}=3.19, S D=$ $1.09)$; to find sources $(\bar{x}=3.01, S D=.98)$; to find different viewpoints $(\bar{x}=2.96, S D=$ 1.05); and to get information from followers about events they witnessed $(\bar{x}=3.08, S D=$ 1.07). The items formed a reliable scale, Cronbach's alpha $=.91$. The second factor has two items (eigenvalue $=1.36$, accounting for $11.34 \%$ of the variance). It is also consistent with the promotion-oriented use, as measured by these two items: to promote a story $(\bar{x}=$ 4.51, $S D=.86$ ), and to direct readers to the site $(\bar{x}=4.33, S D=.90), r(206)=.69, p<$ .001. It is noteworthy that the item "to determine how popular a story is" loaded with the factor of engagement-oriented use for Twitter but not for Facebook (please see Appendix J). First, it shows that editors use Facebook and Twitter differently to some extent. Second, this result is consistent with the nature of Twitter, where popular stories can be gleaned from a list of trending topics, or through a hashtag search, affordances that have just been introduced on Facebook.

Thus, in response to RQ2, online editors integrate social media in their news work through promotion-oriented and engagement-oriented uses. These results that describe 
usage patterns for web analytics and social media now allow me to offer more specific hypotheses using the following variables.

Perception of degree of competition. The habitus is a complicated concept and directly observing it is difficult. It is a complex construct that involves multiple concepts However, its manifestation - the "practices and perceptions" it generates (R. Johnson, 1993, p. 5) - is easier to measure and observe. Thus, in order to test the framework that emerged from my case studies, where the habitus played an important role, I will instead focus on the manifestations rooted into unobservable but equally important set of dispositions that form the journalistic habitus. I therefore decided to measure perception of the evolving journalistic field, particularly of the degree of competition this evolution has brought among news organizations. This is a measure of a journalist's disposition, of locating himself in the field. This decision is rooted not only in my observations and interviews but also in the literature. In the journalistic field, perceptions influence actions (Born, 2003). Thus, at this stage of the study, I am operationalizing perception of the field in terms of editors' perceptions of the degree of competition their newsrooms face. This perception of competition cuts across three areas: advertising, readership, and quality of reporting.

The online editors were asked: "Thinking about your main market, how would you describe the degree of competition among different news organizations for: readership, advertising, and quality of reporting?" This scale was rated on a 5-point scale, with 5 as "very competitive" and 1 as "very not competitive." The scale is reliable, Cronbach's alpha $=.77$. In general, the participants perceived these areas as competitive, 
with the area of advertising as the most competitive $(\bar{x}=4.23, S D=.91)$, followed by readership $(\bar{x}=3.97, S D=.99)$, and quality of reporting $(\bar{x}=3.56, S D=1.03)$.

Web analytics and social media use. These were additive indices. For web analytics, the participants reported how frequently they used each of the following software in their day to day work using a 6-point scale from 0 (not using the program) to 6 (several times a day): Chartbeat, Visual Revenue, Omniture, ComScore, Google Analytics, and another program if they are using one that was not listed. Since the variable seeks to measure the degree of exposure to metrics data, a summative index is more appropriate than averaging across different programs. The same procedure was done for social media use. The participants reported how frequently they used for their work each of the following: their personal Facebook account, their personal Twitter account, their company's official Facebook account and their company's official Twitter account. They also used a 6-point scale, from 0 (no account) to 6 (several times a day). Following these operationalizations, I now offer the rest of my hypotheses, the results of which will be presented through a series of structural models that test each hypothesis as a structural path. Thus:

H2. Perception of a competitive field leads to the conception of the audience as economic and symbolic capital, but more so to the former than to the latter.

H3. Perception of a competitive field leads to web analytics use.

H4. Web analytics use leads to the conception of the audience as economic and symbolic capital, but more so to the former than to the latter.

H5. Web analytics use leads to integration of web analytics in news construction in the form of a) site-oriented, b) traffic-oriented, and c) content-oriented uses. 
H6. Conceiving of the audience as a form of economic capital leads to a) siteoriented and b) traffic-oriented uses of web analytics.

H7. Conceiving of the audience as a form of symbolic capital leads to contentoriented use of web analytics.

H8. Perception of a competitive field leads to social media use.

H9. Web analytics use leads to social media use.

H10. Conceiving of the audience as a form of economic capital leads to promotion-oriented use of social media.

H11. Conceiving of the audience as a form of symbolic capital leads to engagement-oriented use of social media.

H12. Social media use leads to integration of social media in news construction through a) promotion-oriented and b) engagement-oriented uses. 


\section{Pathways to Using Audience Information Systems}

Structural equation modeling is a two-step analytical process: The first component involves a measurement model while the second component involves the structural model (Beaudoin \& Thorson, 2006; Byrne, 2010; Kline, 1998; Schreiber, et al., 2006). The first stage is basically a confirmatory factor analysis which tests the multidimensionality of theoretical constructs involved in a structural model while the second stage involves testing of the hypothesized causal model itself (Byrne, 2010; Schreiber, et al., 2006). This sequential approach is appropriate: measurement models need to be evaluated first before they are tested within structural models (Schumacker \& Lomax, 2004). Therefore, this chapter begins with a discussion of the constructs involved in my hypothesized models and a presentation of the measurement models. It will be followed by hypothesis-testing through the presentation of the results of the structural analyses.

In assessing the goodness of fit of the measurement and structural models to be presented below, I used the recommended measures outlined by Schreiber and colleagues (2006). They recommended reporting the root mean square of approximation (RMSEA), the comparative fit index (CFI), and the Tucker-Lewis Index (TLI) (Schreiber, et al., 2006). RMSEA is recognized as "one of the most informative criteria in covariance structure modeling" (Byrne, 2010, p. 80). It comes with a closeness of fit test, referred to as the PCLOSE value. An RMSEA value of .06 or smaller (Hu \& Bentler, 1999) and values close to 95 for CFI (Schreiber, et al., 2006) and TLI (Schumacker \& Lomax, 2004) indicate a good fit. In comparing models, the expected cross-validation index 
(ECVI) is also useful, as the model with a lower ECVI represents a better fit to the data (Byrne, 2010). I will refer to this set of goodness of fit measures when I present the models that I tested.

\section{Perception of the Journalistic Field}

In the preceding chapter I argued the appropriateness of my operationalization of the concept of habitus in terms of its manifestation by measuring the participants' perception of the degree of competition their newsrooms are facing. This is because the concept of habitus is a complex multi-layered concept that is not directly observable, but whose manifestations in the form of perceptions that can affect actions are easier to measure (Born, 2003; Willig, 2013). I also presented the results that supported H1: the participants in the survey conceived of the audience as both economic and symbolic capital, but more as the former than the latter.

But consistent with the first stage of the two-step modeling process of SEM, I also tested a measurement model that included these three latent constructs - perception of competition, audience as economic capital, and audience as symbolic capital—with their corresponding observed variables to validate their multidimensional structure. The CFA model yielded a good fit, $R M S E A=.07, P C L O S E=.09 ; C F I=.97 ; T L I=.95$. This confirms the results of the exploratory factor analysis for conception of the audience and also validates the reliability of the scale for perception of degree of competition.

\section{Patterns of Web Analytics Use}

The next latent construct refers to how journalists integrate web analytics in their news work. From the 16 statements that described different uses of web analytics based on my qualitative results and from the growing literature on web analytics, an exploratory 
factor analysis found three underlying constructs: site-oriented use which refers to using web analytics to make sure the website is running smoothly; traffic-oriented use which refers to using the site to monitor traffic; and content-oriented use which refers to using metrics for editorial decisions (please see Appendix H).

The measurement model to validate these constructs using the observed variables as reported in the preceding chapter also showed a good fit to the data: $R M S E A=.07$,

$P C L O S E=.14 ; C F I=.98 ; T L I=.97$. In terms of web analytics programs, the most popular among the editors in the survey was the free program Google Analytics, used at least once or several times a day by $27.2 \%$ of the participants. Omniture was a close second $(25.2 \%)$ followed by Chartbeat $(22.2 \%)$.

\section{Patterns of Social Media Use}

Finally, the last set of latent constructs refers to how editors integrated social media in their news work. Facebook and Twitter use were tested separately because initial paired samples t-test analysis revealed differences between how editors used the two social media platforms. However, the same patterns emerged from separate exploratory factor analyses: online editors use social media for promotion and engagement. Since these are closely related constructs, I included them in the same measurement model.

The CFA showed that the model also fits the data well: RMSEA $=.06$, PCLOSE $=$ $.117 ; C F I=.96 ; T F I=.95$. Some $77.4 \%$ of the participants used their newsroom's official Facebook account at least once or several times a day while $58.6 \%$ used their personal Facebook accounts at least once or several times a day. Some $75.6 \%$ used their 
newsroom's official Twitter account at least once or several times a day while $52.4 \%$ used their personal Twitter accounts at least once or several times a day.

\section{Explaining Web Analytics Use}

The hypotheses proposed in this study concerning web analytics use are nested in my hypothesized model (please see Appendix K). The hypotheses I presented in the preceding chapter address each of the proposed paths. Having confirmed the validity of my latent variables and their respective observed indicators, I proceeded to add the observed variable of web analytics use. The hypothesized model, grounded in both theory and my qualitative results, fits the data well, $\chi^{2}(160)=246.48, p<.001 ; R M S E A=.05$, $P C L O S E=.418 ; C F I=.96 ; T L I=.95 ; E C V I=1.885$. However, it still contained nonsignificant estimates that had to be cleared for parsimony (Byrne, 2010). This process yielded a simpler model, one that is still consistent with my theoretical framework but also with unexpected relationship patterns (please see Appendix L).

$\mathrm{H} 2$ predicted that one's perception of the degree of competition would affect conception of the audience. This is not supported. H3 predicted that this perception of competition would also affect the extent of web analytics use. This is supported, $\beta=.22$, $p<.01$. H4 predicted the extent of web analytics use would affect conception of the audience, leading to conception of the audience as economic capital more than as symbolic capital. This is not supported.

H5 predicted that the extent of web analytics use would lead to particular patterns of integration of web metrics in news construction, particularly a) site-oriented, b) trafficoriented, and c) content-oriented uses. Only H5a and H5b are supported: Those who use web analytics more often tend to engage in site-oriented $(\beta=.46, p<.01)$ and traffic- 
oriented $(\beta=.22, p<.001)$ uses of web analytics more than those who use analytics less often. Web analytics use did not predict content-oriented use. This shows that the adoption of web analytics does not directly translate into its normalization, or using technology in editorial decisions. The use of web analytics, at best, directly leads to its practical applications of running the site and keeping track of traffic.

So what predicts integration of web analytics into the decision-making process? H6 predicted that the conception of the audience as a form of economic capital would lead to a) site-oriented and b) traffic-oriented uses of web analytics. Neither is supported. $\mathrm{H} 7$ predicted that conception of the audience as a form of symbolic capital would lead to content-oriented use of web analytics. This is supported, $\beta=.18, p<.001$. Conception of the audience as a form of symbolic capital directly predicts using web analytics in content-related decisions, such as determining stories to write about.

The final model also showed other significant pathways that were not included in the original set of hypotheses. First, there was a significant link from conceiving of the audience as a form of economic capital to conceiving of the audience as a form of economic capital, $\beta=.43, p<.01$. This is consistent with my interpretation of my qualitative results, that editors perceived the audience primarily as economic capital, but that with the current reality of the online platform still not making revenues as much as the print platform, growing the audience as a form of symbolic capital comes with the hope, if not expectation, that symbolic capital would soon be converted into economic capital. If we focus on this particular pathway, from economic capital to symbolic capital to content-oriented use of web analytics, we see a move from perception to action. The general conception of the audience as a form of economic capital leads journalists to 
conceive of the audience at present as a form of symbolic capital that then leads them to integrate audience feedback in the form of web metrics in their news work.

This is parallel to the other pathway from perception of competition to adoption of web analytics to site-oriented and traffic-oriented uses of web analytics. An awareness of the reality of the journalism business leads to adoption of new audience information systems that leads to practical uses of technology (please see Appendix L).

Second, an interesting relationship exists between the three types of web analytics use that was not included in the original set of hypotheses. Traffic-oriented use leads to content-oriented use $(\beta=.60, p<.001)$, which leads to site-oriented use $(\beta=.47, p<$ .001). It appears that while integrating web metrics in editorial decisions is directly influenced by conception of the audience as symbolic capital, it is also indirectly affected by an awareness of the changing field that has made adoption of web analytics inevitable. Exposure to web traffic exposes editors to audience preferences, which then leads to a renegotiation of editorial judgment that now incorporates this awareness of what the audience wants, which then leads to maintaining the site for users.

\section{Explaining Social Media Use}

The final set of hypotheses focused on social media and how they were being integrated in the news construction process. In the structural model, I adopted the same predicted interrelationships between perception of competition, conception of the audience, and web analytics use. Subsequently, I predicted that web analytics use will predict use of social media (H9), consistent with my qualitative results of how information about performances of stories based on web traffic inform use of social media for content promotion, among other things. 
The hypothesized model tried to predict promotion and engagement uses of both Facebook and Twitter, which were considered separate but related latent constructs as confirmed by the earlier measurement model that I discussed (please see Appendix M). It did not fit the data well, $\chi^{2}(393)=932.18, p<.001 ;$ RMSEA $=.08$, PCLOSE $<.001$; $C F I=.84 ; T L I=.82 ; E C V I_{\text {default model }}=5.54 ; E C V I_{\text {saturated model }}=4.83$. Therefore, $\mathrm{I}$ turned to the modification indices to see possible sources of misspecifications (Byrne, 2010). Following this process, I proceeded to test Model 2 that displayed a good fit to the data, $\chi^{2}(383)=569.32, p<.001 ;$ RMSEA $=.05$, PCLOSE $=.592 ; C F I=.94 ; T L I=.94 ;$ $E C V I=3.87$. The chi-square difference between the two models was significant, $\chi^{2}(10)$ $=362.86$. However, Model 2 also had non-significant parameters that had to be removed for model parsimony (Byrne, 2010).

The final model was similar to the web analytics model, in that conception of the audience as economic capital leads to conception of the audience as symbolic capital, and that perception of competition leads to adoption of web analytics. However, perception of the field did not predict social media use. H8 is not supported (please see Appendix N).

$\mathrm{H} 9$ predicted that the use of web analytics would predict use of social media. This is supported, $\beta=.21, p<.01$. H10 predicted that conception of the audience as a form of economic capital would predict promotion-oriented use of social media in news work. This is not supported. H11 predicted that conception of the audience as a form of symbolic capital would predict engagement-oriented use of social media in news work. This is also not supported. Conception of the audience as a form of capital did not predict patterns of social media use. Instead, social media use predicted using it for promotion purposes for both Facebook $(\beta=.37, p<.001)$ and Twitter $(\beta=.31, p<.001)$. Thus, 
editors who used social media a lot tend to use it for promoting content, consistent with the normalization hypothesis. However, social media use does not directly lead to using either Facebook or Twitter for engagement. H12b is therefore not supported. Instead, promotion-oriented use leads to engagement-oriented use for both Facebook $(\beta=.59, p<$ $.001)$ and Twitter $(\beta=.65, p<.001)$. Thus, the obvious use of social media to promote news organizations leads to using social media for engagement. In effect, usefulness of social media to increase traffic is a prerequisite to a realization that it can also be used to engage audiences, itself a form of increasing brand loyalty.

It begs the question as to why conception of the audience as a form of capital influenced patterns of web analytics use but not social media use. Though they both provide forms of audience feedback, the kinds of feedback they supply differ as I have demonstrated in my qualitative results. How this difference, and other factors, account for this divergence of pathways from conception of the audience to patterns of web analytics use on one hand and patterns of social media use on the other is further explained in the concluding chapter. 


\section{Conclusion}

This study is generally interested in understanding the influence of the audience on the news construction process. I argued that with how much the audience has evolved, and with the new ways that journalists keep track of their audiences, this influence on the gatekeeping process has grown stronger. No longer is this influence mediated solely by how journalists imagine the audience, for preferences of the online audience are now directly communicated to the newsroom through new audience information systems: web analytics and social media. There is still guesswork involved-journalists still imagine audiences based on metrics and then segment audiences based on these constructions. But even these constructions are now largely based on metrics from the actual audience. Therefore, the crucial question is not whether the audience exerts any influence on the news construction process, but how this influence comes about.

\section{The Mechanism of Audience Influence}

I proposed a framework looking at the mechanism of influence on gatekeepers, arguing that mechanisms operate at the individual level, even as journalists exist within social and occupational settings (Breed, 1955; Reese \& Ballinger, 2001). I borrowed the assumptions of field theory (Bourdieu, 1993, 1998, 2005), arguing that journalists participate in a struggle within the journalistic field by accumulating forms of capital. This makes capital as both the means and the ends in this constant struggle, for it is needed for participation — if not survival — and is therefore also constantly sought (Bourdieu, 1986; Emirbayer \& Johnson, 2008). When agents in the field perceive 
instability in their capital, they become open to the influence of forces external to the field.

The audience, however, is not only a force that can increase or decrease journalistic capital, for it can also be conceived of as a form of capital itself. This is particularly because of the business model that has sustained traditional journalism, which journalists also hope, if not expect, to sustain digital journalism. This reliance on advertising revenues, determined by the purchasing power of accumulated audiences, turns the audience into a form of economic capital. Journalism, however, is also considered the fourth estate (Schultz, 1998). The normative ideals of the press speak of social responsibility rooted in editorial autonomy, which then looks at the audience as the public to be served. The audience then becomes a form of symbolic capital for journalists. In the end, what matters is how journalists conceive of their audience (de Sola Pool \& Shulman, 1959; Ettema \& Whitney, 1994), for perceptions in the journalistic field influence actions (Born, 2003). Thus, with respect to the audience as a force in the gatekeeping process, this is a mechanism of influence based on capital accumulation: how journalists conceive of the audience as a form of capital can influence the extent to which they allow audience preferences to impact their news work.

I demonstrated this mechanism in this study: Faced with the reality of declining economic capital for traditional journalism still unmatched by the slow increase in digital revenues, journalists clearly perceive capital instability within the journalistic field. This instability is leading journalists to open up to influences from the audience, in the form of audience preferences as communicated through web analytics and social media. This perception of instability, along with their conception of the audience as a form of capital 
crucial for survival, shapes the extent to which they incorporate audience feedback in their news work. I engaged in theory development to refine this framework, using observations and interviews with online editors. I subsequently tested this refined framework using survey data from online editors in the US, specifying a model of this mechanism, and refining it during analysis. The framework remained consistent throughout all the stages of this mixed methods study: conception of the audience as a form of capital leads journalists to integrate audience feedback in their news work. This, however, is just one pathway through which the audience exerts its influence.

\section{Web Analytics and Social Media}

Online editors use web analytics mainly to keep track of audience behavior, but what they do with this information is what affects editorial decisions. Metrics are being used for editorial decisions such as story selection, story placement, and even headline writing. The survey findings showed that online editors still use web analytics primarily for monitoring traffic, but this application is leading them to use information from the audience in their decision-making processes. Social media, particularly Facebook and Twitter, are used mainly for promoting stories, although some editors, to a limited extent, also use these platforms to interact with the audience. For example, they use it for crowdsourcing, particularly by seeking comments, photos, videos, or information about particular stories. This use, however, is still rooted in the logic of promoting the organization, of cultivating audience loyalty — a strategy to increase symbolic capital that is a loyal following hoped to be transformable into economic capital that is online traffic and the revenues it can bring. In general, social media use in the newsroom remains to be oriented to increasing traffic to the website. 
It is in content-promotion that web analytics and social media use intersect. Web analytics allows journalists to keep track of stories that attract a lot of traffic. But through web analytics, editors also get to see stories that are not attracting traffic. A way to increase traffic on these unpopular stories, particularly if editors judge them as stories that are important, is promoting them on social media. This is a classic example of normalization of technology—combining the affordances of web analytics and social media consistent with the conventional role of journalists to supply the audience of what they think the audience ought to know (Heinonen, 2011). This way, web analytics and social media are complementary tools for journalists to enact their normative roles, consistent with the hypothesis of normalization.

\section{Normalizing or Negotiating?}

Journalists are not exactly known to be early adopters of technology, and studies showed that when they adopt new communication technologies, such as blogs and social media, they tend to normalize it, adapting new technologies to fit into their existing norms and routines (Lasorsa, et al., 2011; Susan Robinson, 2006; Singer, 2005). Online editors at the three newsrooms where I observed have embedded web analytics and social media in their online news cycles. They routinely checked their social media accounts for comments and web analytics software for metrics. Journalists have long been trying to understand the audience through audience research, and now they do this through web analytics. They also have long been disseminating content, and now they can also do it through social media. But these new audience information systems have also required journalists to reorganize their routines. In my observations, online editors talked about how reporters should tweet about a story first before actually writing it. Budget meetings 
started with a quick glance of web analytics data. Journalists are not only inserting new audience information systems into existing routines, but they are also seeing their routines change around these technologies.

Thus, discourse on normalization should look beyond just the use of technology. A basic question in the normalization hypothesis is to which norms are journalists normalizing. For example, social media were used in the newsrooms I observed mostly to promote news content. These social media posts included links that directed readers back to the website. I found the same pattern in my online survey that showed editors ranking promotion-oriented use of social media higher than engagement-oriented use. This use is an example of an asynchronous, top-down logic that has dominated traditional journalism. This is consistent with the idea of dissemination instead of conversation. However, an implication of this normalized use of technology is a reworking of journalistic roles at the individual level. The journalist now finds herself as a marketer, to some extent, of her own work. This is inconsistent with the once sacred divide between editorial and marketing, between editorial autonomy and business strategy.

The use of web analytics is another example. Journalists have normalized the use of web analytics in the newsroom, with numerous editorial decisions now routinely being based on web metrics. But the exposure of journalists to web analytics data that detail preferences of the audience is feared to compromise the norm of editorial autonomy. Set against the backdrop of decreasing economic capital for the journalistic field as a whole that has made increasing online traffic an imperative for many online newsrooms, knowing what the audience wants has led to headlines about Amanda Bynes' vagina or top stories about Miley Cyrus' twerkings. As my survey results showed, the use of web 
analytics to monitor traffic leads to the integration of metrics in content-related decisions, as awareness of what the audience wants makes it easier for journalists to increase traffic by giving in to these preferences. And yet based on my observations, some editors also used web analytics to determine articles that were important but were not attracting traffic, so that they can promote it, place it more prominently on the site, or update it to get the attention and traffic they think these articles deserved. This use of web analytics is consistent with the norm of privileging editorial judgment, of using technology outside the routine use of monitoring traffic but within a traditional journalistic norm-in a way, normalizing it. In contrast, seeking to increase traffic by giving the audience what they will likely click on betrays the norm of editorial autonomy. However, these contrasting uses of technology now co-exist in many newsrooms, for while editorial autonomy still dominates the newsroom, market logic is also a traditional norm on the other side of the narrowing editorial divide.

Journalists are also using social media to engage the audience by providing an avenue for some interaction. This constitutes a reworking of the norms, giving rise to what Heinonen (2011) referred to as the dialogical role of journalism. The gates, so to speak, are opening up to the audience. But based on my observations, online editors interacted with the audience and paid attention to their comments on social media, which are third party platforms, instead of within their own editorial space, such as the online comments sections on their own websites. This is a form of territorializing - editors interacting with the audience outside their protected journalistic space. This is a form of compromise - a negotiation instead of normalization. Faced with the novel affordances 
of new audience information systems, journalists are renegotiating their norms. They are balancing editorial autonomy and the increasing influence exerted by the audience.

Journalists have integrated audience feedback into their news judgment—filtering it, sorting it, mediating it. They do not see this process as them being influenced by the audience. In order to protect editorial autonomy, they are instead renegotiating their other norms, such as what constitutes newsworthiness. They are also redefining what it means for a story to do well.

\section{Pathways to Negotiation}

This balancing act, as documented in the results of my case study, is clearly seen from the structural model explaining web analytics use based on my survey. The integration of web metrics in editorial decisions, measured by the content-oriented use of web analytics, flows from a journalist's conception of the audience: considering the audience as a form of economic capital leads to considering the audience as symbolic capital, which then leads to content-oriented use of web analytics (please see Appendix L). This is the mechanism of influence through capital accumulation. The pathway from economic capital conception of the audience to symbolic capital conception is also consistent with the results of my qualitative study, for while journalists considered the online audience as economic capital, the online platform is still not the money-maker they want it to be, and accumulating audience as a form of symbolic capital comes with the expectation that symbolic capital in the present can be converted into economic capital in the immediate digital future.

But a parallel pathway also starts from the perception of the degree of competition faced by one's organization that leads to adoption of web analytics that then leads to 
using web analytics for its obvious applications: monitoring traffic and keeping the website functional. Traffic-oriented use of web analytics then leads to content-oriented use (please see Appendix L). This shows that a consequence of being exposed to audience preferences by monitoring traffic is using this information for editorial decisions. Thus, while one pathway to integration of audience feedback into news work is through an individual's agency, consistent with the mechanism of influence through capital accumulation that operates at the individual level, another pathway is through constraining structures - in this case the influence of perceived competition and the presence of technology. In other words, while a journalist retains individual agency to mediate the impact of audience feedback on her news work through her conception of capital, she also faces organizational and socio-institutional structures that make acts of negotiation unavoidable, leading her to open up the gates to accommodate the audience.

These constraints also come in the form of how the changing journalistic field is changing expectations of the online journalist. There is no longer a deadline, so to speak. Breaking news stories have to be uploaded ahead of everyone else. They have to be tweeted out as soon as possible, even before the actual story is written. The website also has to be refreshed when traffic goes down. To a large extent, every minute becomes a deadline during a busy day. There is also no longer a single responsibility that comes with a particular job. The editor-in-chief is now a strategist as much as a journalist. The web editor now has to manage content within and outside the website, outside referring to social media. She also needs to edit articles, photos, photo galleries, videos, and infographics. On top of that, she needs to keep track of what the audience wants. Faced with a seemingly unlimited amount of tasks in such a limited time, journalists try to survive by 
routinizing their work. This makes news work manageable. But this also takes them away from the much-needed pause, reflection, and thought that have marked what are considered the best pieces of journalism ever produced. This also provides them an excuse, so that the institutionalized routine can be blamed, when routines are also social constructions. They are structured in as much as they structure actions.

This is not an apology on behalf of online journalists, for as what the quantitative findings showed, organizational constraints are parallel with individual agency. This is not to blame the daily reality they face and the organizational setting they inhabit, but this is rather a realistic depiction of the context within which they make or unmake decisions that can collectively make or unmake journalism. This is understanding why they do what they do, particularly with their use of web analytics, a game-changer in the journalistic field, for it is through this understanding that the field itself can look at how much it has changed and whether or not this trajectory determined by a will to survive is something that will indeed keep journalism alive. The question is interestingly the same for journalists and their audiences: Is this the journalism we want—or is this the journalism we need? If we allow and facilitate more and more changes to journalism, what will guarantee that the final product of this negotiation process will remain to be the journalism that we believe in?

\section{The Anomaly with Social Media}

The discourse on journalists' agency with respect to determining patterns of web analytics use in their news work is consistent with the focus on individuals in the analysis of the mechanisms that underlie the processes of news construction. And yet what is intriguing is how the individual route is missing in the structural model that explains 
social media use (see Appendices $\mathrm{M}$ and $\mathrm{N}$ ). Only the pathway from perception of the field, to adoption of analytics, to adoption of social media, to promotion-oriented use of social media, and then to engagement-oriented use was present. The pathway from analytics use to social media use is consistent with the intersection for content promotion that exists between these two types of audience information systems. But conception of the audience was not a significant predictor of any of the two types of social media use in news construction.

There are three main differences between web analytics and social media. First, web analytics provides immediate and quantifiable forms of audience feedback directed to the website being monitored, compared with social media feedback that ranges from qualitative comments to trending issues that cut across multiple sources and websites. Second, web analytics is an organizational-level adoption, while social media ranges from organizational to individual. In the survey, most of the respondents reported using official social media accounts for their newsrooms instead of just their personal accounts, but they also maintain their own personal social media accounts, so that the use of one might be influencing the use of the other. Finally, it seems that the use of web analytics to monitor audience preferences is more straightforward than the use of social media for a similar purpose. To a large extent, social media are considered as platforms for promotion, a push rather than a pull model, for even the use of social media for engagement remains to be for the purpose of promoting the brand. It appears that conceptions of the audience as a form of capital exerts some impact, at least so far, only with respect to editorial decisions where journalists need to balance personal judgment 
with other factors, and not very much on content promotion, which remains to be an organization-oriented activity.

The survey respondents in this study are also editors — and reporters might be using social media in a different manner. This is another plausible explanation to the final structural model for social media use. Reporters might be using social media for crowdsourcing more than editors do just because of the nature of their jobs. Thus, future studies should also look at how reporters use social media in their news work.

\section{Gatekeeping Implications}

Online journalists are accommodating audience feedback in their editorial decisions, motivated by their conception of the audience as a form of capital and facilitated by the structures built around the affordances of new audience information systems, thereby further increasing the influence of the audience on the gatekeeping process. The process of negotiation with the affordances of technology is facilitating this increasing influence of the audience on traditional gatekeeping processes. Gatekeeping explains the process of news selection, of what pieces of information gets in and what is left out. Online editors now incorporate what they know about audience preferences in their selection of stories to prioritize on the homepage.

But online news operations are also demonstrating a new process of selection. The limited space on the homepage and the need to keep it fresh requires editors to engage in a process of de-selection, deciding which among articles that have made it through the gates and ended up on the homepage will be taken out of the homepage to be replaced by a new story. Unlike in the process of selection, where editors try to balance editorial judgment with audience preferences, the process of de-selection, at least based 
on my observations, is largely determined by audience metrics. An editor from the second newsroom specified a particular window of time he gives a story. If it does not perform well within that window of time, the story will be replaced. News judgment for the process of de-selection has been replaced by a metric-based logic, where a story needs to outperform others based on traffic instead of outweigh other articles based on substance or importance as reflected on by a gatekeeper.

The process of gatekeeping has traditionally considered the journalist as the gatekeeper, the one who controls news selection. But gatekeeping no longer ends at selection, for online gatekeeping now requires de-selection. Furthermore, publication is no longer the culmination of the gatekeeping process. Shoemaker and Reese (2013) argued: "The audience is the ultimate consumer of the media product - the end of the news process" (p. 177). But the online audience, confronted with a seemingly unlimited source of information, has become harder to reach. Furthermore, while the internet seems to be a limitless portal of information, it has also developed its own winnowing processthe search engine. In my observations, I came across editors figuring out the best headline not based on traditional rules of journalistic headline writing, but based on the rules of Google, the most popular search engine, similar to what Dick (2011) had found. The social media editor at the second newsroom asks reporters to start a Google+ account not because it is a popular social media site — which it is not—but because it will help reporters turn up higher on Google searches. To some extent, the gatekeeping process of news is finding itself within a larger field outside the journalistic field - a larger field with its own set of logic and its own gates that journalists also find themselves having to 
hurdle. Journalists now have to navigate not only the market logic of increasing online traffic, but also, to some extent, some form of Google logic.

\section{Methodological Implications}

This study is not without limitations. First, my case studies were limited to the access allowed by the three newsrooms I observed. For example, my observation period at the second newsroom was cut short to only about three days while the first newsroom allowed me to stay for almost two weeks. But in studying multiple cases instead of one case, I was able to fully develop my concepts through the process of methodological replication (Yin, 2009). Second, the survey was also limited to the willingness of the online editors to participate. Their responses were also self-reports and were dependent on how willing they were to share information about their work. Anticipating this, I started this research with my case studies, so that empirical observations of how online newsrooms worked informed the questions I asked in the survey.

The case study methodology has weak external validity, but it allows holistic analysis. The survey method addresses issues of external validity with its breadth of observations but at the expense of depth. In combining these two approaches in this mixed methods research, I sought to draw from their individual strengths to be able to thoroughly understand the impact of new audience information systems on the news construction process. I experienced the advantages of being in the newsroom to observe and understand the news construction process, consistent with what Paterson (2008) argued, that only ethnographic methodologies "can come close to providing an adequate description of the culture and practice of media production, and the mindset of media producers" (p. 2). Interviews allowed me to understand the editors' beliefs and 
interpretations, but many of these were ideals that, as I found in my observations, are difficult to carry out within the constraints of the daily news routine. The case study approach was particularly appropriate for the goal of theory development. But the survey also allowed me to develop my proposed theoretical framework further by empirically testing it, thereby coming closer to the ideal of theoretical generalization of the case study approach.

\section{Theoretical Implications}

Shoemaker and Vos (2009) outlined how gatekeeping research can benefit from the framework of field theory. They are joined by a growing number of journalism scholars pointing out the appropriateness of field theory in understanding the complexities of the news construction process (Benson, 2004, 2005, 2006; Benson \& Neveu, 2005; Siapera \& Spyridou, 2012; Willig, 2013). This study also demonstrated how gatekeeping theory could explain the mechanism of influence on gatekeepers through the concepts of field theory.

The mechanism of influence through capital accumulation, as proposed in this research, allows a better understanding of how journalists get influenced. I tested this framework by focusing on audience influence on the gatekeeping process. This mechanism can also be tested to account for the influence of other forces. State control, for example, creates a fragile stockpile of economic capital, especially if the government finances the media. The state can threaten to decrease economic capital, which can open gatekeepers to being influenced. It also affects other forms of capital. For example, a press controlled by an oppressive government also loses its grip on its symbolic capital. A way to advance theorizing on influences on journalists is to consider that capital 
instability goes both ways: a force can threaten to either decrease or increase journalistic capital. In this study, conception of the audience as a form of capital takes into consideration both directions, for growing the audience by offering them click-bait stories can increase economic capital at the expense of symbolic capital, and ignoring audience preferences might decrease both.

The findings of this study echo what Born (2003) had concluded: that in the journalistic field, projections of the future can affect actions in the present. This highlights the importance of the concept of habitus, a concept that is complicated, difficult to measure, and is often taken for granted in discourses about news construction. This is plausibly rooted in the problematic norm of objectivity that has dominated the journalistic field that takes a journalist's personal context out of her news work, and, to some extent, in the omission of the central role of the individual in the sociology of news. Field theory is considered a holistic framework studying the journalistic field as a whole and how it relates to other fields. And yet its concepts clearly operate at the individual level, where mechanisms of influence operate. I echo the argument that "explanations must offer causal mechanisms, and the mechanisms must pass through individuals (but may not reduce to them) to connect to action" (Parsons, 2007, p. 25).

Finally, the findings of this study have theoretical implications even outside field and gatekeeping theories. For example, the discussion on the growing consciousness among journalists to give the audience what it will likely click on - a strategy for survival in a field marked by decreasing economic capital—betrays the agenda-setting function of the media (McCombs \& Shaw, 1972; Shaw \& Martin, 1992). Setting the agendaincreasing the salience of an issue among the public — is an "awesome responsibility" 
(McCombs, 2005, p. 556). It also carries a normative implication: Journalists are in a position to direct public attention to important issues. But how can journalists perform this function when editorial decisions are increasingly informed by what the audience wants? How should we define the media agenda in a period when journalism increasingly relies on a click-based logic?

\section{Practical Implications}

Finally, as early as during the planning stage, I envisioned this study to be useful to both scholars studying the evolving news construction processes and to the journalists who engage in them. This is most likely based on my background as a journalist and as a student of journalism. Students of journalism, such as myself, will hopefully find the theoretical framework I proposed, tested, and refined useful not only in the study of audience influence on news construction but also in the study of other gatekeeping influences. Agents of the journalistic field, such as myself, will hopefully find my description of the online news processes I observed relatable, if not illuminating. In trying to make the "strange familiar and the familiar strange" (Tracy, 2013, p. 119) by examining taken-for-granted routines and norms through the prism of gatekeeping and field theory and by pinpointing and shedding light on emerging rules and routines, I hope this study can jumpstart some form of self-reflection among online editors caught up in their ever-evolving and demanding routines.

I hope more and more journalists will ask and answer questions they usually take for granted. Why are we doing what we do? For while it is true that there are many things beyond their control, individual agency also shapes news work. There is empirical evidence to support this (please see Appendix L). What does the audience mean to us? 
Future explorations in the area of audience influence on gatekeeping should also consider the ethical implications of using web analytics and social media. In this study, I have demonstrated how journalists are using new forms of audience feedback in their news work and why. I have also hinted at direct and immediate consequences of these usage patterns on the gatekeeping process. But how do new routines and norms that are brought about by the negotiation process between editorial autonomy and audience influence impact the kind of journalism we produce, consume, and expect?

\section{A Final Twerk}

Journalism, to some extent, is twerking.

The Online Oxford Dictionary defines "twerk" as an informal verb that means to "dance to popular music in a sexually provocative manner involving thrusting hip movements and a low, squatting stance" ("Definition of twerk in English," 2013)

The journalistic field, threatened by its shrinking social capital, is dancing to the popular music of consumer-driven logic, for it appears - at least so far - that this is the only way to survive. Still dependent on an advertising-driven business model, online journalism finds itself having to chase online traffic, a routine made possible and further enabled by new audience information systems. In order to attract an audience no longer loyal to legacy news, for information is abundant and free in the seemingly unlimited online space, journalism dances in a provocative manner-publishing stories about the wildest celebrities, uploading adorable and outrageous cat videos, highlighting salacious headlines - hoping to attract attention, to increase traffic. For media critics, this is a low, almost squatting stance, for an institution that relies a lot on respect and reputation. For a few others, this is journalism trying to survive. 
Let me return to where I started this dissertation.

The satirical piece published by The Onion that criticized CNN.com's decision to put the Miley Cyrus twerking story as its main story on August 26, 2013 had this funny but chilling proposition: "So you see, there's no stopping this. And what is this, you ask? Modern-day journalism. And what is modern-day journalism? Getting you to click on this link" (Onion, 2013).

The satirical article contains an actual link, and it takes the reader to the original story on CNN.com, already relegated to the entertainment section. But for a few hours on that Monday morning, in this age of "modern-day journalism," online readers read this headline, splashed on the homepage of a news organization that prides itself as "the worldwide leader in news."

"Miley Cyrus twerks, stuns VMAs crowd." 


\section{A Researcher's Habitus}

This dissertation pushed me, in many ways, out of my comfort zone.

The research process was fun and stressful, exciting and nerve-racking, humbling and fulfilling. Being a journalist myself, I have always been passionate about studies of news construction processes. This background might have served as the lens through which I conducted my observations, drafted questions for my interviews, analyzed my qualitative data, and even phrased the items in my survey questionnaire. Lenses, to some extent, can affect what we see. But it is also through them that we get to see clearly.

In this section, I document my process of reflexivity, where researchers "critically think about their role in the research process" (Brennen, 2013, p. 169). It refers to the ideal of how researchers "should be aware of the opinions and biases they bring to the research and of the way these inevitably impact the scene and the data collected" (Tracy, 2013, p. 255). In effect, the concept of reflexivity asks researchers to reflect on their own habitus to locate themselves and their roles in the - quite literally-field.

\section{My Habitus}

My background is more than just my six years of experience as a newspaper journalist. I am also a 30-year-old postgraduate student from the Philippines who looks as Filipino as I can get. I spoke with a different accent. I tried to blend in during my observations. But inside three newsrooms composed of mostly White Americans, I looked different. I felt different. One time, I sat a meter away from the rectangular desk where all the editors at the second newsroom were gathered for their budget meeting. The 
managing editor looked at me and said: "Please don't discuss with anyone anything you will hear today." I smiled at her and nodded my head. In the afternoon meeting, a college intern, a white American girl, was introduced to the same group. The editors started joking with her. The managing editor asked her about school. But she never warned her about confidentiality. I was different. I felt different.

I also come from a culture that is very deferential, particularly based on seniority. In my fieldwork, I had to overcome my shyness to introduce myself to people I have never met before and request to observe them, and spend time with them during interviews. For example, I felt intimidated by the managing editor at the first newsroom. He was tall and spoke with an authoritative voice. He was the one who granted me access, and yet I felt shy talking to him. One time he offered me some donuts. I politely declined, despite the fact that I loved donuts. I was more comfortable talking with editors about the same age as I am. However, as the days went on, as I spent more time in the field, I gained more and more courage, that one time when I ran across the editor-inchief, I finally introduced myself and requested an interview. He finally knew who was the stranger he had been seeing show up at the budget meetings in the last three days.

\section{Cultural Capital}

The managing editor of the first newsroom called me a "college kid" one time, despite my previous emails to him introducing myself as a doctoral student. But somehow, that worked to my advantage. When he sat down with me, the managing editor explained to me his work detail by detail. He showed me how he used web analytics, and even did an experiment for me to show how some social media strategies could quickly draw traffic. I have read about web analytics. I tinkered with Adobe's Omniture. But I 
have never used web analytics formally. So being treated as a college student worked to my advantage, because there were many things I did not know.

I asked a lot of questions, even during my observations, and the editors I observed patiently answered all of my queries. On hindsight I think it was because I sounded really curious, and I really was, but also probably because in their minds, I was a college kid who was observing a newsroom for the first time.

This was my first time to conduct participant observation. I learned the method from a few classes I took. I read a lot of textbooks and examples of case studies. I even taught a qualitative methods class. I started my participant observations feeling well prepared, although I still brought my favorite case study textbook with me. But I guess nothing prepares for the real thing — except the real thing. On my fourth day of observation, when the excitement finally waned off, I got into a serious bout of selfdoubt. Am I doing it right? Do people here like me? Can I get editors to sit down with me for interviews? The best antidote, I realized, was to keep on going. I was focused on my research goals, and I ended up interviewing 15 people from the first newsroom.

Interviewing is something I have been used to, particularly as a journalist. And yet as a qualitative researcher I was also aware of how respondent interviews differ from journalistic interviews. I had to ask questions whose answers might seem so obvious to me, considering my journalism background. I had to alert my interviewees beforehand that I had to ask those types of questions because I was more interested in what they thought than in what I knew.

I wrote my field notes the night right after each day's worth of observation. This allowed me to write what I saw, heard, and even felt, as soon as possible, while the 
scenes, dialogues, and feelings were still fresh in my memory. I also engaged in constant memoing — jotting down patterns, ideas, and realizations in between my observations. I also used NVivo for my analysis. This was the first time I used a computer-assisted qualitative data analysis software (CAQDAS) in my research. I also conducted a full structural equation modeling for the first time for my quantitative analysis. In many ways, I managed to push my limits in this research.

\section{Social Capital}

When I finally overcame feeling shy, I realized that many people at the first newsroom were actually very nice. One editor asked me to come to his office to talk about Manny Pacquiao, a well-known Filipino boxer. A digital editor managed to get me my own identification card that worked as a gate pass, complete with the company lanyard, despite an initial refusal from the human resources office that issued IDs. Many editors started calling me by my first name. They started treating me as one of them.

The metro editor started giving me my own copies of the budget list. I sat next to the editors during budget meetings, but I never spoke. I was there. The editors welcomed me. But consistent with my observer-as-participant stance, I did not want them to notice me. I wanted them to act as normal as possible, and to a large extent I think I achieved this goal. It is a funny irony, I think, that when they start seeing you at the newsroom every day is when you start disappearing to them as a researcher, becoming part of their routine.

I had a great time at the first newsroom, probably not so much at the second newsroom. My contact person cut short my observation period. She started thinking I was spying for the competition. It was not very pleasant. But it was also beyond my control. 
To some extent, when we enter the scene, we are at the mercy of our contact persons. I was able to observe a full news cycle and talk to eight people, including the company's publisher, who was very accommodating. But I realized when we enter a scene, not everything goes our way. Sometimes, the best response is just to accept that.

Therefore, I did not know what to expect when I showed up at my third newsroom. But it turned out that the editors I observed there were very accommodating. One editor was just hilarious and would always trade jokes with me all the time. To some extent, being different in that setting was being cool, as I felt these editors were happy to interact with someone from the outside world, so to speak.

\section{And Some Sort of Economic Capital}

Observing at three newsrooms was a great learning experience, not just for the purpose of my research, but also for the purpose of how research goes about. I was fortunate that for the most part, I came across accommodating and helpful individuals, a few of which I remained in contact through email and Twitter after I exited the scene. Another surprise came from my experience in inviting participants to my online survey.

I sent emails to a random sample of online editors. I offered a $\$ 10$ gift card of their choice between Amazon and Starbucks. But one third of my participants chose the option that said: "No need to send me anything." I received a few emails that told me they were withholding their email addresses, which I requested in the survey for the purpose of sending gift cards, because they were happy to help and there was no need for any remuneration. I did not consider the gift cards as a form of remuneration. But at best, I think it conferred legitimacy to my study, by showing my commitment to my research by displaying some form of funding, some form of economic capital. 
I also got emails from people who had to decline my invitation, many of them saying information on web analytics was proprietary in nature and their companies would not allow them to take the survey. I appreciated the effort to let me know, instead of just ignoring my email. I got one email one midnight that dropped me the f-word. It was the exception, however. In general, I was amazed by how nice and friendly a lot of people were as they took time to help out a student they did not personally know.

This research pushed me out of my comfort zone, but it also eventually made me feel comfortable, with me coming across many different types of people only similar in their willingness to help.

Faith in humanity—and research—restored. 


\section{Appendices}

\section{A. Proposed Mechanism of Influence}

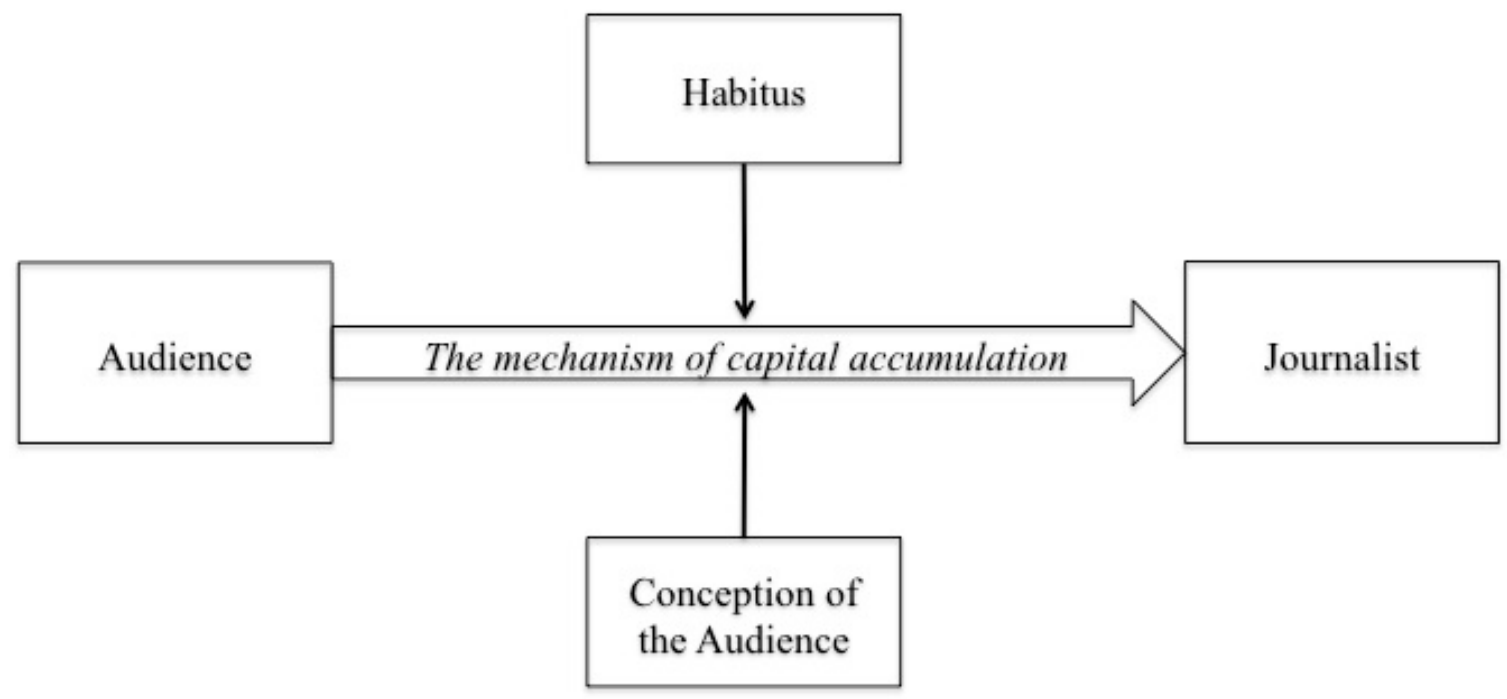




\section{B. Study Outline}

\begin{tabular}{|c|c|c|c|c|}
\hline $\begin{array}{l}\text { Building } \\
\text { theory }\end{array}$ & $\begin{array}{l}\text { October } \\
2012 \\
\text { November } \\
2012\end{array}$ & $\begin{array}{l}\text { Literature Review } \\
\text { Case study planning }\end{array}$ & Coordinating & \\
\hline $\begin{array}{c}\text { Theory } \\
\text { development }\end{array}$ & $\begin{array}{c}\text { March } \\
2013 \\
\text { May } 2013 \\
\text { June 2013 } \\
\text { August } \\
2013 \\
\end{array}$ & $\begin{array}{c}\text { Case study } 1 \\
\text { Case study } 2 \\
\text { Case study } 3 \\
\text { Data analysis } \\
\text { Data interpretation }\end{array}$ & $\begin{array}{l}\text { Initial coding } \\
\text { Coding } \\
\text { Memoing }\end{array}$ & $\begin{array}{l}\text { Planning survey } \\
\text { Drafting survey } \\
\text { Pretesting survey }\end{array}$ \\
\hline $\begin{array}{l}\text { Theory } \\
\text { testing }\end{array}$ & $\begin{array}{l}\text { September } \\
2013 \\
\\
\text { October } \\
2013\end{array}$ & $\begin{array}{l}\text { Member checks } \\
\text { Writing the report }\end{array}$ & & $\begin{array}{c}\text { Conducting } \\
\text { survey } \\
\text { Following up } \\
\text { Data analysis } \\
\text { Interpretation } \\
\text { Writing the } \\
\text { report }\end{array}$ \\
\hline
\end{tabular}




\section{Interview Guide}

Thank you for agreeing to participate in my study! Your thoughts and opinions will be very valuable. I am a $\mathrm{PhD}$ in Journalism candidate at the University of MissouriColumbia. For this project, I am interested in exploring the decision-making processes of journalists. I am particularly interested in how web analytics data figure in your news routines. Our interview will be tape-recorded but none of your responses will be identified with you in either the transcript or the final paper.

Again, your participation is voluntary and you can opt out at any time you want. If you have questions about your rights as a study participant, or are dissatisfied with any aspect of this study, you may contact, anonymously if you wish, the Campus Institutional Review Board, 483 McReynolds, University of Missouri, Columbia, MO 65211, (573) $882-9585$

I will now start asking you a few questions:

\section{Rapport-Building}

1. How long have you been working as a journalist?

2. How long have you been working with this news organization?

\section{Non-directive Questions}

1. How would you describe your typical day as a journalist?

2. In the routines you mentioned, do you get to encounter some sort of feedback from the audience? How? Can you cite some examples?

3. How important is the audience in your work as a journalist? What made you think this way? (probe for conception of the audience as a form of capital)

4. What is your organization's policy in terms of audience feedback, if any? How do you think about this policy? 


\section{Directive Questions}

1. Do you think journalists should know what the audience wants? Why (or why not)?

2. How do you find out what your audience thinks about your work? Does their opinion matter to you? Why?

3. How do you receive feedback from your audience? (probe for different forms of audience feedback)

4. Can you think of a time you used that information? How did you use it? Can you think of any discussions you've had where you or others have brought in audience feedback?

5. How would you compare the different ways that you receive feedback from your audience? Which do you use most often? Why? (recall probe: review the different audience feedback mechanisms mentioned by the interviewee)

6. How do you think audience feedback affects your work as a journalist, if at all?

7. How do you think audience feedback affects your news organization, if at all?

\section{Web Analytics}

1. Does your newsroom use web analytics? How? (if not covered by previous questions; otherwise, skip)

2. As far as you know, what is the purpose of web analytics in your newsroom? How do you know this?

3. As far as you know, how does your newsroom monitor web metrics?

4. As far as you know, how does your newsroom discuss web analytics data? (probe whether or not reports are being disseminated to everyone)

5. What do you think of web analytics in general? (probe for perceptions of use, evaluations, impact on news work)

6. How do web metrics figure in your work as (reporter, editor, etc.)? Can you cite some examples? (probe for specific uses, routines) 
7. How do you think web metrics affect the quality of your work?

\section{Closing Questions}

1. What role do you think should online journalists such as you play in society?

2. What made you think about this particular role? (probe for influences of routines, organization, training, education, audience)

3. What was your background or training prior to being a journalist? How about your peers? (probe for training in online technology)

4. Is there anything you would like to add or point out? Please let me know. 


\section{List of Interviewees}

\begin{tabular}{|c|c|c|}
\hline Newsroom & Participant & Minutes \\
\hline 1 & $\begin{array}{l}\text { Editor-in-chief } \\
\text { Managing editor } \\
\text { Deputy managing editor for digital } \\
\text { Assistant managing editor for content and presentation } \\
\text { Metro Editor } \\
\text { Business Editor } \\
\text { Arts \& Entertainment Editor } \\
\text { Shared news editor } \\
\text { Social media editor } \\
\text { Digital editor } \\
\text { Copy editor } \\
\text { Reporter-editor } \\
\text { Digital development manager } \\
\text { Digital development staff member } \\
\text { Digital development staff member }\end{array}$ & $\begin{array}{l}45 \\
44 \\
32 \\
15 \\
17 \\
25 \\
35 \\
28 \\
36 \\
42 \\
33 \\
54 \\
23 \\
* \\
*\end{array}$ \\
\hline 2 & $\begin{array}{l}\text { Publisher } \\
\text { Vice president for digital } \\
\text { Social media manager } \\
\text { Public editor } \\
\text { Audience relations manager } \\
\text { Social media editor } \\
\text { Homepage editor } \\
\text { Home page editor }\end{array}$ & $\begin{array}{l}26 \\
30 \\
88 \\
33 \\
30 \\
* \\
* \\
*\end{array}$ \\
\hline 3 & $\begin{array}{l}\text { General manager } \\
\text { Assistant managing editor for digital } \\
\text { Assistant managing editor for presentation and innovation } \\
\text { Public editor } \\
\text { Marketing analyst } \\
\text { Web editor } \\
\text { Web editor } \\
\text { Business reporter }\end{array}$ & $\begin{array}{l}32 \\
26 \\
47 \\
36 \\
40 \\
31 \\
32 \\
21\end{array}$ \\
\hline
\end{tabular}

Note. * refers to ethnographic interviews 


\section{E. Theoretical Framework}

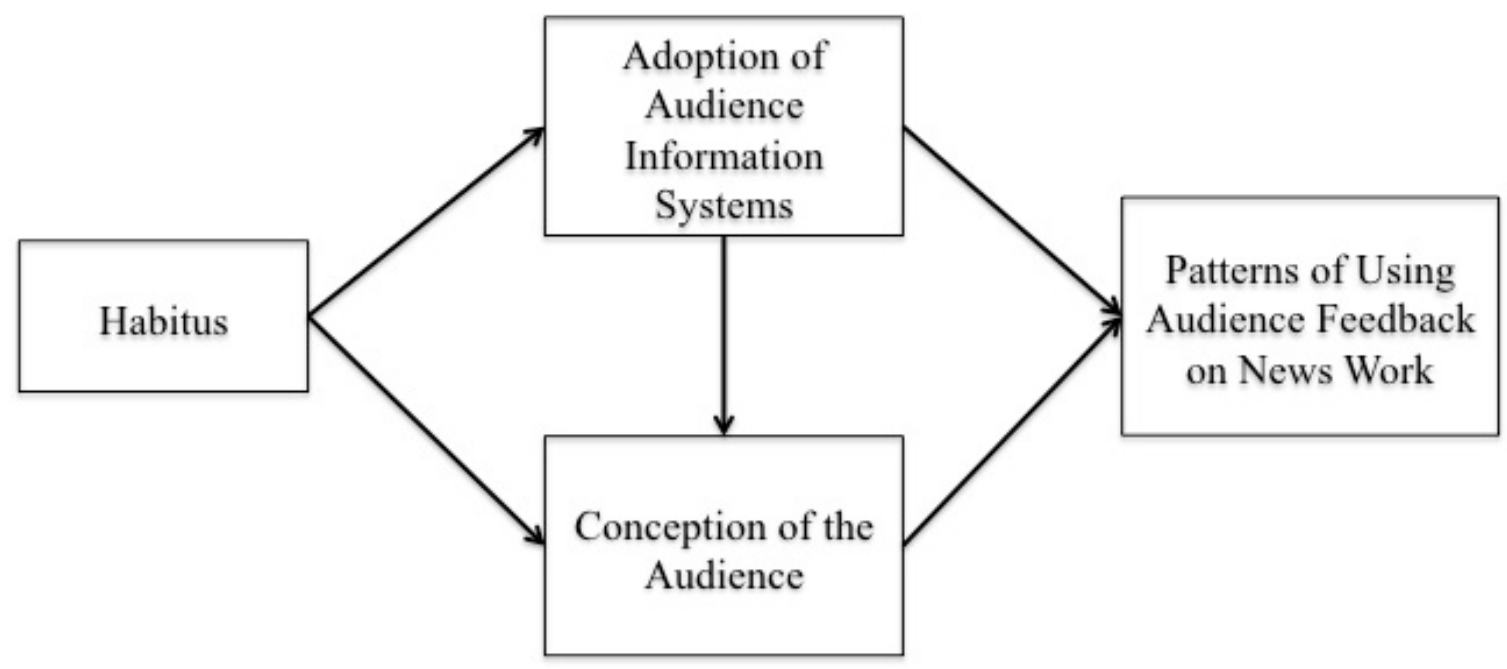




\section{F. Conceptual Framework}
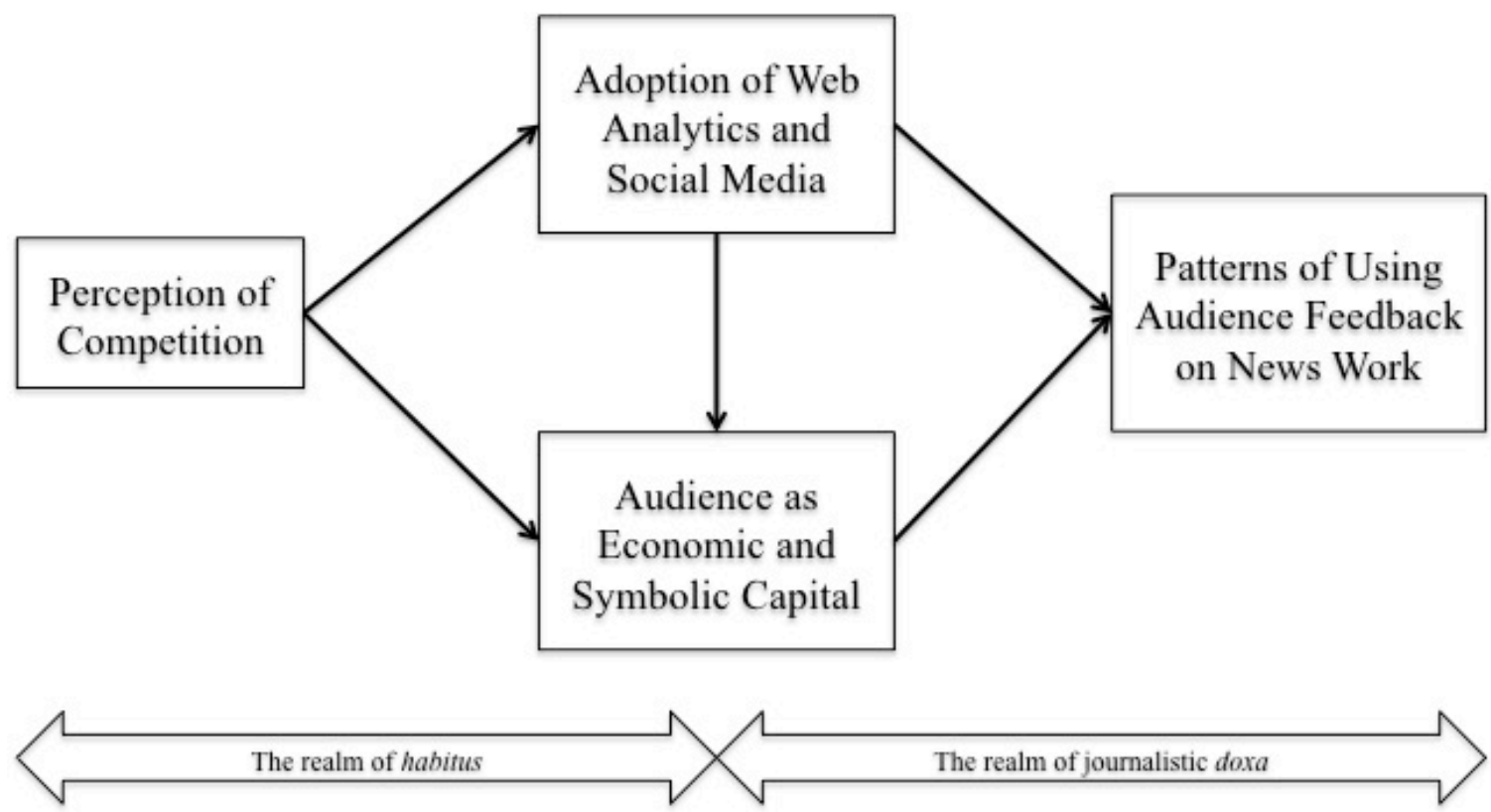


\section{G. Conception of the Audience}

The audience is important because: Symbolic Economic

The more advertisers we will get

$-.013$

.881

The higher our advertising revenues will be.

.034

.957

The more credible our company will become.

.752

.043

The more the public will trust us.

.896

$-.038$

The better our reputation will become.

.945

$-.108$

The more influence our news organization

.493

.173

will have in our community.

Eigenvalue

Variance explained

$57.07 \%$

$21.27 \%$

Note. An exploratory factor analysis (principal axis factoring) using oblique rotation (oblimin) found two underlying factors of how the participants conceived of the audience, explaining $78 \%$ of the variance, $K M O=.75$, Bartlett's Test of Sphericity, $X^{2}$ $(15)=734.39, p<.001)$. 


\section{H. Patterns of Web Analytics Use}

\begin{tabular}{|c|c|c|c|c|c|}
\hline & $\begin{array}{c}\text { Site- } \\
\text { Oriented }\end{array}$ & $\begin{array}{l}\text { Content- } \\
\text { Oriented }\end{array}$ & $\begin{array}{l}\text { Traffic- } \\
\text { Oriented }\end{array}$ & Mean & SD \\
\hline $\begin{array}{l}\text { To determine which stories are } \\
\text { doing well }\end{array}$ & -.039 & -.010 & -.899 & 4.26 & 1.00 \\
\hline $\begin{array}{l}\text { To determine which stories are } \\
\text { not doing well }\end{array}$ & .022 & -.100 & -.706 & 3.82 & 1.21 \\
\hline To decide which stories to cover & -.116 & -.810 & -.146 & 2.47 & 1.01 \\
\hline $\begin{array}{l}\text { To determine what stories to do } \\
\text { follow ups on }\end{array}$ & .060 & -.709 & -.114 & 2.96 & 1.13 \\
\hline $\begin{array}{l}\text { To determine how to cover a } \\
\text { story }\end{array}$ & -.058 & -.950 & .125 & 2.17 & 1.04 \\
\hline To plan deployment of reporters & .030 & -.804 & .102 & 2.20 & .97 \\
\hline $\begin{array}{l}\text { To help evaluate the performance } \\
\text { of employees }\end{array}$ & .085 & -.466 & -.111 & 2.01 & .98 \\
\hline $\begin{array}{l}\text { To know which topic areas to } \\
\text { increase coverage in }\end{array}$ & .034 & -.666 & -.180 & 3.03 & 1.06 \\
\hline $\begin{array}{l}\text { To know where to increase } \\
\text { coverage in terms of geographic } \\
\text { location }\end{array}$ & .258 & -.392 & .017 & 2.24 & .96 \\
\hline $\begin{array}{l}\text { To monitor if the site is working } \\
\text { properly }\end{array}$ & .530 & -.015 & -.222 & 3.16 & 1.23 \\
\hline $\begin{array}{l}\text { To determine where traffic is } \\
\text { coming from }\end{array}$ & .393 & .023 & -.404 & 3.79 & 1.00 \\
\hline $\begin{array}{l}\text { To decide how to write the } \\
\text { headline }\end{array}$ & .374 & -.210 & -.226 & 2.65 & 1.18 \\
\hline $\begin{array}{l}\text { To determine story placement in } \\
\text { the homepage }\end{array}$ & .478 & -.147 & -.216 & 3.04 & 1.24 \\
\hline To help design the website & .835 & -.017 & .074 & 2.68 & 1.16 \\
\hline To improve user experience & .926 & .002 & .065 & 3.11 & 1.15 \\
\hline $\begin{array}{l}\text { To monitor how the story I } \\
\text { wrote/edited is doing }\end{array}$ & .186 & -.159 & -.429 & 3.46 & 1.14 \\
\hline Eigenvalues & 7.54 & 1.65 & 1.10 & -- & -- \\
\hline Variance explained & $47.15 \%$ & $10.34 \%$ & $6.84 \%$ & -- & -- \\
\hline
\end{tabular}

Note. An exploratory factor analysis (principal components analysis) using oblique rotation (oblimin) found three underlying patterns of use, $K M O=.90$, Bartlett's Test of Sphericity, $X^{2}(120)=1425.89, p<.001$, accounting for $67 \%$ of the variance. 


\section{Patterns of Facebook Use}

$\begin{array}{ccc}\begin{array}{c}\text { Engagement- } \\ \text { oriented }\end{array} & \begin{array}{c}\text { Promotion- } \\ \text { oriented }\end{array}\end{array}$ Mean $\quad$ SD

To break a story

.492

.018

3.50

1.36

To promote a story

$-.052$

.887

4.53

.82

To promote the organization

.176

.382

3.61

1.05

To get suggestions from

followers

.574

.118

3.31

.98

To direct readers to the

website

.026

.765

4.44

.86

To read what people are saying

about a story

$\begin{array}{llll}.535 & .317 & 3.93 & 1.02\end{array}$

To see what issues are trending

.635

.026

3.61

1.13

To communicate with

followers

$\begin{array}{llll}.612 & .164 & 3.86 & 1.00\end{array}$

To determine how popular a

story is

.167

3.72

1.07

To find sources

.796

$-.127$

3.06

.97

To find different viewpoints

.810

$-.117$

2.98

1.04

To get information from

followers about events they

.767

$-.041$

3.09

.99

witnessed

Eigenvalues

5.38

1.31

Variance explained

$44.81 \%$

$10.95 \%$

$--$

Note. An exploratory factor analysis (principal axis factoring) using oblique rotation (oblimin) found two factors, $K M O=.88$, Bartlett's Test of Sphericity, $X^{2}(66)=1069.85$, $p<.001$. These factors accounted for $55.76 \%$ of the variance. 


\section{J. Patterns of Twitter Use}

To break a story

.263

$-.074$

.144

To promote the organization

To get suggestions from

followers

To direct readers to the website

To read what people are saying

about a story

To see what issues are trending

To communicate with followers

To determine how popular a

story is

To find sources

To find different viewpoints

To get information from

followers about events they

witnessed

.730

.030

.655

.581

.560

.636

.894

.938

.787

\begin{tabular}{|c|c|c|}
\hline $\begin{array}{c}\text { Engagement- } \\
\text { oriented }\end{array}$ & $\begin{array}{c}\text { Promotion- } \\
\text { oriented }\end{array}$ & Mean \\
\hline
\end{tabular}

SD

317

3.93

1.22

.871

4.51

.86

3.59

1.13

$3.08 \quad 1.00$

.100

.813

4.33

.90

.225

3.39

1.11

.208

3.68

1.15

.219

3.64

1.07

.111

3.19

1.09

$-.102$

3.01

.98

$-.196$

2.96

1.05

$-.037$

3.08

1.07
Eigenvalues

Variance explained
6.14

$51.18 \%$

\subsection{6}

$11.34 \%$

Note. An exploratory factor analysis (principal axis factoring) using oblique rotation (oblimin) found two factors that accounted for $62.52 \%$ of the variance, $K M O=.90$, Bartlett's Test of Sphericity, $X^{2}(66)=1381.77, p<.001$. 


\section{K. Hypothesized Model for Web Analytics}

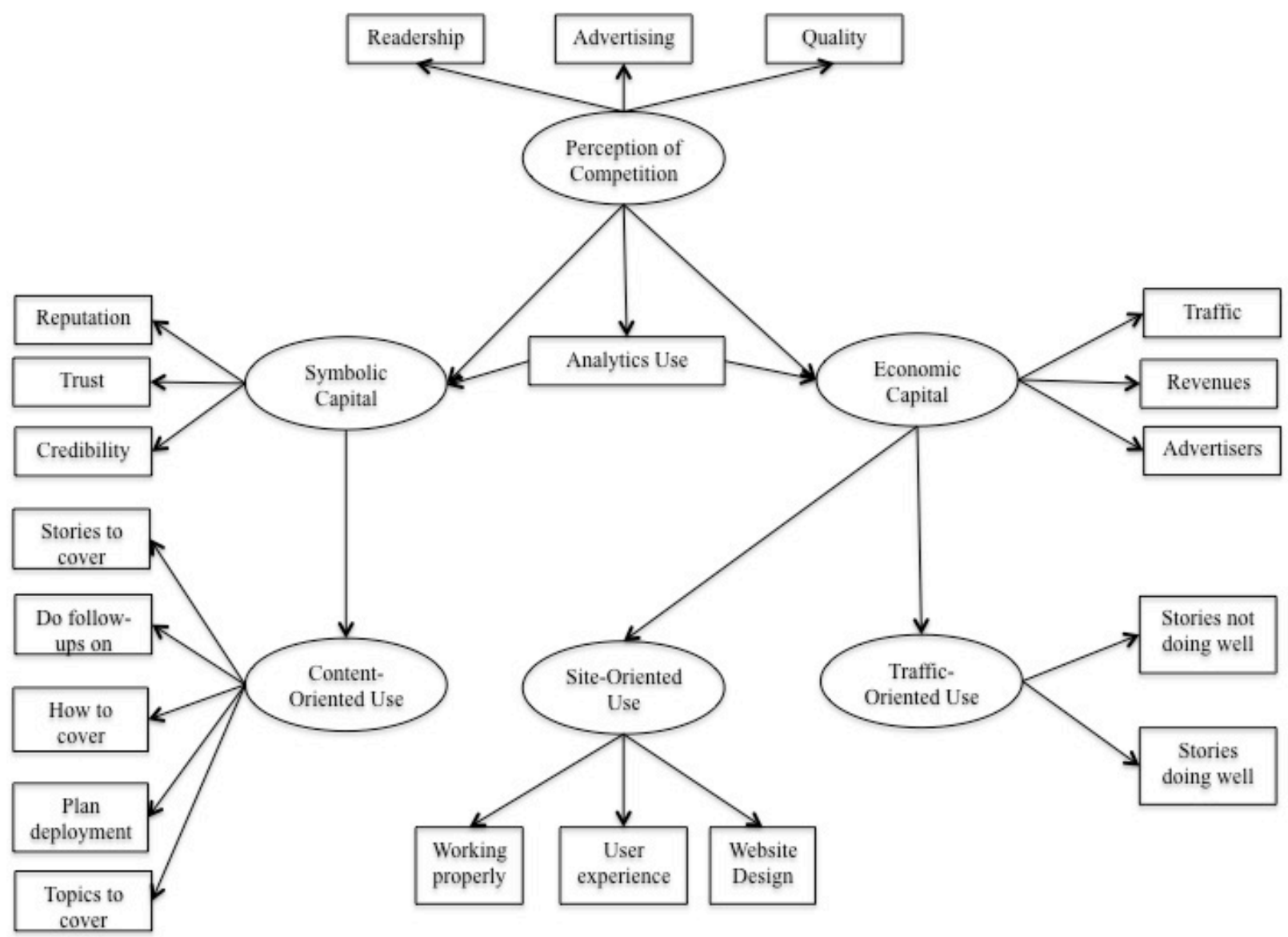

Note. The hypothesized model, grounded in both theory and my qualitative results, fits the data well, $\chi^{2}(160)=246.48, p<.001 ; R M S E A=.05, P C L O S E=.418 ; C F I=.96$; $T L I=.95 ; E C V I=1.885$. 


\section{Final Model for Web Analytics}

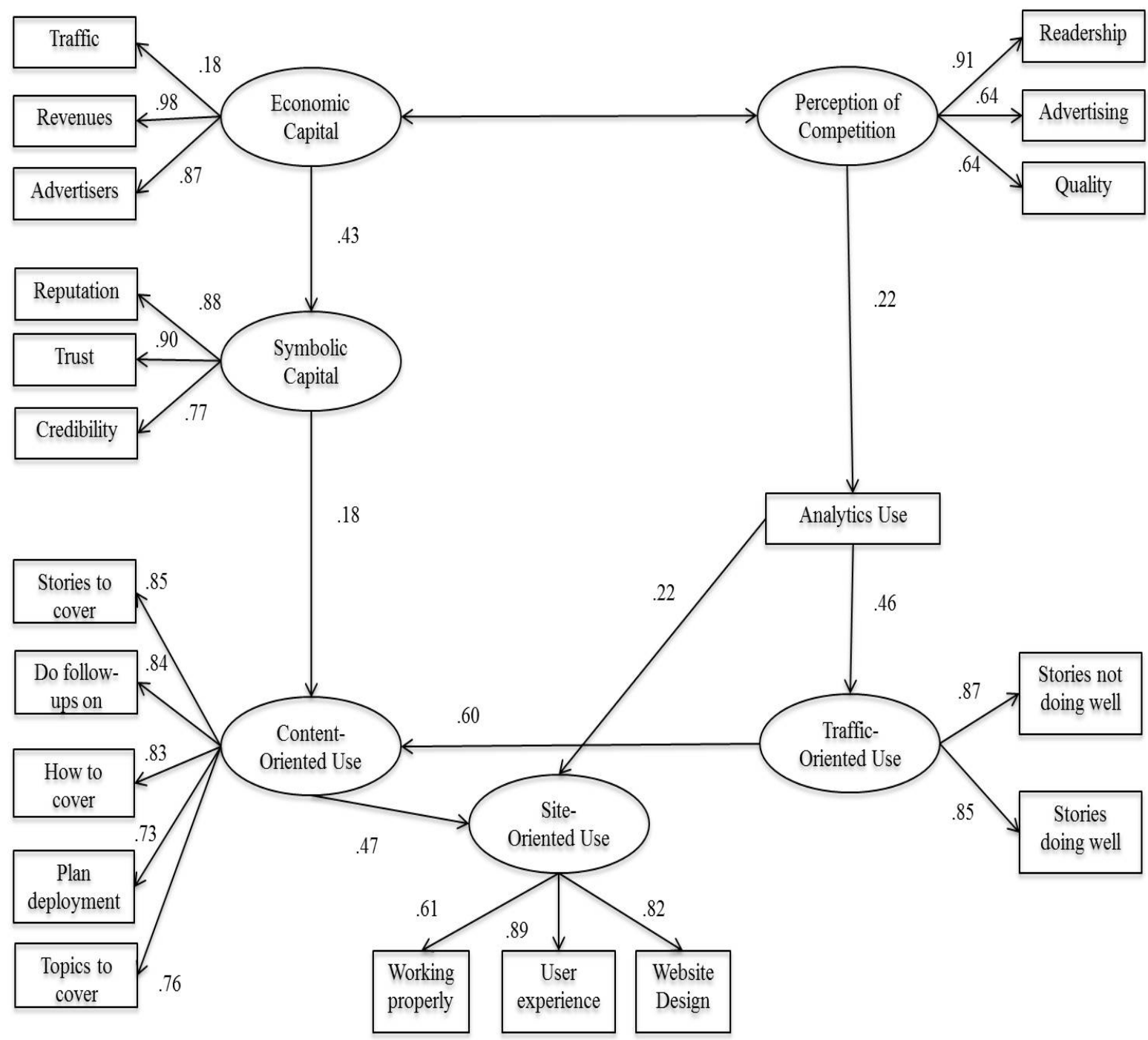




\section{Hypothesized Model for Social Media}

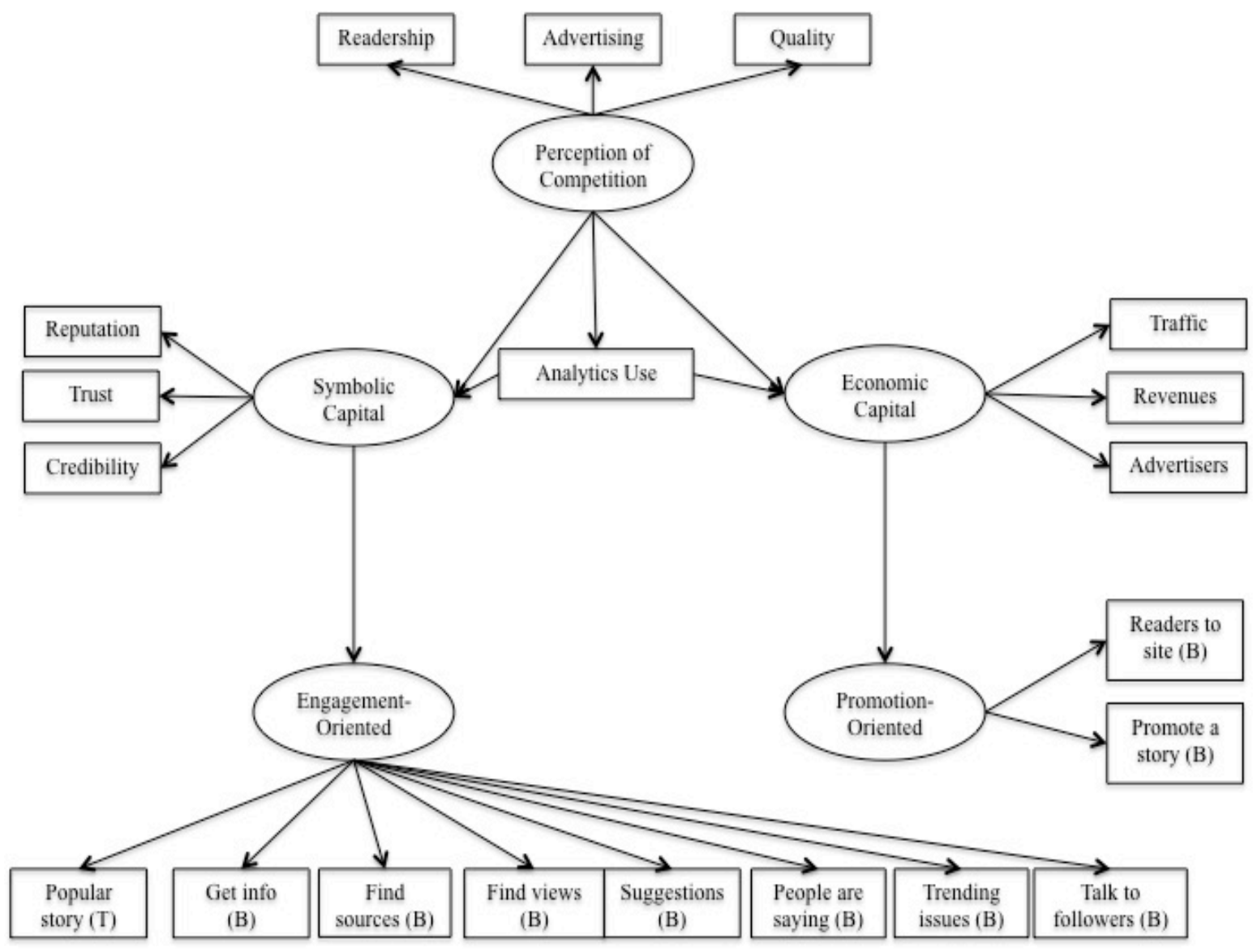

Note. B refers to both Facebook and Twitter; T refers to Twitter only; the model does not fit to the data well, $\chi^{2}(393)=932.18, p<.001 ; R M S E A=.08, P C L O S E<.001 ; C F I=$ $.84 ; T L I=.82 ; E C V I_{\text {default model }}=5.54 ; E C V I_{\text {saturated model }}=4.83$. 


\section{N. Final Model for Social Media}

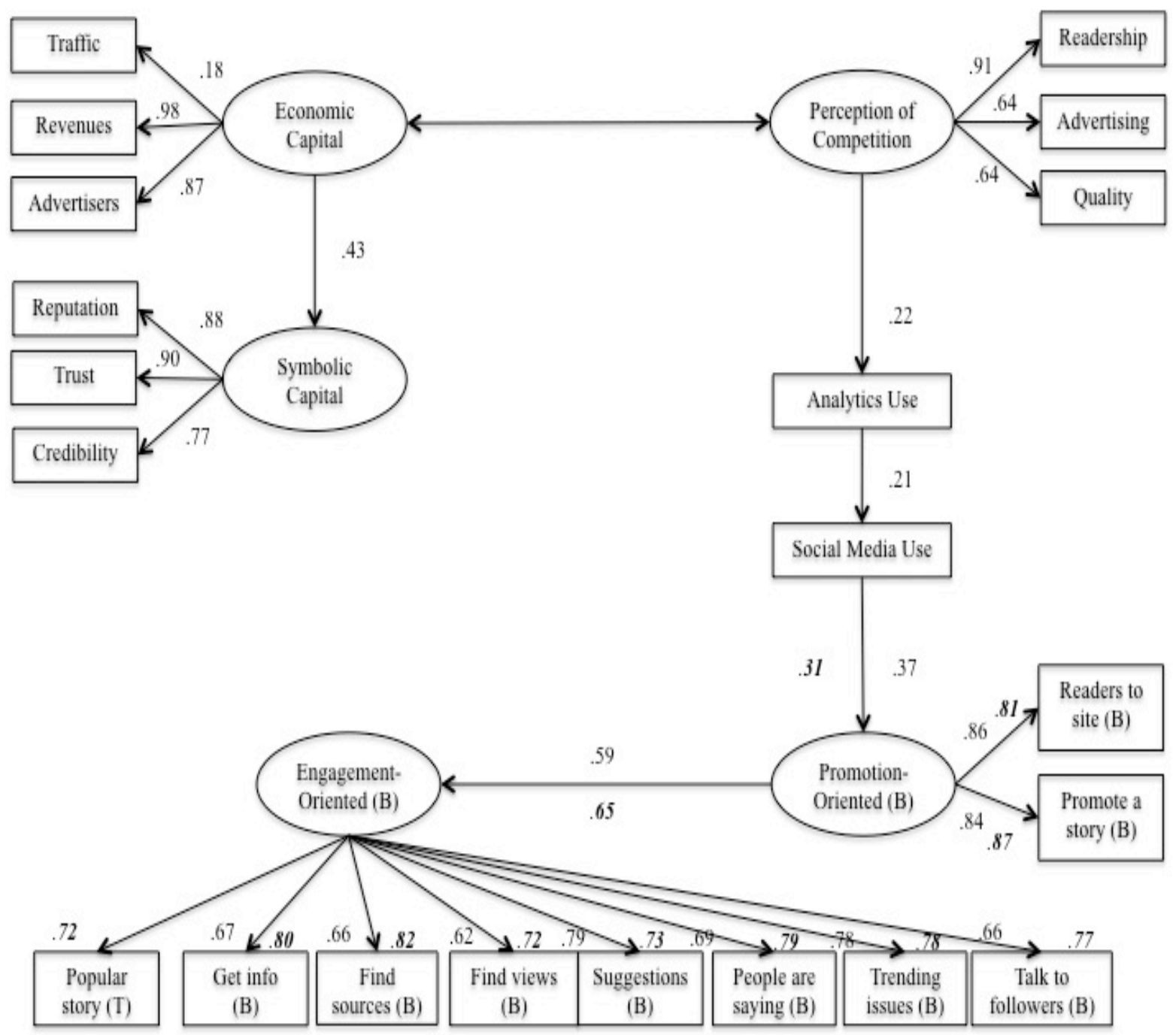

Note. B refers to both Facebook and Twitter; T refers to Twitter only; for the latent variables engagement and promotion, coefficients in both italics and boldface refer to observed variables for Twitter; the rest refers to observed variables for Facebook. The model fits to the data well, $\chi^{2}(383)=569.32, p<.001 ; R M S E A=.05, P C L O S E=.592$; $C F I=.94 ; T L I=.94 ; E C V I=3.87$. 


\section{REFERENCES}

Abbott, A. (1992). What do cases do? Some notes on activity in sociological analysis. In C. Ragin \& H. Becker (Eds.), What is a case? Exploring the foundations of social inquiry. Cambridge: Cambridge University Press.

Akagi, K., \& Linning, S. (2013). Crowdsourcing done right. Between the spreadsheets. Retrieved from cjr.org website: http://www.cjr.org/between_the_spreadsheets/crowdsourcing_done_right.php

Anderson, C. W. (2011a). Between creative and quantified audiences: Web metrics and changing patterns of newswork in local US newsrooms. Journalism, 12(5), 550566. doi: $10.1177 / 1464884911402451$

Anderson, C. W. (2011b). Deliberative, agonistic, and algorithmic audiences: Journalism's vision of its public in an age of audience transparency. International Journal of Communication.

Ang, I. (1991). Desperately seeking the audience. New York: Routledge.

Atkin, C. K., Burgoon, J. K., \& Burgoon, M. (1983). How journalists perceive the reading audience. Newspaper Research Journal, 4(2), 51-63.

Attfield, S., \& Dowell, J. (2003). Information seeking and use by newspaper journalists. Journal of Documentation, 59(2), 187.

Atton, C., \& Wickenden, E. (2005). Sourcing routines and representation in alternative journalism: A case study approach. Journalism Studies, 6(3), 347-359. doi: $10.1080 / 1461670050013200810.1080 / 14616700500132008$

Atwood, L. E. (1970). How newsmen and readers perceive each others' story preferences. Journalism \& Mass Communication Quarterly, 47(2), 296-302. doi: $10.1177 / 107769907004700210$

Avery, E., Lariscy, R., \& Sweetser, K. D. (2010). Social media and shared-or divergentuses? A coorientation analysis of public relations practitioners and journalists. International Journal of Strategic Communication, 4(3), 189-205. doi: 10.1080/1553118x.2010.489501

Avraham, E. (2002). Social-political environment, journalism practice and coverage of minorities: the case of the marginal cities in Israel. Media, Culture \& Society, 24(1), 69-86. doi: 10.1177/016344370202400104

Avraham, E., Wolfsfeld, G., \& Aburaiya, I. (2000). Dynamics in the news coverage of minorities: The case of the Arab citizens of Israel. Journal of Communication Inquiry, 24(2), 117-133. doi: 10.1177/0196859900024002002 
Baker, C. E. (2002). Media, markets, and democracy: Cambridge University Press.

Beam, R. A. (1995). How newspapers use readership research. Newspaper Research Journal, 16(2), 28-38.

Beam, R. A. (2003). Content differences between daily newspapers with strong and weak market orientations. Journalism \& Mass Communication Quarterly, 80(2), 368390.

Beaudoin, C. E., \& Thorson, E. (2006). The social capital of Blacks and Whites: Differing effects of the mass media in the United States. Human Communication Research, 32(2), 157-177. doi: 10.1111/j.1468-2958.2006.00007.x

Beaujon, A. (2012). Pew: Half of Americans get news digitally, topping newspapers, radio. Retrieved from http://www.poynter.org/latestnews/mediawire/189819/pew-tv-viewing-habit-grays-as-digital-newsconsumption-tops-print-radio/

Bechmann, A. (2011). Closer apart? The networks of cross-media news production. In D. Domingo \& C. Paterson (Eds.), Making Online News (Vol. 2). New York: Peter Lang Publishing Inc.

Beleaga, T., \& Geary, J. (2012). ScorecardResearch (ComScore): What is it and what does it do? The Guardian, (April 23, 2012). Retrieved from

Benkoil, D. (2010). What web analytics can - and can't - tell you about your site's traffic and audience. Poynter. Retrieved from http://www.poynter.org/how-tos/digitalstrategies/e-media-tidbits/104772/what-web-analytics-can-and-cant-tell-youabout-your-sites-traffic-and-audience/

Benson, R. (2004). Bringing the sociology of media back in. Political Communication, 21(3), 275-292. doi: 10.1080/10584600490481299

Benson, R. (2005). Mapping the field variation: Journalism in France and the United States. In R. Benson \& E. Neveu (Eds.), Bourdieu and the journalistic field (pp. 85-112). Malden, MA: Polity Press.

Benson, R. (2006). News media as a "journalistic field": What Bourdieu adds to new institutionalism, and vice versa. Political Communication, 23(2), 187-202. doi: $10.1080 / 10584600600629802$

Benson, R., \& Neveu, E. (2005). Introduction: Field theory as a work in progress. In R. Benson \& E. Neveu (Eds.), Bourdieu and the journalistic field (pp. 1-28). Malden, MA: Polity Press.

Berkowitz, D. (1990). Refining the gatekeeping metaphor for local television news. Journal of Broadcasting \& Electronic Media, 34(1), 55-68. 
Bermejo, F. (2007). The internet audience: constitution and measurement. New York: Peter Lang Publishing Inc.

Besley, J. C., \& Roberts, M. C. (2009). Qualitative interviews with journalists about deliberative public engagement. Journalism Practice, 4(1), 66-81. doi: $10.1080 / 17512780903172031$

Bissell, K. L. (2000). A return to 'Mr. Gates': Photography and objectivity. Newspaper Research Journal, 21(3), 81.

Blumer, H. (1954). What is wrong with social theory. American Sociological Review, 18, 3-10.

Boczkowski, P. J. (2004). The processes of adopting multimedia and interactivity in three online newsrooms. Journal of Communication, 54(2), 197-213. doi:

10.1111/j.1460-2466.2004.tb02624.x

Boczkowski, P. J. (2005). Digitizing the news: Innovation in online newspapers: MIT Press.

Boczkowski, P. J. (2010a). The divergent online news preferences of journalists and readers. Communications of the ACM, 53(11), 24-26. doi:

$10.1145 / 1839676.1839685$

Boczkowski, P. J. (2010b). News at work: Imitation in an age of information abundance. Chicago, IL: University of Chicago Press.

Boczkowski, P. J., Mitchelstein, E., \& Walter, M. (2011). Convergence across divergence: Understanding the gap in the online news choices of journalists and consumers in Western Europe and Latin America. Communication Research, 38(3), 376-396. doi: 10.1177/0093650210384989

Born, G. (2003). Strategy, positioning and projection in digital television: Channel Four and the commercialization of public service broadcasting in the UK. Media, Culture \& Society, 25(6), 774-799. doi: 10.1177/0163443703256004

Bourdieu, P. (1977). Outline of a theory of practice. Cambridge: Cambridge University Press.

Bourdieu, P. (1980). The logic of practice. Cambridge: Polity.

Bourdieu, P. (1984). Distinction: A social critique of the judgement of taste. Cambridge: Harvard University Press.

Bourdieu, P. (1985). The social space and the genesis of groups. Theory and Society, 14(6), 723-744. 
Bourdieu, P. (1986). The forms of capital. In J. Richardson (Ed.), Handbook of Theory and Research for the Sociology of Education (pp. 241-258). New York:

Greenwood.

Bourdieu, P. (1993). Field of power, literaty field and habitus. In R. Johnson (Ed.), The field of cultural production: essays on art and literature: Columbia University Press.

Bourdieu, P. (1998). On Television. New York: The New Press.

Bourdieu, P. (2005). The political field, the social science field and the journalistic field. In R. Benson \& E. Neveu (Eds.), Bourdieu and the journalistic field (pp. 29-47). Malden, MA: Polity Press.

Braun, J., \& Gillespie, T. (2011). Hosting the public discourse, hosting the public: When online news and social media converge. Journalism Practice, 5(4), 383-398. doi: $10.1080 / 17512786.2011 .557560$

Breed, W. (1955). Social control in the newsroom: A functional analysis. Social Forces, 33(4), 326-335.

Brennen, B. (2013). Qualitative research methods for media studies. New York: Routledge.

Brown, R. (1979). The gatekeeper reassessed: A return to Lewin. Journalism Quarterly, $56(3)$.

Bruns, A. (2003). Gatewatching, not gatekeeping: Collaborative online news. Media International Australia Incorporating Culture \& Policy(107), 31-44.

Butsch, R. (2000). The making of American audiences: From stage to television, 17501990. New York: Cambridge University Press.

Butsch, R. (2011). Audiences and publics, media and public spheres. In V. Nightingale (Ed.), The Handbook of Media Audiences. Malden, MA: John Wiley \& Sons.

Byrne, B. M. (2010). Structural equation modeling with AMOS : Basic concepts, applications, and programming. New York: Routledge.

Cassidy, W. P. (2006). Gatekeeping similar for online, print journalists. Newspaper Research Journal, 27(2), 6-23.

Castells, M. (2007). Communication, power, and counter-power in the network society. International Journal of Communication, 1(1), 238-266.

Champagne, P. (2005). The "double dependency": The journalistic field between politics and markets. In R. Benson \& E. Neveu (Eds.), Bourdieu and the journalistic field (pp. 48-64). Malden, MA: Polity Press. 
Christians, C. G., \& Carey, J. (1989). The logic and aims of qualitative research. Research methods in mass communication, 354-374.

Cobanoglu, C., Warde, B., \& Moreo, P. J. (2001). A comparison of mail, fax and webbased survey methods. International Journal of Market Research, 43(4), 441-452.

Corbin, J., \& Strauss, A. (1990). Grounded theory research: Procedures, canons, and evaluative criteria. Qualitative Sociology, 13(1), 3.

Couldry, N. (2003). Media meta-capital: Extending the range of Bourdieu's field theory. Theory and Society, 32(5/6), 653-677. doi: 10.2307/3649655

Couper, M. P., \& Miller, P. V. (2008). Web survey methods: introduction. Public Opinion Quarterly, 72(5), 831-835. doi: 10.1093/poq/nfn066

Craft, S., \& Wanta, W. (2004). Women in the newsroom: Influences of female editors and reporters on the news agenda. Journalism \& Mass Communication Quarterly, 81(1), 124-138.

Creswell, J. W. (2007). Qualitative inquiry \& research design: choosing among five approaches: Sage Publications.

Creswell, J. W., \& Plano Clark, V. L. (2011). Designing and conducting mixed methods research. Thousand Oaks: CA: Sage.

Curtin, P. A., \& Maier, S. R. (2001). Numbers in the newsroom: A qualitative examination of a quantitative challenge. Journalism and Mass Communication Quarterly, 78(4), 720-738.

D'Addario, D. (2013). After the Onion goes after CNN's Miley Cyrus coverage, Anderson Cooper spotlights twerking. Salon. Retrieved from http://www.salon.com/2013/08/27/after_the_onion_goes_after_cnns_miley_cyrus _coverage_anderson_cooper_spotlights_twerking/

de Sola Pool, I., \& Shulman, I. (1959). Newsmen's fantasies, audiences, and newswriting. The Public Opinion Quarterly, 23(2), 145-158.

Definition of twerk in English. (2013). Retrieved October 31, 2013, from Oxford Dictionaries http://www.oxforddictionaries.com/us/definition/american_english/twerk

Delo, C. (2011). Your guide to who measures what in the online space. Ad Age. Retrieved from Ad Age website: http://adage.com/article/media/guide-measures-onlinespace/229858/

Dick, M. (2011). Search engine optimisation in UK news production. Journalism Practice, 5(4), 462-477. doi: 10.1080/17512786.2010.551020 
Domingo, D. (2011). The centrality of online journalism today (and tomorrow). In D. Domingo \& C. Paterson (Eds.), Making Online News (Vol. 2). New York: Peter Lang Publishing Inc.

Domingo, D., \& Heinonen, A. (2008). Weblogs and journalism: A typology to explore the blurring boundaries. NORDICOM Review, 29(1), 3-15.

Duncan, S. (2010). Using web analytics to measure the impact of earned online media on business outcomes: A methodological approach San Francisco: Institute for Public Relations.

Edmonds, R. (2013). ASNE census finds 2,600 newsroom jobs were lost in 2012. Poynter. Retrieved from http://www.poynter.org/latest-news/business-news/thebiz-blog/216617/asne-census-finds-2600-newsroom-jobs-were-lost-in-2012/

Eisenhardt, K. M. (1989). Building theories from case study research. The Academy of Management Review, 14(4), 532-550. doi: 10.2307/258557

Eisenhardt, K. M., \& Graebner, M. E. (2007). Theory building from cases: Opportunities and challenges. The Academy of Management Journal, 50(1), 25-32. doi: $10.2307 / 20159839$

Ekdale, B., Namkoong, K., Fung, T. K. F., \& Perlmutter, D. D. (2010). Why blog? (then and now): exploring the motivations for blogging by popular American political bloggers. New Media \& Society, 12(2), 217-234. doi: $10.1177 / 1461444809341440$

Elster, J. (1989). Nuts and bolts for the social sciences. Cambridge: University of Cambridge.

Elster, J. (1998). A plea for mechanisms. In P. Hedström \& R. Swedberg (Eds.), Social mechanisms: an analytical approach to social theory. Cambridge: Cambridge University Press.

Emirbayer, M., \& Johnson, V. (2008). Bourdieu and organizational analysis. Theory and Society, 37(1), 1-44. doi: 10.1007/s11186-007-9052-y

Eshbaugh-Soha, M. (2008). Local newspaper coverage of the Presidency. The International Journal of Press/Politics, 13(2), 103-119. doi: $10.1177 / 1940161208315141$

Ettema, J., \& Whitney, D. C. (1994). The money arrow: An introduction to audiencemaking. In J. Ettema \& D. C. Whitney (Eds.), Audiencemaking: How the Media Create the Audience. New York: Sage.

Fishman, M. (1988). Manufacturing the News. Austin, Texas: University of Texas Press. 
Flegel, R. C., \& Chaffee, S. H. (1971). Influences of editors, readers, and personal opinions on reporters. Journalism \& Mass Communication Quarterly, 48(4), 645651. doi: $10.1177 / 107769907104800404$

Gambetta, D. (1998). Concatenations of mechanisms. In P. Hedström \& R. Swedberg (Eds.), Social mechanisms: an analytical approach to social theory. Cambridge: Cambridge University Press.

Gans, H. (1979). Deciding what's news (1st ed.). New York: Pantheon Books.

Gillmor, D. (2004). We the media: The rise of citizen journalists. National Civic Review, 93(3), 58-63. doi: 10.1002/ncr.62

Glaser, B. G. (1965). The constant comparative method of qualitative analysis. Social Problems, 12(4), 436-445.

Glaser, B. G., \& Strauss, A. (1967). The discovery of grounded theory: Strategies for qualitative research. London: Weidenfeld and Nicolson.

Greene, J. C. (2008). Is mixed methods social inquiry a distinctive methodology? Journal of Mixed Methods Research, 2(1), 7-22. doi: 10.1177/1558689807309969

Grenfell, M., \& James, D. (2004). Change in the field, changing the field: Bourdieu and the methodological practice of educational research. British Journal of Sociology of Education, 25(4), 507-523. doi: 10.2307/4128674

Haile, T. (2013). Cargo cults or the Wright Brothers? Metrics can improve newsrooms but only if the culture is ready. paidContent. Retrieved from http://paidcontent.org/2013/09/08/cargo-cults-or-the-wright-brothers-metrics-canimprove-newsrooms-but-only-if-the-culture-is-ready/

Hammersley, M., \& Gomm, R. (2000). Introduction. In R. Gomm, M. Hammersley \& P. Foster (Eds.), Case study method. London: Sage.

Hammersley, M., Gomm, R., \& Foster, P. (2000). Case study and theory. In R. Gomm, M. Hammersley \& P. Foster (Eds.), Case study method. London: Sage.

Handley, R. L., \& Rutigliano, L. (2012). Journalistic field wars: defending and attacking the national narrative in a diversifying journalistic field. Media, Culture \& Society, 34(6), 744-760. doi: 10.1177/0163443712449500

Hanitzsch, T. (2008). Comparing journalism across cultural boundaries. State of the art, strategies, problems, and solutions. In M. Löffelholz \& D. Weaver (Eds.), Global Journalism Research. Theories, Methods, Findings, Future. Malden: Blackwell publishing. 
Hanitzsch, T. (2011). Populist disseminators, detached watchdogs, critical change agents and opportunist facilitators. International Communication Gazette, 73(6), 477494. doi: $10.1177 / 1748048511412279$

Hanitzsch, T., Anikina, M., Berganza, R., Cangoz, I., Coman, M., Hamada, B., .. . Yuen, K. W. (2010). Modeling perceived influences on journalism: Evidence from a cross-national survey of journalists Journalism and Mass Communication Quarterly, 87(1), 5.

Hanitzsch, T., \& Mellado, C. (2011). What shapes the news around the world? How journalists in eighteen countries perceive influences on their work. The International Journal of Press/Politics, 16(3), 404-426. doi: $10.1177 / 1940161211407334$

Hansen, K., Neuzil, M., \& Ward, J. (1998). Newsroom topic teams: Journalists' assessments of effects on news routines and newspaper quality. Journalism and Mass Communication Quarterly, 75(4), 803.

Harcup, T., \& O'Neill, D. (2001). What is news? Galtung and Ruge revisited. Journalism Studies, 2(2), 261-280.

Hardin, M. (2005). Stopped at the gate: Women's sports, "reader interest," and decision making by editors. Journalism and Mass Communication Quarterly, 82(1), 62.

Hare, B. (2013). Miley Cyrus twerks, stuns VMAs crowd. CNN. Retrieved from http://www.cnn.com/2013/08/26/showbiz/music/miley-cyrus-mtv-vmasgaga/index.html

Harrison, A. (2006). Definition of economic assets. Paper presented at the Fourth meeting of the Advisory Expert Group on National Accounts (AEG).

Harrison, J. (2009). User-generated content and gatekeeping at the BBC hub. Journalism Studies, 11(2), 243-256. doi: 10.1080/14616700903290593

Hedström, P., \& Swedberg, R. (1998a). Social mechanisms: An introductory essay. In P. Hedström \& R. Swedberg (Eds.), Social mechanisms: an analytical approach to social theory. Cambridge: Cambridge University Press.

Hedström, P., \& Swedberg, R. (Eds.). (1998b). Social mechanisms: an analytical approach to social theory. Cambridge: Cambridge University Press.

Hedström, P., \& Ylikoski, P. (2010). Causal mechanisms in the social sciences. Annual Review of Sociology, 36(1), 49-67. doi: doi:10.1146/annurev.soc.012809.102632

Heinonen, A. (2011). The journalist's relationship with users: New dimensions to conventional roles. In J. Singer, A. Hermida, D. Domingo, A. Heinonen, S. Paulussen, T. Quandt, Z. Reich \& M. Vujnovic (Eds.), Participatory journalism: Guarding open gates at online newspapers. Malden, MA: John Wiley \& Sons. 
Herbst, S., \& Beniger, J. (1994). The changing infrastructure of public opinion. In J. Ettema \& D. C. Whitney (Eds.), Audiencemaking: How the Media Create the Audience. New York: Sage.

Herman, E. S., \& Chomsky, N. (2002). Manufacturing consent: The political economy of the mass media. New York: Knopf Doubleday Publishing Group.

Hermida, A. (2010). Twittering the news. Journalism Practice, 4(3), 297-308. doi: $10.1080 / 17512781003640703$

Hermida, A. (2011). Fluid spaces, fluid journalism: The role of the "active recipient" in participatory journalism. In J. Singer, A. Hermida, D. Domingo, A. Heinonen, S. Paulussen, T. Quandt, Z. Reich \& M. Vujnovic (Eds.), Participatory journalism: Guarding open gates at online newspapers. Malden, MA: John Wiley \& Sons.

Hermida, A. (2012). Social journalism: Exploring how social media is shaping journalism. In E. Siapera \& A. Veglis (Eds.), The handbook of global online journalism. Malden, MA: John Wiley \& Sons, Inc.

Hermida, A., Fletcher, F., Korell, D., \& Logan, D. (2012). Share, like, recommend. Journalism Studies, 13(5-6), 815-824. doi: 10.1080/1461670x.2012.664430

Hernes, G. (1998). Real virtuality. In P. Hedström \& R. Swedberg (Eds.), Social mechanisms: an analytical approach to social theory. Cambridge: Cambridge University Press.

Hinnant, A., Len-Ríos, M. E., \& Oh, H. J. (2011). Are health journalists' practices tied to their perceptions of audience? An attribution and expectancy-value approach. Health Communication, 27(3), 234-243. doi: 10.1080/10410236.2011.578331

Hong, S. (2012). Online news on Twitter: Newspapers' social media adoption and their online readership. Information Economics and Policy, 24(1), 69-74. doi: 10.1016/j.infoecopol.2012.01.004

Hu, L. t., \& Bentler, P. M. (1999). Cutoff criteria for fit indexes in covariance structure analysis: Conventional criteria versus new alternatives. Structural Equation Modeling: A Multidisciplinary Journal, 6(1), 1-55. doi: 10.1080/10705519909540118

Jewitt, R. (2009). The trouble with twittering: Integrating social media into mainstream news. International Journal of Media \& Cultural Politics, 5(3), 233-246. doi: 10.1386/macp.5.3.233_3

Johnson, B. (2009). Experts puzzled over Adobe's surprise purchase of Omniture. The Guardian. Retrieved from http://www.theguardian.com/technology/2009/sep/16/adobe-mergers-acquisitions 
Johnson, R. (1993). Editor's introduction: Pierre Bourdieu on art, literature and culture. In R. Johnson (Ed.), The field of cultural production: essays on art and literature: Columbia University Press.

Johnson, R. B., Onwuegbuzie, A. J., \& Turner, L. A. (2007). Toward a definition of mixed methods research. Journal of Mixed Methods Research, 1(2), 112-133. doi: $10.1177 / 1558689806298224$

Johnstone, J., Slawski, E., \& Bowman, W. (1972). The professional values of American newsmen. Public Opinion Quarterly, 36(4), 522.

Jones, R. W. (1993). Coorientation of a news staff and its audience. Communication Reports, 6(1), 41-46.

Kaplowitz, M. D., Hadlock, T. D., \& Levine, R. (2004). A comparison of web and mail survey response rates. Public Opinion Quarterly, 68(1), 94-101. doi: $10.1093 / \mathrm{poq} / \mathrm{nfh} 006$

Kaushik, A. (2010). Web analytics 2.0: The art of online accountability and science of customer centricity. Indianapolis: Wiley Publishing, Inc.

Kim, H. S. (2010). Forces of gatekeeping and journalists' perceptions of physical danger in post-Saddam Hussein's Iraq. Journalism and Mass Communication Quarterly, 87(3/4), 484.

Kline, R. B. (1998). Principles and Practice of Structural Equation Modeling. New York: Guilford Press.

Krall, J. (2009). Using social metrics to evaluate the impact of online healthcare communications. Journal of Communication in Healthcare, 2(4), 387-394.

Kwak, N., \& Radler, B. (2002). A comparison between mail and web surveys: Response pattern, respondent profile, and data quality. Journal of Official Statistics, 18(2), 257.

Lariscy, R. W., Avery, E. J., Sweetser, K. D., \& Howes, P. (2009). An examination of the role of online social media in journalists' source mix. Public Relations Review, 35(3), 314-316. doi: http://dx.doi.org/10.1016/j.pubrev.2009.05.008

Lasorsa, D. L., Lewis, S. C., \& Holton, A. E. (2011). Normalizing Twitter: Journalism practice in an emerging communication space. Journalism Studies, 13(1), 19-36. doi: 10.1080/1461670x.2011.571825

Lee, A. M., Lewis, S. C., \& Powers, M. (2012). Audience clicks and news placement: A study of time-lagged influence in online journalism. Communication Research. doi: $10.1177 / 0093650212467031$ 
Lewis, N. P., \& Zhong, B. (2013). The root of journalistic plagiarism: Contested attribution beliefs. Journalism \& Mass Communication Quarterly, 90(1), 148166.

Lindlof, T. R., \& Taylor, B. C. (2010). Qualitative communication research methods (3rd ed.). Thousand Oaks, CA: SAGE.

Loosen, W., \& Schmidt, J.-H. (2012). (Re-) discovering the audience. Information, Communication \& Society, 15(6), 867-887. doi: 10.1080/1369118x.2012.665467

Lowrey, W., \& Woo, C. W. (2010). The news organization in uncertain times: business or institution? Journalism and Mass Communication Quarterly, 87(1), 41-61.

Lynley, M. (2013). Recommendation engine Outbrain acquires editorial data startup Visual Revenue. The Wall Street Journal. Retrieved from http://blogs.wsj.com/digits/2013/03/07/recommendation-engine-outbrainacquires-editorial-data-startup-visual-revenue/

Lysak, S., Cremedas, M., \& Wolf, J. (2012). Facebook and Twitter in the newsroom: How and why local television news is getting social with viewers? Electronic News, 6(4), 187-207. doi: 10.1177/1931243112466095

MacGregor, P. (2007). Tracking the online audience. Journalism Studies, 8(2), 280-298. doi: $10.1080 / 14616700601148879$

Mahoney, J. (2003). Tentative answers to questions about causal mechanisms. Paper presented at the American Political Science Association Conference, Philadelphia, PA.

Maier, S. R. (2003). Numeracy in the newsroom: A case study of mathematical competence and confidence. Journalism \& Mass Communication Quarterly, 80(4), 921-936.

Maier, S. R. (2010). Newspapers offer more news than do major online sites. Newspaper Research Journal, 31(1), 6-19.

Martin, J. L. (2003). What is field theory? The American Journal of Sociology, 109(1), 149.

Martin, R. K., O'Keefe, G. J., \& Nayman, O. B. (1972). Opinion agreement and accuracy between editors and their readers. Journalism \& Mass Communication Quarterly, 49(3), 460-468. doi: 10.1177/107769907204900305

Mayer, J. (2011). Highlights from the 2011 journalists engagement survey. Retrieved from RJI website: http://rjionline.org/news/highlights-2011-journalistsengagement-survey 
McCluskey, M., Stein, S. E., Boyle, M. P., \& McLeod, D. M. (2009). Community structure and social protest: Influences on newspaper coverage. Mass Communication and Society, 12(3), 353-371. doi: 10.1080/15205430802478685

McCombs, M. E. (2005). A Look at agenda-setting: Past, present and future. Journalism Studies, 6(4), 543-557. doi: 10.1080/14616700500250438

McCombs, M. E., \& Shaw, D. L. (1972). The agenda-setting function of mass media. The Public Opinion Quarterly, 36(2), 176-187. doi: 10.2307/2747787

McKenzie, C. T., Lowrey, W., Hays, H., Chung, J. Y., \& Woo, C. W. (2011). Listening to news audiences: The impact of community structure and economic factors. Mass Communication and Society, 14(3), 375-395. doi: $10.1080 / 15205436.2010 .491934$

McQuail, D. (2010). Mass Communication Theory. Thousand Oaks, CA: SAGE.

Miller, M. (2011). The ultimate web marketing guide. Indianapolis, IN: Pearson Education, Inc.

Mindich, D. (1998). Just the facts: How "objectivity" came to define American journalism. New York: New York University Press.

Modell, S. (2005). Triangulation between case study and survey methods in management accounting research: An assessment of validity implications. Management Accounting Research, 16(2), 231-254. doi: http://dx.doi.org/10.1016/j.mar.2005.03.001

Morgan, D. (1998). Practical strategies for combining qualitative and quantitative methods: Applications to health research. Qualitative Health Research, 8. doi: $10.1177 / 104973239800800307$

NAA. (2013). The American newspaper media industry revenue profile 2012. Newspaper Association of America. Retrieved from http://www.naa.org/Trends-andNumbers/Newspaper-Revenue/Newspaper-Media-Industry-Revenue-Profile2012.aspx

Napoli, P. (2011). Audience evolution: New technologies and the transformation of media audiences. New York: Columbia University Press.

Neveu, E. (2007). Pierre Bourdieu. Journalism Studies, 8(2), 335-347. doi: $10.1080 / 14616700601149026$

Norkus, Z. (2005). Mechanisms as miracle makers? The rise and inconsistencies of the "mechanismic approach" in social science and history. History and Theory, 44(3), 348-372. doi: 10.1111/j.1468-2303.2005.00329.x 
O'Sullivan, J., \& Heinonen, A. (2008). Old values, new media. Journalism Practice, 2(3), 357-371. doi: 10.1080/17512780802281081

Onion. (2013). Let me explain why Miley Cyrus' VMA performance was our top story this morning. the Onion. Retrieved from http://www.theonion.com/articles/let-meexplain-why-miley-cyrus-vma-performance-was,33632/

Parsons, C. (2007). How to map arguments in political science. Oxford: Oxford University Press.

Paterson, C. (2008). Introduction: Why ethnography? In C. Paterson \& D. Domingo (Eds.), Making Online News (Vol. 1). New York: Peter Lang Publishing Inc.

Peters, J., \& Tandoc, E. (2013). People who aren't really reporters at all, who have no professional qualifications: Defining a journalist and deciding who may claim the privileges. N.Y.U. Journal of Legislation and Public Policy Quorum, 34-63.

Phillips, J. (2013). 'The Onion's' CNN article draws response from network's Meredith Artley over Miley Cyrus. Epoch Times. Retrieved from http://www.theepochtimes.com/n3/264928-the-onions-cnn-article-drawsresponse-from-networks-meredith-artley-over-miley-cyrus/

Plooy, G. M. (2004). Communication research: Techniques, methods and applications: Juta Academic.

Poell, T., \& Borra, E. (2012). Twitter, YouTube, and Flickr as platforms of alternative journalism: The social media account of the 2010 Toronto G20 protests. Journalism, 13(6), 695-713. doi: 10.1177/1464884911431533

Potter, W. J. (2009). Conceptualizing the audience. In R. Nabi \& M. B. Oliver (Eds.), The SAGE handbook of media processes and effects. Thousand Oaks, CA: Sage.

Putnam, R. D. (1995). Tuning in, tuning out: The strange disappearance of social capital in America. PS: Political Science and Politics, 28(4), 664-683.

Putnam, R. D. (2000). Bowling alone. NY: Simon \& Schuster.

Ragin, C. (1992). "Casing" and the process of social inquiry. In C. Ragin \& H. Becker (Eds.), What is a case? Exploring the foundations of social inquiry. Cambridge: Cambridge University Press.

Rakow, L. F. (2011). Commentary: Interviews and focus groups as critical and cultural methods. Journalism \& Mass Communication Quarterly, 88(2), 416-428. doi: $10.1177 / 107769901108800211$

Reese, S. D. (2001). Understanding the global journalist: A hierarchy-of-influences approach. Journalism Studies, 2(2), 173-187. doi: 10.1080/14616700118394 
Reese, S. D., \& Ballinger, J. (2001). The roots of a sociology of news: Remembering Mr. Gates and social control in the newsroom. Journalism \& Mass Communication Quarterly, 78(4), 641-658.

Robinson, S. (2006). The mission of the j-blog. Journalism, 7(1), 65-83. doi: $10.1177 / 1464884906059428$

Robinson, S. (2009). The cyber-newsroom: A case study of the journalistic paradigm in a news narrative's journey from a newspaper to cyberspace. Mass Communication \& Society, 12(4), 403-422. doi: 10.1080/15205430802513234

Romenesko, J. (2013). Georgia newspaper chain closes its photo department, tells reporters to take pictures. Retrieved from http://jimromenesko.com/2013/07/12/georgia-newspaper-chain-closes-its-photodepartment-tells-reporters-to-take-pictures/

Rosen, J. (2006). The people formerly known as the audience. Huffington Post. Retrieved from Huffington Post website:

Rossman, G. (2004). Elites, masses, and media blacklists: The Dixie Chicks controversy. Social Forces, 83(1), 61-79.

Rubin, H. J., \& Rubin, I. S. (2005). Qualitative interviewing: The art of hearing data. Thousand Oaks: CA: Sage.

Russell, A. (2007). Digital communication networks and the journalistic field: The 2005 French riots. Critical Studies in Media Communication, 24(4), 285-302. doi: $10.1080 / 07393180701560880$

Saldaña, J. (2009). The coding manual for qualitative researchers. Thousand Oaks, CA: Sage.

Sallaz, J. J., \& Zavisca, J. (2007). Bourdieu in American sociology, 1980-2004. Annual Review of Sociology, 33, 21-41. doi: 10.2307/29737752

Schlesinger, P. (1978). Putting 'reality' together. Beverly Hills, CA: Sage.

Schreiber, J. B., Nora, A., Stage, F. K., Barlow, E. A., \& King, J. (2006). Reporting structural equation modeling and confirmatory factor analysis results: A review. The Journal of Educational Research, 99(6), 323-338. doi: 10.3200/joer.99.6.323338

Schudson, M. (2003). The sociology of news. New York: W.W. Norton \& Company, Inc.

Schultz, J. (1998). Reviving the fourth estate. Cambridge, UK: Cambridge University Press. 
Schumacker, R. E., \& Lomax, R. G. (2004). A Beginner's Guide to Structural Equation Modeling (2nd ed.). Mahwah: NJ: Lawrence Erlbaum Associates.

Shaw, D. L., \& Martin, S. E. (1992). The function of mass media agenda setting. Journalism Quarterly, 69(4), 902-920.

Shoemaker, P. J. (1991). Gatekeeping. Newbury Park: Sage Publications.

Shoemaker, P. J., \& Cohen, A. (2006). News around the world: Content, practitioners, and the public. New York, NY: Routledge.

Shoemaker, P. J., Eichholz, M., Kim, E., \& Wrigley, B. (2001). Individual and routine forces in gatekeeping. Journalism and Mass Communication Quarterly, 78(2), 233-246.

Shoemaker, P. J., \& McCombs, M. E. (2003). Survey Research. In G. Stempel, D. Weaver \& G. C. Wilhoit (Eds.), Mass Communication Research and Theory. Boston: Pearson Education.

Shoemaker, P. J., \& Reese, S. D. (1996). Mediating the message: Theories of influences on mass media content (2nd ed.). White Plains, NY: Longman.

Shoemaker, P. J., \& Reese, S. D. (2013). Mediating the message in the 21st century: A media sociology perspective (3rd ed.). New York: Routeledge.

Shoemaker, P. J., Vos, T., \& Reese, S. D. (2008). Journalists as gatekeepers. In K. WahlJorgensen \& T. Hanitzsch (Eds.), Handbook of journalism studies (pp. 73-87). New York: Routledge.

Shoemaker, P. J., \& Vos, T. P. (2009). Gatekeeping Theory. New York: Routledge.

Siapera, E. (2008). The political subject of blogs. Information Polity: The International Journal of Government \& Democracy in the Information Age, 13(1/2), 51-63.

Siapera, E., \& Spyridou, L.-P. (2012). The field of online journalism: A Bourdieusian analysis. In E. Siapera \& A. Veglis (Eds.), The handbook of global online journalism. Malden, MA: John Wiley \& Sons, Inc.

Siebert, F., Peterson, T., \& Schramm, W. (1963). Four theories of the press; the authoritarian, libertarian, social responsibility, and Soviet communist concepts of what the press should be and do. Urbana: University of Illinois Press.

Singer, J. (2001). The metro wide web: Changes in newspapers' gatekeeping role online. Journalism and Mass Communication Quarterly, 78(1), 65.

Singer, J. (2005). The political j-blogger. Journalism, 6(2), 173-198. doi: $10.1177 / 1464884905051009$ 
Singer, J. (2008). Ethnography of newsroom convergence. In C. Paterson \& D. Domingo (Eds.), Making Online News (Vol. 1). New York: Peter Lang Publishing Inc.

Singer, J., \& Ashman, I. (2009). "Comment is free, but facts are sacred": User-generated content and ethical constructs at the Guardian. Journal of Mass Media Ethics, 24(1), 3-21. doi: 10.1080/08900520802644345

Snider, P. B. (1967). "Mr. Gates” revisited: A 1966 version of the 1949 case study. Journalism Quarterly, 44, 419-427.

Sonderman, J. (2011). New generation of Web analytics applies 'big data' to newsroom decisions. Poynter. Retrieved from http://www.poynter.org/latest-news/topstories/143389/new-generation-of-web-analytics-applies-big-data-to-newsroomdecisions-visual-revenue-jumptime/

Stassen, W. (2010). Your news in 140 characters: exploring the role of social media in journalism. Global Media Journal: African Edition, 4(1), 1-16.

Stecher, B., \& Borko, H. (2002). Combining surveys and case studies to examine standards-based educational reform: National Center for Research on Evaluation, Standards, and Student Testing (CRESST).

Stempel, C. (2005). Adult participation sports as cultural capital: A test of Bourdieu's theory of the field of sports. International Review for the Sociology of Sport, 40(4), 411-432. doi: 10.1177/1012690206066170

Sterne, J. (2003). Bourdieu, technique and technology. Cultural Studies, 17(3-4), 367389. doi: $10.1080 / 0950238032000083863 \mathrm{a}$

Stinchcombe, A. (1991). The conditions of fruitfulness of theorizing about mechanisms in social science. Philosophy of the Social Sciences, 21(3), 367-388. doi: $10.1177 / 004839319102100305$

Sullivan, J. (2013). Media audiences: Effects, users, institutions, and power. Thousand Oaks, CA: Sage.

Sumpter, R. S. (2000). Daily newspaper editors' audience construction routines: A case study. Critical Studies in Media Communication, 17(3), 334-346. doi: 10.1080/15295030009388399

Swanborn, P. (2010). Case study research: What, why and how? Thousand Oaks: CA: Sage.

Tai, Z., \& Chang, T.-K. (2002). The global news and the pictures in their heads: A comparative analysis of audience interest, editor perceptions and newspaper coverage. International Communication Gazette, 64(3), 251-265. doi: $10.1177 / 17480485020640030301$ 
Tandoc, E., Hellmueller, L., \& Vos, T. P. (2012). Mind the gap: Between role conception and role enactment. Journalism Practice, 7(5), 539-554. doi:

$10.1080 / 17512786.2012 .726503$

Tandoc, E., \& Jenner, M. (2013). Analyzing web analytics: How newsrooms use web metrics in news construction and why. Paper presented at the International Communication Association, London.

Tandoc, E., \& Takahashi, B. (2013). Playing a crusader role or just playing by the rules? Role conceptions and role inconsistencies among environmental journalists. Journalism. doi: 10.1177/1464884913501836

Telecomworldwire. (2011). Cision Media Database lists 10,000 UK blogs. Telecomworldwire.

Tewksbury, D. (2003). What do Americans really want to know? Tracking the behavior of news readers on the Internet. Journal of Communication, 53(4), 694-710. doi: 10.1111/j.1460-2466.2003.tb02918.x

Thorson, E. (2008). Changing patterns of news consumption and participation. Information, Communication and Society, 11(4), 473-489. doi: 10.1080/13691180801999027

Tilly, C. (2001). Mechanisms in political processes. Annual Review of Political Science, 4(1), 21-41. doi: doi:10.1146/annurev.polisci.4.1.21

Tracy, S. (2013). Qualitative research methods: Collecting evidence, crafting analysis, communicating impact. Malden, MA: Wiley-Blackwell.

Tuchman, G. (1972). Objectivity as strategic ritual: An examination of newsmen's notions of objectivity. American Journal of Sociology, 77(4), 660-679. doi: $10.2307 / 2776752$

Tuchman, G. (1978). Making news: a study in the construction of reality. New York: Free Press.

Turow, J. (2005). Audience construction and culture production: Marketing surveillance in the digital age. Annals of the American Academy of Political and Social Science, 597, 103-121.

Usher, N. (2013). Al Jazeera English Online: Understanding Web metrics and news production when a quantified audience is not a commodified audience. Digital Journalism, 1-17. doi: 10.1080/21670811.2013.801690

Vos, T. (2011). A mirror of the times: A history of the mirror metaphor in journalism. Journalism Studies, 12(5), 575-589. doi: 10.1080/1461670x.2010.536449 
Vos, T., Craft, S., \& Ashley, S. (2011). New media, old criticism: Bloggers’ press criticism and the journalistic field. Journalism, 13(7), 850-868. doi: $10.1177 / 1464884911421705$

Wallenstein, A. (2013). Why the Onion is wrong about CNN and Miley Cyrus. Variety. Retrieved from Variety website: http://variety.com/2013/digital/news/why-theonion-is-wrong-about-cnn-and-miley-cyrus-1200589821/

Wardle, C., \& Williams, A. (2010). Beyond user-generated content: a production study examining the ways in which UGC is used at the BBC. Media, Culture \& Society, 32(5), 781-799. doi: 10.1177/0163443710373953

Weaver, D. H., Beam, R. A., Brownlee, B. J., Voakes, P. S., \& Wilhoit, G. C. (2007). The American journalist in the 21st century. U.S. news people at the dawn of a new millennium. Mahweh, New Jersey, London: Lawrence Erlbaum Associates.

Weaver, D. H., \& Wilhoit, G. C. (1986). The American journalist. A portrait of US news people and their work. Bloomington: Indiana University Press.

Weaver, D. H., \& Wilhoit, G. C. (1996). The American journalist in the 1990s: U.S. news people at the end of an era. Mahwah, NJ: Erlbaum.

Web analytics definitions. (2008). Retrieved from http://www.digitalanalyticsassociation.org/Files/PDF_standards/WebAnalyticsDe finitions.pdf

Weber, K. (2006). From nuts and bolts to toolkits: Theorizing with mechanisms. Journal of Management Inquiry, 15(2), 119-123.

Webster, J., \& Phalen, P. (1994). Victim, consumer, or commodity? Audience models in communication policy. In J. Ettema \& D. C. Whitney (Eds.), Audiencemaking: How the Media Create the Audience. New York: Sage.

White, D. M. (1950). The 'gatekeeper.' A case study in the selection of news. Journalism Quarterly, 27, 383-390.

Wiggins, A. (2007). Data-driven design: Using web analytics to validate heuristics. Bulletin of the American Society for Information Science and Technology (Online), 33(5), 20-24.

Williams, A., Wardle, C., \& Wahl-Jorgensen, K. (2010). "Have they got news for us?" Audience revolution or business as usual at the BBC? Journalism Practice, 5(1), 85-99. doi: 10.1080/17512781003670031

Willig, I. (2013). Newsroom ethnography in a field perspective. Journalism, 14(3), 372387. doi: $10.1177 / 1464884912442638$ 
Wimmer, R. D., \& Dominick, J. R. (2011). Mass media research: An introduction (9th ed.). Boston, MA: Wadsworth.

Woodside, A. G. (2010). Bridging the chasm between survey and case study research: Research methods for achieving generalization, accuracy, and complexity. Industrial Marketing Management, 39(1), 64-75. doi: http://dx.doi.org/10.1016/j.indmarman.2009.03.017

Wright, K. B. (2005). Researching internet-based populations: Advantages and disadvantages of online survey research, online questionnaire authoring software packages, and web survey services. Journal of Computer-Mediated Communication, 10(3), 00-00. doi: 10.1111/j.1083-6101.2005.tb00259.x

Wulfemeyer, K. T. (1984). Perceptions of viewer interests by local TV journalists. Journalism Quarterly, 61(2), 432-435.

Yang, J. H. (2004). Constraints on environmental news production in the U. S.: Interviews with American journalists. Journal of International and Area Studies, $11(2), 89$.

Yang, N. (2012). How web analytics are shaping advertising dollars and the newsroom. Editor \& Publisher. Retrieved from http://www.editorandpublisher.com/Features/Article/How-Web-Analytics-AreShaping-Advertising-Dollars-And-The-Newsroom

Yin, R. K. (2009). Case study research: Design and methods: Sage Publications.

Yin, R. K. (2011). Qualitative research from start to finish. New York: NY: Guilford Publications.

Yoon, Y. (2005). Legitimacy, public relations, and media access: Proposing and testing a media access model. Communication Research, 32(6), 762-793. doi: $10.1177 / 0093650205281081$

Zhu, J.-H., Weaver, D., Lo, V.-h., Chen, C., \& Wu, W. (1997). Individual, organizational, and societal influences on media role perceptions: A comparative study of journalists in China, Taiwan, and the United States. Journalism \& Mass Communication Quarterly, 74(1), 84-96. 


\section{VITA}

Edson C. Tandoc Jr. (Ph.D., 2013, University of Missouri-Columbia) is an assistant professor at the Wee Kim Wee School of Communication and Information at the Nanyang Technological University in Singapore. He worked as a national reporter for the Philippine Daily Inquirer (circ. 260,000) for six years. His research is generally focused on the sociology of message production, particularly on the construction of news and social media messages. In his three and half years as a Fulbright Fellow and doctoral student at the Missouri School of Journalism, he produced more than 30 conference papers, eight of which won awards at the International Communication Association, the Association of Educators in Journalism and Mass Communication, and the World Communication Association conferences. His research has appeared in the following journals: Cyberpsychology, Behavior and Social Networking; Asian Journal of Communication; Journal of Information, Technology and Politics; Social Indicators Research; Howard Journal of Communications, Journalism Practice, and Journalism. He earned his undergraduate journalism degree from the University of the Philippines, Summa cum Laude, and his Master of Mass Communication degree from the Nanyang Technological University in Singapore, where he was awarded the Media Development Authority Award (top MMC graduate) in 2008. 